\title{
Physiological and pathophysiological investigation of lacrimal and pancreatic ductal epithelial cells
}

\author{
Máté Katona, M.Sc.
}

Ph.D. Thesis

\section{Basic Medical Sciences Doctoral School}

Supervisors: Edit Tóth-Molnár, M.D., Ph.D.

Viktória Venglovecz, Ph.D.

Department of Pharmacology and Pharmacotherapy,

First Department of Medicine,

University of Szeged,

Szeged, Hungary

2015 


\section{LIST OF FULL PAPERS RELATED TO THE THESIS}

\section{Articles closely related to the subject of the thesis and cited in the thesis}

I. Katona M, Vizvári E, Németh L, Facskó A, Venglovecz V, Rakonczay Z Jr, Hegyi P, Tóth-Molnár E. Experimental evidence of fluid secretion of rabbit lacrimal gland duct epithelium.

Invest Ophthalmol Vis Sci. 2014;55(7):4360-7.

[IF 2014: 3.661]

II. Katona M, Hegyi P, Kui B, Balla Zs, Rakonczay Z Jr, Rázga Zs, Tiszlavicz L, Maléth J, Venglovecz V. A novel, protective role of ursodeoxycholate in bileinduced pancreatic ductal injury.

Am J Physiol Gastrointest Liver Physiol. Accepted for publication [IF 2014: 3.737]

\section{Articles related to the subject of the thesis}

III. Maléth J, Balázs A, Pallagi P, Balla Z, Kui B, Katona M, Judák L, Németh I, Kemény LV, Rakonczay Z Jr, Venglovecz V, Földesi I, Pető Z, Somorácz Á, Borka K, Perdomo D, Lukacs GL, Gray MA, Monterisi S, Zaccolo M, Sendler M, Mayerle J, Kühn JP, Lerch MM, Sahin-Tóth M, Hegyi P. Alcohol disrupts levels and function of the cystic fibrosis transmembrane conductance regulator to promote development of pancreatitis.

Gastroenterology. 2015;148(2):427-39.e16.

[IF 2014: 16.716]

Number of full publications: 3 (2 first author)

Cumulative impact factor: $\mathbf{2 4 . 1 1 4}$ 


\section{TABLE OF CONTENTS}

$\begin{array}{lr}\text { LIST OF FULL PAPERS RELATED TO THE THESIS } & 1\end{array}$

LIST OF ABBREVIATIONS

1. INTRODUCTION 5

1.1. Basic transport components of epithelial secretion 5

$\begin{array}{ll}\text { 1.2. Transporters at the basolateral membrane } & 6\end{array}$

$\begin{array}{lr}\text { 1.2.1. } \mathrm{Na}^{+-}-\mathrm{HCO}_{3}-\text { cotransporters } & 6\end{array}$

$\begin{array}{lr}\text { 1.2.2. } \mathrm{Na}^{+} / \mathrm{K}^{+}-\text {ATPase } & 6\end{array}$

$\begin{array}{lr}\text { 1.2.3. Basolateral } \mathrm{K}^{+} \text {channels } & 6\end{array}$

$\begin{array}{ll}\text { 1.2.4. } \mathrm{Na}^{+} / \mathrm{H}^{+} \text {exchangers } & 7\end{array}$

$\begin{array}{ll}\text { 1.2.5. Basolateral NKCC1 } & 7\end{array}$

$\begin{array}{ll}\text { 1.2.6. Basolateral anion exchangers } & 7\end{array}$

1.3. Transporters at the apical membrane $\quad 8$

$\begin{array}{lr}\text { 1.3.1. Apical CFTR } & 8\end{array}$

$\begin{array}{lr}\text { 1.3.2. Calcium-activated chloride channels } & 8\end{array}$

$\begin{array}{lr}\text { 1.3.3. Luminal anion exchangers } & 8\end{array}$

$\begin{array}{ll}\text { 1.4. Epithelial secretion in exocrine glands } & 9\end{array}$

$\begin{array}{ll}\text { 1.4.1. Lacrimal gland } & 9\end{array}$

$\begin{array}{lr}\text { 1.4.2. Pancreas } & 10\end{array}$

2. AIMS OF THE STUDY 14

2.1. Investigation of lacrimal gland ductal secretion 14

$\begin{array}{ll}\text { 2.2. The effect of bile acids on pancreatic ductal cells } & 14\end{array}$

3. MATERIALS AND METHODS 16

$\begin{array}{ll}\text { 3.1. Animals } & 16\end{array}$

3.2. Ethics 16

$\begin{array}{lr}\text { 3.3. Solutions and chemicals } & 17\end{array}$

3.4. Isolation and culture of lacrimal and pancreatic duct segments $\quad 17$

3.5. Measurement of osmotic water permeability and ductal fluid secretion of $\begin{array}{lr}\text { lacrimal gland interlobular duct epithelium } & 18\end{array}$

$\begin{array}{lr}\text { 3.6. Bile acid treatments } & 19\end{array}$

3.7. Measurement of intracellular $\mathrm{Ca}^{2+}$ concentration, $\mathrm{pH}$ and ATP level 19

3.8. Measurement of the activity of acid/base transporters 20

3.9. Measurement of mitochondrial membrane potential 21

3.10. Measurement of mitochondrial permeability transition pore opening 21 
3.11. TUNEL cell death assay

3.12. Transmission electron microscopy

3.13. Induction of acute pancreatitis

3.14. Histologic examination and laboratory parameter measurements

3.15. Statistical Analysis

4. RESULTS

4.1. Investigation of lacrimal gland ductal secretion

4.1.1. Osmotic water permeability of lacrimal gland interlobular duct epithelium

4.1.2. Forskolin-stimulated fluid secretion of lacrimal gland interlobular ducts in the presence and in the absence of HCO3-

4.1.3. Effects of different inhibitors on fluid secretion

4.1.4. The role of basolateral $\mathrm{HCO}_{3}$-transporters in fluid secretion

4.1.5. Carbachol-stimulated fluid secretion of lacrimal gland interlobular ducts in the presence and in the absence of $\mathrm{HCO}_{3}$ -

4.2.Effect of bile acids on pancreatic ductal cells

4.2.1. Effect of UDCA and CDCA on $\mathrm{pH}_{\mathrm{i}}$

4.2.2. Effect of UDCA pretreatment on the inhibitory effect of CDCA on the acid/base transporters

4.2.3. Effect of UDCA pretreatment on the CDCA-induced calcium signallin 33

4.2.4. Effect of UDCA pretreatment on the CDCA-induced mitochondrial injury

4.2.5.Effect of UDCA pretreatment on the CDCA-induced cell death

4.2.6. In vivo investigation of the effect of UDCA pretreatment in CDC-induced AP model

5. DISCUSSION

5.1. Investigation of lacrimal gland ductal secretion

5.2. Effect of different bile acids on pancreatic duct epithelial cell functon

6. SUMMARY

6.1. Investigation of lacrimal gland ductal secretion

6.2. Effect of acids on pancreatic ductal cells

7. ACKNOWLEDGEMENTS

8. REFERENCES 


\section{LIST OF ABBREVIATIONS}

$(\mathbf{A T P})_{\mathbf{i}} \quad$ intracellular ATP level

BCECF-AM 2'7'-bis(carboxyethyl)-5(6)-carboxyfluorescein acetoxymethyl ester

$\left[\mathrm{Ca}^{2+}\right]_{\mathbf{i}} \quad$ intracellular $\mathrm{Ca}^{2+}$ concentration

cAMP cyclic adenosine monophosphate

AE anion exchanger $\left(\mathrm{Cl}^{-} / \mathrm{HCO}_{3}{ }^{-}\right.$exchanger $)$

CA carbonic anhydrase

CaCC calcium-activated $\mathrm{Cl}^{-}$channel

CFTR cystic fibrosis transmembrane conductance regulator $\mathrm{Cl}^{-}$channel

EIPA 5-(N-Ethyl-N-isopropyl)amiloride

FURA-2-AM 5-Oxazolecarboxylic acid, 2-(6-(bis(carboxymethyl)amino)-5-(2-(2(bis(carboxymethyl)amino)-5-methylphenoxy)ethoxy)-2benzofuranyl)-5-oxazolecarboxylic acetoxymethyl ester

DIDS diisothiocyanostilbene-2,2'-disulfonic acid

LG lacrimal gland

LGDEC lacrimal gland ductal epithelial cells

NBC $\quad \mathrm{Na}^{+} / \mathrm{HCO}_{3}{ }^{-}$contransporter

NHE $\quad \mathrm{Na}^{+} / \mathrm{H}^{+}$exchanger

PDEC pancreatic ductal epithelial cells

$\mathbf{p H}_{\mathbf{i}} \quad$ intracellular $\mathrm{pH}$

$\mathbf{p H}_{\mathbf{L}} \quad$ intraluminal $\mathrm{pH}$

PKA protein kinase A

SLC26 solute carrier family 26 


\section{INTRODUCTION}

Vectorial transport of water and electrolytes is a fundamental physiological function of epithelial cells which ensures the appropriate volume and electrolyte composition of the various fluids. In exocrine glands, fluid and electrolyte secretion is carried out by both acinar and ductal cells. The composition of fluid, secreted by these cell types varying among glands. Acinar cells mainly secrete isotonic, plasma-like fluid which is mostly modified by the ductal cells. The key transporters mediating acinar fluid and electrolyte secretion are the $\mathrm{Na}^{+} / \mathrm{K}^{+} / 2 \mathrm{Cl}^{-}$cotransporter type 1 (NKCC1), the $\mathrm{Ca}^{2+}$ - activated $\mathrm{Cl}^{-}$channels $(\mathrm{CaCC})$ and the $\mathrm{Ca}^{2+}$-activated $\mathrm{K}^{+}$ channels[1-3]. Whereas, ductal fluid and electrolyte secretion are mainly mediated by the $\mathrm{Na}^{+} / \mathrm{HCO}_{3}{ }^{-}$cotransporter (NBC), the $\mathrm{Cl}^{-} / \mathrm{HCO}_{3}{ }^{-}$anion exchanger (AEs), the cystic fibrosis transmembrane conductance regulator $\mathrm{Cl}^{-}$channel (CFTR) and the $\mathrm{CaCC}[1,4]$.

Decrease or damage of ductal fluid secretion can contribute to the development of numerous diseases such as pancreatitis, cystic fibrosis (CF) or dry eye disease.

\subsection{Basic transport components of epithelial secretion}

A Danish, Nobel Laureate physiologist, August Krogh concluded from his experiments, that metabolic energy was required to maintain the ionic gradients between the organism and its external environment. Hans Ussing combined isotopic ion fluxes and biophysical approaches to form our basic knowledge of epithelial polarity, transport mechanisms, the paracellular pathway, and the origin of epithelial "bioelectric" potentials" [5]. Later, Skou and colleagues identified $\mathrm{Na}^{+} / \mathrm{K}^{+}$ATPase as an important member in cation transport [6]. This active transport process provides the driving force for secondary active transport of various ions and nutrients. These principles were applied in the context of active anion secretion, leading to the classical cellular model of epithelial secretory functions (Figure 1). Later, researchers focused attention on active $\mathrm{Cl}^{-}$secretion and second-messenger pathways. Ussing chamber studies on rabbit intestine revealed that cAMP or agents that increase its cellular level, stimulated $\mathrm{Cl}^{-}$secretion [7]. Another important pathway for the transport of $\mathrm{Cl}^{-}$in epithelial cells is CaCCs activated by intracellular $\mathrm{Ca}^{2+}\left(\left[\mathrm{Ca}^{2+}\right]_{\mathrm{i}}\right)$ 
elevation. These findings have laid the foundation for creating the basic transport principles and during the following decades their molecular identities were established $[1,8]$.

Basolateral and apical ion transport mechanisms are essential for cellular homeostasis and to maintain apical secretory functions by providing electrochemical gradients and by regulating ion transport processes. Although some of the below mentioned transporters were not the direct target of the study, it is important to describe briefly some of the most important proteins for better understanding of epithelial secretory processes.

\subsection{Transporters at the basolateral membrane}

\subsection{1. $\mathrm{Na}^{+}-\mathrm{HCO}_{3}{ }^{-}$cotransporters}

$\mathrm{HCO}_{3}{ }^{-}$-entry across the basolateral membrane is mainly mediated by $\mathrm{Na}^{+}$ copuled $\mathrm{HCO}_{3}{ }^{-}$cotransport [9-11]. At least five isoforms of $\mathrm{NBC}$ is expressed at the basolateral membrane of most epithelia, including pancreatic and salivary gland acinar and duct cells [11-13]. However in rabbit LG, if present, NBC activity has only marginal role in secretion [14]. NBC is an electrogenic transporter with the stoichiometry of $1 \mathrm{Na}^{+}: 2 \mathrm{HCO}_{3}{ }^{-}$, although it appears to depend on the cell type in which it is expressed [15]. $\mathrm{NBC}$ uses the $\mathrm{Na}^{+}$-gradient to mediate basolateral $\mathrm{HCO}_{3}{ }^{-}$ uptake during ductal fluid and $\mathrm{HCO}_{3}{ }^{-}$-secretion [4].

\subsection{2. $\mathrm{Na}^{+} / \mathrm{K}^{+}$-ATPase}

The basolateral electrogenic $\mathrm{Na}^{+} / \mathrm{K}^{+}$-ATPase is essential in establishing the electrochemical gradients for secondary active anion secretion. It transports $\mathrm{Na}^{+}$ions out of the cell in exchange for two $\mathrm{K}^{+}$ions pumped into the cell with the stoichiometry of 3:2. Leakage of $\mathrm{K}^{+}$out of the cell via basolateral (in some cell types apical) $\mathrm{K}^{+}$channels is the primary determinant of membrane voltage $[6,16]$. In epithelia this pump accounts approximately $2 / 3$ of the cells energy expenditure[1].

\subsubsection{Basolateral $\mathrm{K}^{+}$channels}

Basolateral $\mathrm{K}^{+}$conductance is essential for $\mathrm{K}^{+}$recycling. $\mathrm{Na}^{+} / \mathrm{K}^{+}$-ATPase 
activity is the main source of the electrical driving force for anion exit across the apical membrane. In response to second-messenger pathways, basolateral $\mathrm{K}^{+}$channels are also activated, to coordinate membrane repolarization with the activation of apical $\mathrm{Cl}^{-}$conductance and permit the membrane potentials to repolarize toward the $\mathrm{K}^{+}$ equilibrium potential, establishing the electrical driving force for $\mathrm{Cl}^{-}$exit across the apical membrane. In many epithelia, the basolateral $\mathrm{K}^{+}$conductance is composed of at least two $\mathrm{K}^{+}$channel types like the cAMP/PKA activated KCNQ1 and the $\mathrm{Ca}^{2+}$ activated channel KCNN4 [17-19].

\subsection{4. $\mathrm{Na}^{+} / \mathrm{H}^{+}$exchangers}

The $\mathrm{Na}^{+} / \mathrm{H}^{+}$-exchanger (NHE) family has five members located in the plasma membrane (NHE1-5) [12,13]. In glandular duct epithelia NHE1 is localized at the basolateral membrane and is essential for cytoplasmic $\mathrm{pH}$ homeostasis of the cells [14,20-22]. NKCC1 and NHE1 are the main sources of the basolateral $\mathrm{Na}^{+}$-uptake which is essential for the $\mathrm{Na}^{+} / \mathrm{K}^{+}$-ATPase activity in secretory epithelia and it also can provide a minor portion of basolateral $\mathrm{HCO}_{3}{ }^{-}$uptake during secretion [4,23-26].

\subsubsection{Basolateral NKCC1}

NKCC1 mediates the basolateral $\mathrm{Cl}^{-}$uptake in most epithelial cells. The driving force for $\mathrm{Cl}^{-}$uptake and accumulation is supplied by the chemical gradient of $\mathrm{Na}^{+}$ established by NKCC1 and NHE1 which process is electrically neutral. Ultimately NKCC1 determines the overall rate of $\mathrm{Cl}^{-}$secretion. The activation of NKCC1 generally follows the activation of CFTR and $\mathrm{K}^{+}$channels resulting in $\mathrm{Cl}^{-}$and $\mathrm{K}^{+}$exit and decrease in the cell volume. NKCC1 activity is the main source of the basolateral $\mathrm{Cl}^{-}$-uptake which is secreted across the luminal membrane to drive fluid secretion in secretory glands $[17,27,28]$.

\subsubsection{Basolateral anion exchangers}

$\mathrm{Na}^{+}$-coupled $\mathrm{Cl}^{-}$entry at the basolateral membrane is not the only possible source of intracellular $\mathrm{Cl}^{-}$. Fluid secretion showed to be insensitive to the NKCC1 inhibitors but was sensitive to inhibitors of carbonic anhydrase (CA), NHEs and AEs in salivary glands and other epithelia. This component of secretion was assigned to 
the parallel operation of basolateral AEs ${ }^{-}$and NHEs $[28,29]$. The contribution of AEs in basolateral $\mathrm{Cl}^{-}$uptake has been suggested in various epithelia $[30,31]$.

\subsection{Transporters at the apical membrane}

\subsubsection{Apical CFTR}

CFTR is one of the members of the ATP-binding cassette (ABC) proteins. Members of this transporter family are composed of two membrane-spanning domains (MSD1 and 2) and two nucleotide-binding domains (NBD1 and 2) [1,32]. CFTR contains a central regulatory $(\mathrm{R})$ region which contains nine consensus sequences for phosphorylation by protein kinase A (PKA) and several additional sites of phosphorylation by other kinases (e.g., AMPK, PKC). CFTR has another PKA phosphorylation site in the regulatory insertion of NBD1. As discussed below, CFTR is the predominant pathway for secretion in response to agonists that act via cAMP/PKA-dependent phosphorylation, although it is not the only pathway for apical $\mathrm{Cl}^{-}$exit. In addition, CFTR exhibits a significant conductance to $\mathrm{HCO}_{3}^{-}$, which highlights its importance in pancreatic $\mathrm{HCO}_{3}{ }^{-}$secretion [4].

\subsubsection{Calcium-activated chloride channels}

$\mathrm{CaCC}$ is a major pathway for the transport of $\mathrm{Cl}^{-}$in most cell types, but it was first characterized in secretory epithelium. $\mathrm{CaCC}$ is activated by rapid $\left[\mathrm{Ca}^{2+}\right]_{\mathrm{i}}$ increase and also by membrane depolarization. $\mathrm{CaCC}$ is the main apical $\mathrm{Cl}^{-}$pathway during muscarinic stimulation of LGs $[33,34]$. Later, this pathway has been identified in other epithelial cells, where a wide range of $\mathrm{Ca}^{2+-}$ mobilizing agonists, like charbamylcholine, stimulate it [1,35]. We have still limited information about the $\mathrm{CaCC}$ protein. The most promising candidate to mediate $\mathrm{CaCC}$ is TMEM16A $[36,37]$.

\subsubsection{Luminal anion exchangers}

$\mathrm{HCO}_{3}{ }^{-}$secreting epithelial cells, such as PDECs express electrogenic AEs on the luminal membrane. AEs allow the cells to transport $\mathrm{HCO}_{3}^{-}$across the apical membrane and to establish the high intraluminal $\mathrm{HCO}_{3}^{-}$concentration during 
stimulation [4,38]. CFTR mutations, associated with exocrine pancreatic insufficiency, also establish a major deficiency in the apical CFTR-dependent $\mathrm{Cl}^{-}$/ $\mathrm{HCO}_{3}{ }^{-}$exchange activity [39]. Recent studies in the field revealed the "puzzling" role of $\mathrm{CFTR}$ in $\mathrm{HCO}_{3}{ }^{-}$secretion (Figure $1 \mathrm{~A}$ ). The luminal $\mathrm{Cl}^{-}$concentration $\left(\left[\mathrm{Cl}^{-}\right]_{\mathrm{L}}\right)$ is high in the proximal pancreatic duct, therefore CFTR functions as a $\mathrm{Cl}^{-}$channel, providing $\mathrm{Cl}^{-}$for the $\mathrm{Cl}^{-} / \mathrm{HCO}_{3}{ }^{-}$exchange through the SLC26A6 and $\mathrm{A} 3$. In the distal pancreatic ducts, where the $\left[\mathrm{Cl}^{-}\right]_{\mathrm{L}}$ and intracellular $\mathrm{Cl}^{-}$concentration $\left(\left[\mathrm{Cl}^{-}\right]_{\mathrm{i}}\right)$ is low, $\mathrm{HCO}_{3}{ }^{-}$secretion through CFTR can play an important role $[35,40]$.

\subsection{Epithelial secretion in exocrine glands}

Fluid and electrolyte secretion is a vital function of all epithelia and is required for the survival of the tissue however the secretory processes widely differ among organs. Aberrant fluid and anion secretion is associated with various epithelial diseases, such as CF, pancreatitis, Sjögren's syndrome and other epithelial inflammatory and autoimmune diseases $[1,4]$.

\subsubsection{Lacrimal gland}

Preocular tear film is an essential protector of the ocular surface. Tear is produced predominantly in the exocrine tubuloacinar LGs. Appropriate amount of balanced electrolyte, protein and mucin composition of fluid secreted by the LG is fundamental for maintaining preocular tear film integrity. Such as other exocrine tubuloacinar glands, LG is composed mainly of three types of cells: acinar, ductal and myoepithelial cells [20,41]. Acinar cell functions are widely studied, resulting in broad spectrum of information, however much less is known about the possible secretory function of duct cells [42-44]. It has been proposed that primary acinar fluid is modified by ductal secretory processes: an elevated $\mathrm{K}^{+}$and $\mathrm{Cl}^{-}$content of the final product evolves during passage of fluid through the ductal tree [2,42]. Although acini are the determining structures of tear production, the secretory role of ducts beside their piping function was also suspected for a long while. Modifications of $\mathrm{K}^{+}$and $\mathrm{Cl}^{-}$ content of primary acinar fluid by ductal secretory processes were also proposed earlier. However, the role of LG ductal epithelium on fluid, electrolyte and protein secretion is not well understood. 
The first experimental model for the investigation of lacrimal duct function was adapted and applied by our group. Using short-term cultured duct segments allowed studying the role and regulation of various ion transporters in the lacrimal duct. These results showed the functional presence of a $\mathrm{Na}^{+}$dependent proton efflux mechanism (NHE) and a $\mathrm{Cl}^{-}$dependent $\mathrm{HCO}_{3}{ }^{-}$efflux mechanism (AE) using $\mathrm{pH}-$ sensitive fluorescent dye in LG ductal cells [14]. $\mathrm{Ca}^{2+}$ and cAMP signaling pathways in activation of epithelial fluid and electrolyte secretion are well studied in different gland types such as pancreas and salivary gland, however we are lacking of information about LG secretory functions. Based on findings from our laboratory and gene expression studies a scematic figure of lacrimal gland ductal secretion was designed (Figure 1B) [14,45-48].

Dry eye disease is one of the most frequently diagnosed ocular surface pathology. Presently substitution of tear fluid with arteficial tear drops is the main, mostly insufficient, intervention to manage dry eye without treating the underlying pathologic alterations since the causative factors of the disease is mostly unknown [49-51]. Our knowledge about LG function is far from complete and therefore the more detailed understanding of the physiology and pathophysiology of the lacrimal gland is essential.

\subsubsection{Pancreas}

Besides its endocrine function pancreas has an important exocrine function participating in digestion. There are two major cell types in the exocrine pancreas, the acinar and ductal cells. Both cell types play role in the secretion and the release of the pancreatic juice. Acinar cells secrete pancreatic juice rich in $\mathrm{NaCl}$ and digestive enzymes which travels through the pancreatic ductal system into the duodenum. Ductal cells secrete a $\mathrm{HCO}_{3}{ }^{-}$rich fluid and modify the electrolyte composition of the juice by the secretory and absorptive processes. Pancreatic duct $\mathrm{HCO}_{3}{ }^{-}$secretion can be divided to basolateral accumulation of the $\mathrm{HCO}_{3}{ }^{-}$ions and the secretion into the duct lumen across the apical membrane. $\mathrm{HCO}_{3}{ }^{-}$accumulation is mainly carried out by the NBC, whereas a minority of $\mathrm{HCO}_{3}{ }^{-}$forms by the conversion of $\mathrm{CO}_{2}$ to $\mathrm{HCO}_{3}{ }^{-}$ $[4,10]$. PDEC express on the luminal membrane electrogenic AEs (SLC26A6 and

possibly SLC26A3) and the CFTR $\mathrm{Cl}^{-}$channel [52,53]. These transporters are essential for pancreatic ductal $\mathrm{HCO}_{3}^{-}$secretion to generate the $140 \mathrm{mM}$ intraluminal 
$\mathrm{HCO}_{3}{ }^{-}$concentration $[4,38]$. Recent evidences suggest that pancreatic $\mathrm{HCO}_{3}^{-}$ secretion is playing a crucial role in the pathophysiology of the pancreas. Impaired ductal electrolyte and fluid secretion leads to acinar cell damage and to primary defect in membrane trafficking at the apical plasma membrane of acinar cells [54]. Intraluminal $\mathrm{pH}$ is also play a central role in normal pancreatic functions, since luminal acidosis may elevate the risk of AP $[55,56]$. Different etiological factors also can contribute to the development of AP such as excessive ethanol consumption, smoking, viral infections and also gallstones [57-61]. The obstruction of the common biliopancreatic duct by a gallstone is a frequent cause of AP. Although, the exact mechanism is not completely understood $[60,62,63]$. One of the most accepted theories is that bile reflux into the pancreatic ductal system leads to AP. We know from animal studies, that retrograde infusion of bile acids into the pancreatic duct triggers pancreatitis $[3,64,65]$. Therefore the cytotoxic effects of bile acids have been widely investigated in the pancreas [66-69]. Initial studies, in which the main pancreatic duct was perfused with various bile acids, demonstrated that in the $\mathrm{mM}$ range hydrophobic bile acids cause mucosal damage and increase the permeability of the pancreatic ducts to different ions [70,71]. Bile acids also induced $\mathrm{Ca}^{2+}$ release from the intracellular $\mathrm{Ca}^{2+}$ stores [66]. Moreover, Voronina et al. showed that taurolithocholicacid 3-sulfate (TLC-S) decreased intracellular ATP $\left((\mathrm{ATP})_{\mathrm{i}}\right)$ in pancreatic acinar cells and caused the loss of mitochondrial membrane potential $((\Delta \Psi) \mathrm{m})[72,73]$. Studies from our workgroup demonstrated that the nonconjugated bile acid chenodeoxycholic acid (CDCA) has dose-dependent dual effects on pancreatic $\mathrm{HCO}_{3}{ }^{-}$secretion, which might be explained by the intracellular $\mathrm{Ca}^{2+}$ signals, decrease in the $\mathrm{ATP}_{\mathrm{i}}$, mitochondrial damage and the inhibition of acid/base transporter activity caused by CDCA $[68,74]$. The cytotoxic effect of CDCA is basically attributed to its detergent characteristic, which is responsible for the disruption of the membrane integrity and consequently the release of intracellular constituents. However, several studies suggest that non-detergent effects of bile acids are also involved in the bile-induced cellular injury $[66,69,73]$. It has been recently demonstrated that CDCA induces ATP release from both ductal and acinar cells, which probably play a role in the CDCA-induced $\left[\mathrm{Ca}^{2+}\right]_{\mathrm{i}}$ elevation [75]. In the absence of $\mathrm{ATP}_{\mathrm{i}}$, the acid/base transporters fail to function properly, which finally causes decreased fluid and $\mathrm{HCO}_{3}{ }^{-}$secretion [74]. Impaired fluid secretion can lead to pancreatic injury and likely contributes to the development of pancreatitis $[3,76]$. 
Nevertheless not every bile acid has cell damaging effect. Ursodeoxycholic acid (UDCA) is a secondary, hydrophilic bile acid, which is currently used for gallstone dissolution and considered as first-choice therapy in cholestatic diseases[7780]. The mechanism by which UDCA increases liver function is not completely understood. Basically, there are three concepts for the action of UDCA: (i) stimulation of hepatobiliary secretion (ii) displacement of the hydrophobic, toxic bile acids from the liver and (iii) direct cytoprotection against toxic bile acids. The cytoprotective effects of UDCA or its taurin-conjugated form, tauroursodeoxycholic acid (TUDCA) have been widely investigated in the liver. Studies on hepatocytes have shown that UDCA pretreatment significantly reduces bile acid-induced opening of the mitochondrial permeability transition pore (mPTP) and consequently apoptosis, indicating that stabilization of the mitochondrial membrane, at least in part, plays an important role in the cytoprotective action of UDCA [81-85].

This remarcable effect of UDCA on bile acid-induced hepatocellular injury raises up the question, whether UDCA has a similar effect on the pathophysiology of other bile acid-related diseases. 


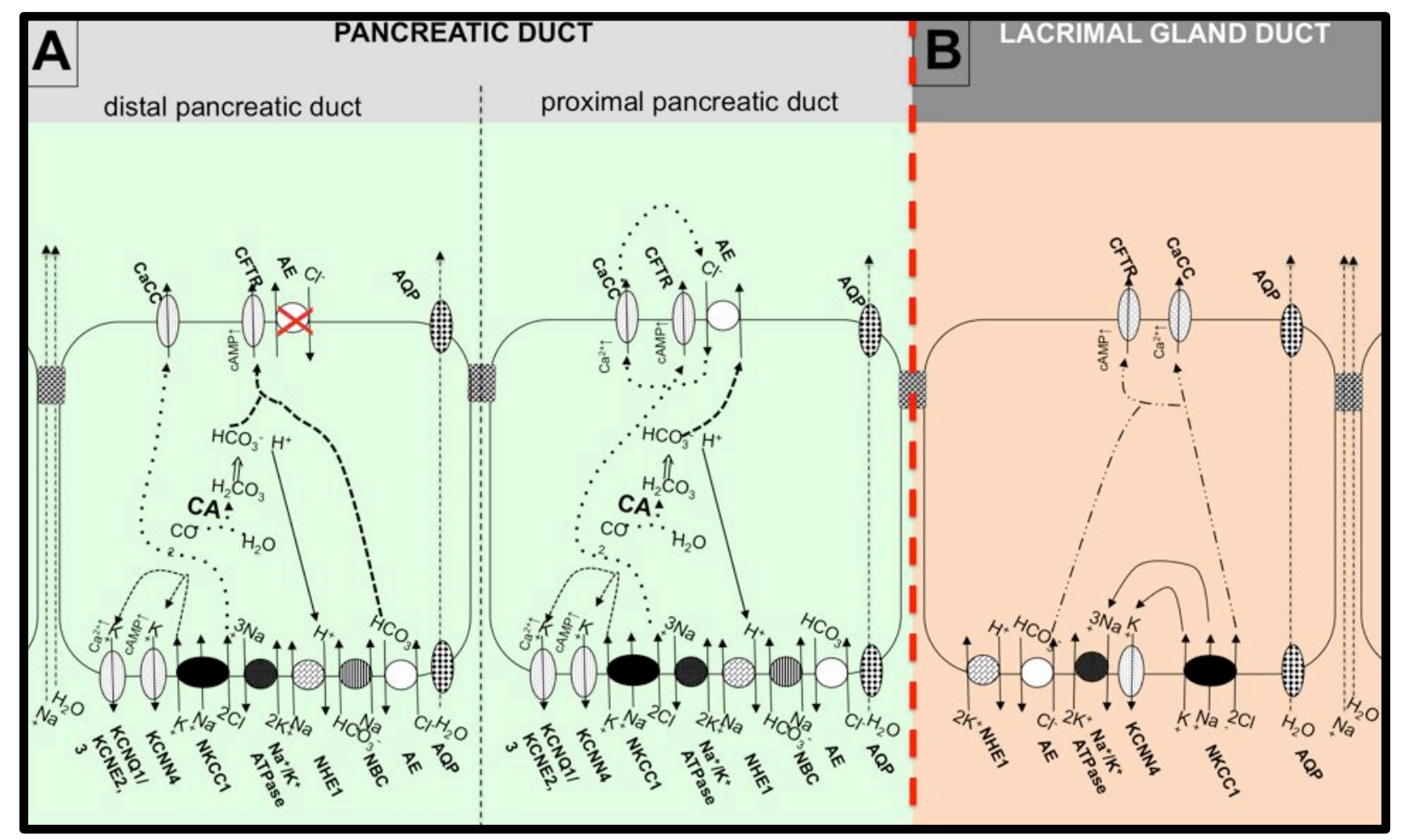

Figure 1. Schematic figure of pancreatic and lacrimal duct secretory processes: In the pancreatic duct the entry of anions across the basolateral membrane is mainly driven by NKCC1, NBC and AEs. Apical $\mathrm{Cl}^{-}$and $\mathrm{HCO}_{3}{ }^{-}$efflux is mediated by cAMP- (CFTR) and $\mathrm{Ca}^{2+}$-activated (CaCC) anion conductances and AEs (SLC26A6 and SLC26A3). In the proximal ducts, where the $\left[\mathrm{Cl}^{-}\right]_{\mathrm{L}}$ is high, $\mathrm{HCO}_{3}{ }^{-}$is secreted via the electrogenic AEs, driven by the high $\left[\mathrm{Cl}^{-}\right]_{\mathrm{L}}$. Under these conditions CFTR functions as a $\mathrm{Cl}^{-}$channel. In the distal ducts, where the $[\mathrm{Cl}-]_{\mathrm{L}}$ is low, the low intracellular $\mathrm{Cl}^{-}$concentration $\left(\left[\mathrm{Cl}^{-}\right]_{\mathrm{i}}\right)$ induces the phosphorylation of CFTR, switching its ion selectivity to $\mathrm{HCO}_{3}{ }^{-}$. Apical $\mathrm{HCO}_{3}{ }^{-}$transport is inhibited under these conditions (A). In the $\mathrm{LG}$ basolateral $\mathrm{Cl}^{-}$uptake is mainly mediated by $\mathrm{NKCC} 1$ and AEs. The luminal secretory processes are supposedly mediated by CFTR and CaCC. There is no evidence of functionally active $\mathrm{AE}$ on the apical membrane of lacrimal gland ductal epithelial cells (B). Transport of fluid is mediated by transcellular and also paracellular pathways in both cell types. 


\section{AIMS OF THE STUDY}

\subsection{Investigation of lacrimal gland ductal secretion}

Our understanding of lacrimal gland function is far from complete and below that can be experienced in other areas of exocrine glands. This is especially true for the LG duct structures and is in striking contrast with the significant amount of information available in case of pancreatic or salivary gland ducts. Until recently there was no experimental method available for the investigation of LG duct function. In the past few years laser capture microdissection technique was introduced for the investigation of gene expression profile, and the first experimental method suitable to study LG duct function was described by our laboratory $[14,45]$. Thanks to these new methods there are continuously gathering experimental results supporting the notion that LG duct structure may play an important role in lacrimal function. In contrast there are no data supported by experimental results regarding the contribution of ductal cells in fluid secretion of the LG.

\section{Our specific aims were:}

* To determine the osmotic water permeability of ductal epithelium by means of calculation of filtration permeability $\left(\mathrm{P}_{\mathrm{f}}\right)$,

To investigate lacrimal gland ductal fluid secretion by means of measurement of fluid secretion evoked by potential agonists (forskolin and carbachol) seeking for evidence of secretory function of lacrimal ductal system.

\subsection{The effect of bile acids on pancreatic ductal cells}

Previous studies shown that bile acids such as CDCA strongly inhibits ion transporters through the destruction of mitochondrial function, resulting in impaired pancreatic ductal fluid and $\mathrm{HCO}_{3}{ }^{-}$secretion $[68,74]$. This effect of bile acids may have significance in the pathomechanism of AP. UDCA is known to protect the mitochondria against hydrophobic bile acids and has ameliorating effect on cell death $[81,84]$. Since the CDCA-induced failure in pancreatic ductal function is also strongly associated with mitochondrial damage, we aimed to investigate, using in vitro and in vivo approaches, if UDCA pretreatment is able to prevent the CDCA-induced ductal 
injury.

\section{Our specific aims were:}

* To investigate the effect of UDCA pretreatment on CDCA-induced pancreatic ductal injury on isolated in vitro

* To study the effect of UDCA pretreatment in CDCA-induced AP in vivo. 


\section{MATERIALS AND METHODS}

\subsection{Animals}

\section{Rabbits}

Adult male New Zealand white rabbits weighing 2-2.5 kg were used (Devai Farm Kondoros Hungary). The animals were narcotised with a mixture of ketamine $(40 \mathrm{mg} / \mathrm{ml})$ and xylazine $(10 \mathrm{mg} / \mathrm{ml})$ and were euthanized with pentobarbital overdose $(80 \mathrm{mg} / \mathrm{kg})$. LGs were carefully dissected as described earlier [14].

\section{Guinea pigs}

Guinea pigs weighing 150-250 g were used in order to examine the effect of bile acids on pancreatic ductal $\mathrm{HCO}_{3}{ }^{-}$secretion. Animals were killed humanly by cervical dislocation, and then the pancreas was removed.

Rats

Male SPRD rats were used for experiments as described below in the section of the „Induction of pancreatitis”.

All animals were kept at a constant room temperature of $22 \pm 2{ }^{\circ} \mathrm{C}$, under $12-\mathrm{h}$ light and dark cycles, and were allowed free access to water and standard laboratory chow (Biofarm, Zagyvaszántó, Hungary).

\subsection{Ethics}

All animal experiments were conducted in compliance with the Guide for the Care and Use of Laboratory Animals (National Academies Press, Eight Edition, 2011), with the 2010/63/EU guideline and the Hungarian 40/2013 (II.14.) government decree and were approved by the Institutional Animal Care and Use Committee of the University of Szeged (I-74-3/2012 MÁB) and also by an independent committee assembled by national authorities (XII./3773/2012.). LG experiments were also conducted in compliance with the ARVO Statement for the Use of Animals in Ophthalmic and Vision Research. 


\subsection{Solutions and chemicals}

Chromatographically pure collagenase was obtained from Worthington (Lakewood, NJ, USA), Isolation solution contained DMEM (Dulbecco modified Eagle medium) supplemented with $100 \mathrm{U} / \mathrm{ml}$ collagenase and $1 \mathrm{mg} / \mathrm{ml}$ bovine serum albumin. Storage solution contained DMEM and 3\% (wt/vol) bovine serum albumin. Culture solution contained McCoy 5A tissue culture medium, 10\% (vol/vol) fetal calf serum, and $2 \mathrm{mmol} / \mathrm{l}$ glutamine. Ingredients of media (DMEM, McCoy, fetal calf serum, glutamine and bovine serum albumin) were purchased from Sigma-Aldrich (Budapest, Hungary).

Standard HEPES-buffered solution contained (mmol/l): $140 \mathrm{NaCl}(67.5 \mathrm{NaCl}$ in case of hypotonic solution: $145 \operatorname{mosM}), 5 \mathrm{KCl}, 2 \mathrm{CaCl}_{2}, 1 \mathrm{MgCl}_{2}, 10 \mathrm{D}$-glucose and $10 \mathrm{Na}-\mathrm{HEPES}$ and $\mathrm{pH}$ was set to 7.4 with $\mathrm{HCl}$ at $37^{\circ} \mathrm{C}(290 \mathrm{mosM})$.

The standard $\mathrm{HCO}_{3}{ }^{-} / \mathrm{CO}_{2}$-buffered solution contained (mmol/l): $115 \mathrm{NaCl}, 25$ $\mathrm{NaHCO}_{3}, 5 \mathrm{KCl}, 1 \mathrm{CaCl}_{2}, 1 \mathrm{MgCl}_{2}, 10 \mathrm{D}$-glucose and was gassed with $95 \% \mathrm{O}_{2} / 5 \%$ $\mathrm{CO}_{2}$ at $37^{\circ} \mathrm{C}$.

CellTak was obtained from Becton Dickinson Labware (Bedford, MA, USA). Carbachol (carbamoylcholine chloride), forskolin, bumetanide, dihydro-4,4'diisothyocyanato-stilbene-2,2'-disulphonic acid (H2DIDS), 5-(N-ethyl-Nisopropyl)amiloride (EIPA) and soybean trypsin inhibitor were obtained from SigmaAldrich (Budapest, Hungary).

\subsection{Isolation and culture of lacrimal and pancreatic duct segments}

Rabbit LG interlobular ducts were isolated as previolusly described by our laboratory based on pancreatic duct isolation methods [14]. Briefly, LGs were dissected and transferred to a sterilized small flat-bottom glass flask containing a cold $\left(+4^{\circ} \mathrm{C}\right)$ storage solution. Isolation solution was injected into the interstitium of the glands and the tissue pieces were transferred to a glass flask containing $2 \mathrm{ml}$ of isolation solution for incubation in shaking water bath at $37{ }^{\circ} \mathrm{C}$ for 25 minutes. Isolation solution was removed after incubation and $5 \mathrm{ml}$ of fresh cold storage $\left(+4^{\circ} \mathrm{C}\right)$ solution was added to the flask. Tissue samples were transferred to a glass microscope slide and viewed under stereo microscope. Interlobular ducts were micro-dissected and after microdissection, intact LG ducts were transferred to the culture solution in a 
Petri dish. Ducts were cultured overnight in a $37^{\circ} \mathrm{C}$ incubator gassed with $5 \%$ $\mathrm{CO}_{2} / 95 \% \mathrm{O}_{2}$.

Guinea pig pancreatic intra/interlobular ducts were isolated and then cultured as described above except that, all used mediums were supplemented with $0.01 \%$ trypsin inhibitor [86].

\subsection{Measurement of osmotic water permeability and ductal fluid secretion of lacrimal gland interlobular duct epithelium}

Ends of LG ducts sealed during overnight incubation forming a closed luminal space. Fluid secretion (or osmotically determined fluid movement) into the closed intraluminal space of the ducts resulted in ductal swelling which could be analyzed using the videomicroscopic method [87,88]. Cultured LG duct segments were carefully transferred to a coverslip pretreated with Cell-Tak. The coverslip formed the base of a perfusion chamber mounted on an inverted microscope (Nikon Diaphot Inverted Tissue Culture Microscope). The chamber was perfused with solutions via an infusion pump at approximately $2.5 \mathrm{ml} / \mathrm{min}$ at $37{ }^{\circ} \mathrm{C}$. Ducts were visualized at high magnification (40 x objective). Bright-field images were acquired at set time intervals ( 5 seconds in case of osmotic permeability measurements and 1 minute in case of ductal fluid secretion experiments) using a charge-coupled device camera coupled to a PC. Both the duration of experiments and the time intervals between images were defined in Image $J$ software. An image series in TIFF-format were generated containing all of the images collected from the same experiment. Scion Image (Scion Corporation, Frederick, MD, USA) software was used to analyze changes to obtain values from the area corresponding to the luminal space in each image.

The initial lumen length $\left(\mathrm{L}_{0}\right)$ and the lumen area $\left(\mathrm{A}_{0}\right)$ were measured directly from the pixel intensities on the first image. The lumen diameter was calculated assuming cylindrical setup of the duct, from the formula $2 \mathrm{R}=\mathrm{A}_{0} / \mathrm{l}_{0}$. The luminal surface area was calculated as $2 \pi \mathrm{R}_{0} \mathrm{~L}_{0}$, also assuming cylindrical geometry. Measurements from subsequent individual images were normalized to the first lumen area in the series $\left(A_{0}\right)$ thus giving values for the relative area $\left(A_{R}=A / A_{0}\right)$. Relative luminal volume $\left(\mathrm{V}_{\mathrm{R}}=\mathrm{V} / \mathrm{V}_{0}\right)$ of the ducts was then calculated from the relative image area. These calculations were done using Scion Image and Microsoft Excel software. Luminal volume change after exposure to hypotonic solution was measured for the 
calculation of osmotic permeability as follows: ducts were perfused with isotonic HEPES-buffered solution (290 mosM) for 5 minutes after equilibration, than the perfusate was changed to hypotonic HEPES-buffered solution (145 mosM) [89]. The osmotic water permeability constant $\left(\left[\mathrm{P}_{\mathrm{f}}\right]=\mu \mathrm{m} / \mathrm{s}\right)$ was calculated using the initial volume $\left(V_{0}=\pi R_{0}^{2} l_{0}\right)$, the initial slope of the relative volume increase $\left(d\left(V / V_{0}\right) / d t\right)$, the initial luminal surface area $\left(2 \pi \mathrm{R}_{0} \mathrm{l}_{0}\right)$, and the molar volume of water $\left(\mathrm{V}_{\mathrm{w}}=18 \times 10^{12}\right.$ $\mu \mathrm{m} / \mathrm{mol})$ as follows [90]:

$$
\mathrm{P}_{\mathrm{f}}=\left[\mathrm{V}_{0} \mathrm{~d}\left(\mathrm{~V} / \mathrm{V}_{0}\right) / \mathrm{dt}\right] /\left[\mathrm{S}_{0} \mathrm{~V}_{\mathrm{w}}\left(\text { osm }_{\text {in }}-\text { osm }_{\text {out }}\right)\right]
$$

where $\mathrm{osm}_{\text {in }}-\mathrm{osm}_{\text {out }}$ is the difference between inner and outer mediums osmolarity. In this case $\mathrm{osm}_{\mathrm{in}}=290 \mathrm{mOsm}$ and $\mathrm{osm}_{\text {out }}=145 \mathrm{mOsm}$.

In the case of fluid secretion measurement, carbachol or forskolin were added to the perfusate after 10 minutes superfusion with HEPES-buffered or $\mathrm{HCO}_{3}{ }^{-} / \mathrm{CO}_{2}$-buffered solution. At the end of each experiment, perfusion was changed to hypotonic solution for 5 minutes in order to confirm epithelial integrity. Complete sealing was proved by rapid swelling as a response to hypotonic challenge. Data obtained from ducts not showing swelling response were discarded.

\subsection{Bile acid treatments}

Pancreatic ducts were treated with bile acids as follows: no treatment (control group), 5 minutes CDCA (1 mM) treatment (CDCA group), $24 \mathrm{~h}$ UDCA (0.5 mM) treatment (UDCA group) and $24 \mathrm{~h}$ preincubation with $0.5 \mathrm{mM}$ UDCA and then parallel incubation for further 5 minutes with $1 \mathrm{mM} \mathrm{CDCA}$ (UDCA+CDCA group).

\subsection{Measurement of intracellular $\mathrm{Ca}^{2+}$ concentration, $\mathrm{pH}$ and ATP level}

$\left[\mathrm{Ca}^{2+}\right]_{\mathrm{i}}, \mathrm{pH}_{\mathrm{i}}$ and $\mathrm{ATP}_{\mathrm{i}}$ were measured by loading the pancreatic ducts with the $\mathrm{Ca}^{2+}$ - sensitive fluorescent dye, FURA 2-AM $(5 \mu \mathrm{M}, 60 \mathrm{~min}$, in the presence of $0.05 \%$ pluronic F-127), the $\mathrm{pH}$-sensitive fluorescent dye, BCECF-AM ( $2 \mu \mathrm{M}, 30 \mathrm{~min})$ and the $\mathrm{Mg}^{2+}$-sensitive fluorescent dye, MgGreen-AM ( $5 \mu \mathrm{M}, 60 \mathrm{~min}$, in the presence of $0.05 \%$ pluronic F-127), respectively. Ducts were attached to a poly-l-lysine-coated cover slip (24 mm) forming the base of a perfusion chamber and were mounted on the stage of an inverted fluorescence microscope linked to an Xcellence imaging system (Olympus, Budapest, Hungary). Ducts were then bathed with different solutions at 
$37^{\circ} \mathrm{C}$ at the perfusion rate of 5-6 $\mathrm{ml} / \mathrm{min}$. 6-7 region of interests (ROIs) were examined in each experiments and one measurement per second was obtained.

To determine the changes of $\left[\mathrm{Ca}^{2+}\right]_{\mathrm{i}}$, cells were excited with 340 and $380 \mathrm{~nm}$ wavelength and the changes in $\left[\mathrm{Ca}^{2+}\right]_{\mathrm{i}}$ were calculated from the $340 / 380$ fluorescence ratio measured at $510 \mathrm{~nm}$. In order to estimate $\mathrm{pH}_{\mathrm{i}}$, cells were excited with 490 and $440 \mathrm{~nm}$ wavelength, and the 490/440 fluorescence emission ratio was measured at $535 \mathrm{~nm}$. The calibration of the fluorescent emission ratio to $\mathrm{pH}_{\mathrm{i}}$ was performed with the high- $\mathrm{K}^{+}$-nigericin technique, as previously described $[91,92]$. Changes in $[\mathrm{ATP}]_{\mathrm{i}}$ was determined by exciting the cells at a wavelength of $490 \mathrm{~nm}$, with emitted light monitored at $535 \mathrm{~nm}$. Fluorescence signals were normalised to initial fluorescence intensity $\left(\mathrm{F} / \mathrm{F}_{0}\right)$ and expressed as relative fluorescence.

\subsection{Measurement of the activity of acid/base transporters}

In order to estimate the activity of the NHE, the $\mathrm{NBC}$ and the AEs the $\mathrm{NH}_{4} \mathrm{Cl}$ prepulse technique was used. Briefly, exposure of PDECs to $20 \mathrm{mM} \mathrm{NH}_{4} \mathrm{Cl}$ for 3 minutes induced an immediate rise in $\mathrm{pH}_{\mathrm{i}}$ due to the rapid entry of lipophilic, basic $\mathrm{NH}_{3}$ into the cells. After the removal of $\mathrm{NH}_{4} \mathrm{Cl}, \mathrm{pH}_{\mathrm{i}}$ rapidly decreased. This acidification is caused by the dissociation of intracellular $\mathrm{NH}_{4}{ }^{+}$to $\mathrm{H}^{+}$and $\mathrm{NH}_{3}$, followed by the diffusion of $\mathrm{NH}_{3}$ out of the cell. In standard Hepes-buffered solution the initial rate of $\mathrm{pH}_{\mathrm{i}}(\Delta \mathrm{pH} / \Delta \mathrm{t})$ recovery from the acid load (over the first $60 \mathrm{sec}$ ) reflects the activities of NHEs, whereas in $\mathrm{HCO}_{3}-/ \mathrm{CO}_{2}$-buffered solutions represents the activities of both NHEs and NBC $[93,94]$. In order to estimate CBE activity the initial rate of $\mathrm{pH}_{\mathrm{i}}$ recovery from alkalosis in $\mathrm{HCO}_{3}-/ \mathrm{CO}_{2}$-buffered solutions was analyzed. Previous data have indicated that under these conditions the recovery over the first 30 seconds reflects the activity of CBE [93,94].

In order to evaluate transmembrane base flux $\left(J\left(\mathrm{~B}^{-}\right)\right)$the following equation was used: $J\left(\mathrm{~B}^{-}\right)=\Delta \mathrm{pH} / \Delta \mathrm{t} X \beta_{\text {total, }}$ where $\Delta \mathrm{pH} / \Delta \mathrm{t}$ was calculated by linear regression analysis, whereas the total buffering capacity $\left(\beta_{\text {total }}\right)$ was estimated by the HendersonHasselbach equation using the following formula: $\beta_{\text {total }}=\beta_{\mathrm{i}}+\beta_{\mathrm{HCO}-}=\beta_{\mathrm{i}}+$ $2.3 x\left[\mathrm{HCO}_{3}{ }^{-}\right]_{\mathrm{i}}$. We denote base influx as $J(\mathrm{~B})$ and base efflux (secretion) as $-J\left(\mathrm{~B}^{-}\right)$. 


\subsection{Measurement of mitochondrial membrane potential}

Mitochondrial membrane potential $\left(\Delta \Psi_{\mathrm{m}}\right)$ was measured using the lipophilic, mitochondria-selective fluorescence dye, TMRM. Accumulation of TMRM in the mitochondria is depend on the $\Delta \Psi_{\mathrm{m}}$. Pancreatic ducts were preincubated with TMRM $(1 \mu \mathrm{M})$ for $30 \mathrm{~min}$ at $37^{\circ} \mathrm{C}$ and transferred to a poly-1-lysine-coated cover slip (24 $\mathrm{mm}$ ) forming the base of a perfusion chamber. Ducts were than perfused continuously with solutions at $37^{\circ} \mathrm{C}$ at a rate of $2-2.5 \mathrm{ml} / \mathrm{min}$. The perfusion solutions were complemented with $100 \mathrm{nM}$ TMRM to avoid dye leakage. Changes in $\Delta \Psi_{\mathrm{m}}$ were monitored using a Fluoview 10i-W confocal microscope (Olympus, Budapest, Hungary). 5-10 ROIs (mitochondria) of 5-10 cells were excited with light at $543 \mathrm{~nm}$ and the emitted light was captured between 560-650 $\mathrm{nm}$. We have employed the dequench method for the estimation of $\Delta \Psi_{\mathrm{m}}$. At the applied concentration of TMRM, depolarisation of the mitochondria causes release of the dye and it's dequenching in the cytosol. Thus increase in fluorescence intensity reflects a decrease in $\Delta \Psi_{\mathrm{m}}$. Fluorescence signals were normalised to initial fluorescence intensity $\left(\mathrm{F} / \mathrm{F}_{0}\right)$ and expressed as relative fluorescence.

\subsection{Measurement of mitochondrial permeability transition pore opening}

To measure mitochondrial inner membrane permeabilization and/or the opening of the mitochondrial permeability transition pore (mPTP), we used the calcein-cobalt dequenching technique. Calcein-AM is a lipid-soluble fluorescent dye which diffuses into all subcellular components including mitochondria. $\mathrm{Co}^{2+}$ is a quencher of calcein which can enter to the cytoplasm but cannot pass through the mitochondrial membrane. Upon transient opening of mPTP, $\mathrm{Co}^{2+}$ diffuses into the mitochondria and quenches the mitochondrial calcein fluorescence which results in a decrease of fluorescence intensity. Pancreatic ducts were loaded with calcein-AM (1 $\mu \mathrm{M})$ for $30 \mathrm{~min}$ then with $\mathrm{CoCl}_{2}(1 \mathrm{mM})$ for further $10 \mathrm{~min}$. Ducts were then washed at $37^{\circ} \mathrm{C}$ at the perfusion rate of $5-6 \mathrm{ml} / \mathrm{min}$ and imaged using an Olympus IX71 fluorescence microscope (Olympus, Budapest, Hungary). 5-6 ROIs were excited with light at $495 \mathrm{~nm}$ and the emitted light was captured at $515 \mathrm{~nm}$. Fluorescence signals were normalised to initial fluorescence intensity $\left(\mathrm{F} / \mathrm{F}_{0}\right)$ and expressed as relative 
fluorescence.

\subsection{TUNEL cell death assay}

For detection of cell death we used the terminal deoxyribonucleotidyl transferase (TDT)-mediated dUTP-digoxigenin nick end labelling (TUNEL) assay (Roche Diagnostics, Mannheim, Germany). Intra-interlobular pancreatic ducts were treated with bile acids as previously described. Control and bile acid-treated isolated duct segments were fixed with $4 \%$ paraformaldehyde overnight and then cryosection and staining of the samples were performed according to the manufacturer's protocol. The CDCA-treated groups were incubated for $3 \mathrm{~h}$ in culture media before fixation. To normalize TUNEL reaction we used tonsil samples. Pictures were taken with the use of a Zeiss AxioImager fluorescent light microscope (Carl Zeiss MicroImaging, Thornwood, NY, USA) fitted with a PixeLINK CCD camera (PixeLINK, Ottawa, ON, Canada)

\subsection{Transmission electron microscopy}

For electron microscopic studies, ducts were fixed in $2.5 \%$ glutaraldehyde immediately after isolation(“Keratoconjunctivitis Sicca and Corneal Ulcers.," n.d.). Samples were then postfixed in $1 \%$ osmium tetroxide, dehydrated in a series of graded ethanols, and subsequently embedded in epoxy resin. Ultrathin sections were contrasted with uranyl acetate and lead citrate. Tissue sections were analyzed under a transmission electron microscope (CM10; Philips, Eindhoven, The Netherlands).

\subsection{Induction of acute pancreatitis}

Male SPRD rats weighing 200-250 g were used for AP experiments. Animals were fasted $12 \mathrm{~h}$ before the surgical procedure. Ursodeoxycholic acid (Ursofalk) was purchased from Dr Falk Pharma Ltd. UDCA was dissolved in $2 \mathrm{~mL}$ of tap water and $250 \mathrm{mg} / \mathrm{kg}$ of body weight was administered orally (gavage) for two weeks. Control animal were only treated with same amount of tap water. Last UDCA treatment was performed one day before the pancreatitis induction. Rats were anesthetized with intraperitoneal injection of a cocktail, containing of $50 \mathrm{mg} / \mathrm{kg}$ Ketamine and $10 \mathrm{mg} / \mathrm{kg}$ Xylazine. After the anesthesia rats were shaven and the abdominal cavity was opened 
with median laparotomy. The common bile duct was temporary occluded with a vessel clip. Duodenum was punctured with a $0.4-\mathrm{mm}$ diameter needle connected to polyethylene tubing. The polyethylene tube was placed into the major pancreatic duct and $1 \mathrm{ml} / \mathrm{kg} 1 \%$ sodium-CDCA (dissolved in physiologic saline) was administered via retrograde ductal infusion with $1 \mathrm{ml} / \mathrm{min}$ speed with an infusion pump (TSE System GmbH, Bad Homburg, Germany). Control animals received intraductal physiological saline instead of bile acid. After bile acid or physiological saline infusion, vessel clip and the polyethylene tube were removed and the abdominal wall and skin were closed. Rats were sacrificed $24 \mathrm{~h}$ later of the surgical procedure.

\subsection{Histologic examination and laboratory parameter measurements}

Terminal anesthesia was performed with $50 \mathrm{mg} / \mathrm{kg}$ sodium pentobarbitale. Abdominal and thoracic cavity was opened with a median laparotomy and thoracotomy and blood was collected with cardiac puncture. Pancreas was removed immediately after the blood collection and it was trimmed from fat and lymphatic tissues on ice. Pancreata were dissected and only the part of head and body were used for histological analysis and for laboratorial measurements. The pancreatic tail didn't show any necrosis or signs of inflammation therefore it was not used later. The pancreatic head and body were longitudinally dissected and one part of pancreas was put into $6 \%$ neutral formaldehyde solution, however other part was immediately frozen in liquid nitrogen. These parts of pancreata were stored at $-80{ }^{\circ} \mathrm{C}$ until for use. The collected blood was centrifuged at $4{ }^{\circ} \mathrm{C}$ with $2500 \mathrm{RCF}$ for $15 \mathrm{~min}$. Sera were collected and it was stored at $-20{ }^{\circ} \mathrm{C}$ until for use. Serum amylase activity was measured with a commercial colorimetric kit (Diagnostikum) with a FLUOstar OPTIMA (BMG Labtech) microplate reader at $405 \mathrm{~nm}$. Wet pancreatic tissues were measured and they were dried for $24 \mathrm{~h}$ at $100{ }^{\circ} \mathrm{C}$. The dry weight-wet weight ratio was calculated. Pancreatic samples were prepared for hematoxylin and eosin staining. Pancreatic histological samples were scanned. Necrotic areas were detected and analyzed with Image J (National Institutes of Health, Bethesda, MD, USA) software. Necrotic areas were compared to the total analyzed pancreatic area. 


\subsection{Statistical Analysis}

Data are expressed as means \pm SEM. Significant difference between groups was determined by analysis of variance (ANOVA). Statistical analysis of the in vitro data was performed using the Mann-Whitney U test. In vivo experiments were evaluated by using ANOVA followed by Bonferroni or Dunnett's multiple comparison post hoc test. Probability values of $p<0.05$ were accepted as being significant in every cases. 


\section{RESULTS}

\subsection{Investigation of lacrimal gland ductal secretion}

\subsubsection{Osmotic water permeability of lacrimal gland interlobular duct epithelium}

The perfusion of the ducts with hypotonic solution the luminal area resulted in rapid increase in the luminal area, indicating that the $\mathrm{NaCl}$ gradient caused rapid water flux into the closed luminal space. $P_{\mathrm{f}}$ proved to be $60.53 \mu \mathrm{m} / \mathrm{s}( \pm 19,76)$. Figure 2. shows the changes in the relative luminal volume $\left(V_{r}\right)$ after the change in bath osmolarity. Data were obtained from nine ducts $(n=9)$ originated from three different animals.

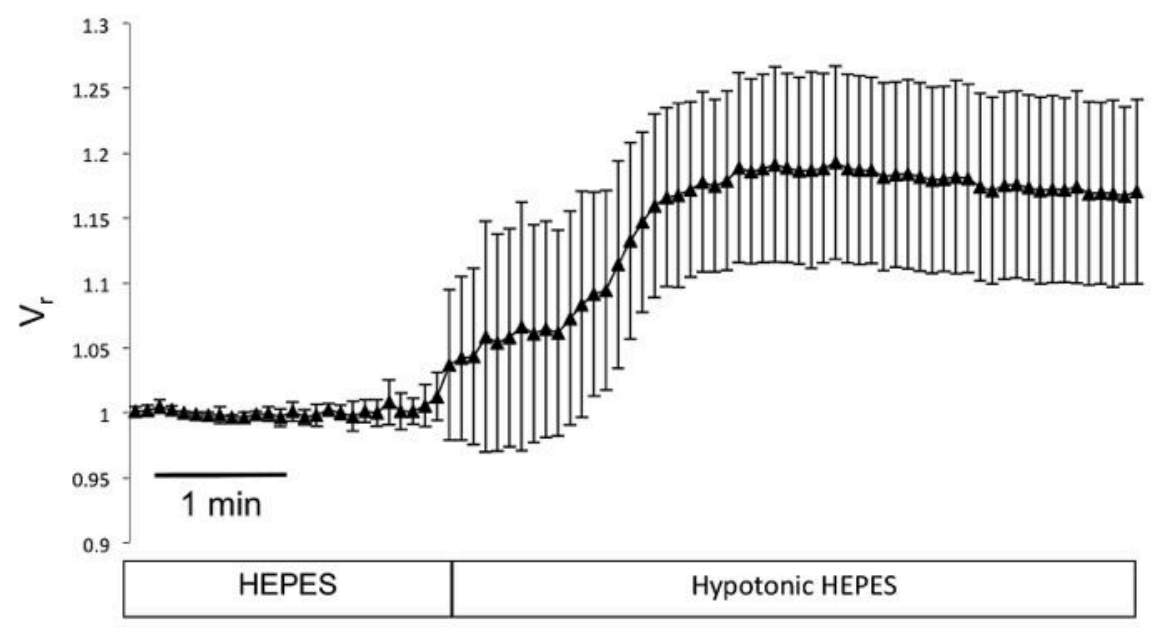

Figure 2. Osmotic permeability of rabbit interlobular duct epithelium. LG ducts were isolated from the LG of rabbits. Changes in the relative luminal volume $\left(\mathrm{V}_{\mathrm{r}}\right)$ induced by a $50 \%$ reduction in the osmolarity of the perfusate are shown. Measurements were performed by video microscopy. Bright field images were captured at 5-second intervals. Data was obtained from nine ducts isolated from three different animals and is presented as the mean \pm SEM.

\subsubsection{Forskolin-stimulated fluid secretion of lacrimal gland interlobular ducts in the presence and in the absence of $\mathrm{HCO3-}$}

LG duct secretion to forskolin stimulation were investigated both in $\mathrm{HCO}_{3}^{-}$ free (HEPES-buffered) and in $\mathrm{HCO}_{3}{ }^{-} / \mathrm{CO}_{2}$-buffered solutions. At first step ducts were superfused with HEPES-buffered solution for 10 minutes, and then $10 \mu \mathrm{mol} / 1$ forskolin was added to the bath. Ducts remained unchanged in HEPES-buffered 
solution, but during forskolin stimulation, rapid, sustained luminal volume increase was observed which remained relatively unchanged over a 30-minutes period (Figure 3A). To evaluate the possible role of $\mathrm{HCO}_{3}{ }^{-}$in forskolin-evoked fluid secretion, ducts were superfused with $\mathrm{HCO}_{3} / \mathrm{CO}_{2}$-buffered solutions for 10 minutes, and then forskolin was added to the bath. There was no detectable secretion in $\mathrm{HCO}_{3}{ }^{-} / \mathrm{CO}_{2}{ }^{-}$ buffered solution, while rapid secretion could be observed as an effect of forskolin stimulation without decline in the swelling response over a 30 minutes period (Figure 3B). The secretory effect of forskolin did not differ in HEPES-buffered and in $\mathrm{HCO}_{3}{ }^{-}$ $/ \mathrm{CO}_{2}$-buffered solution.
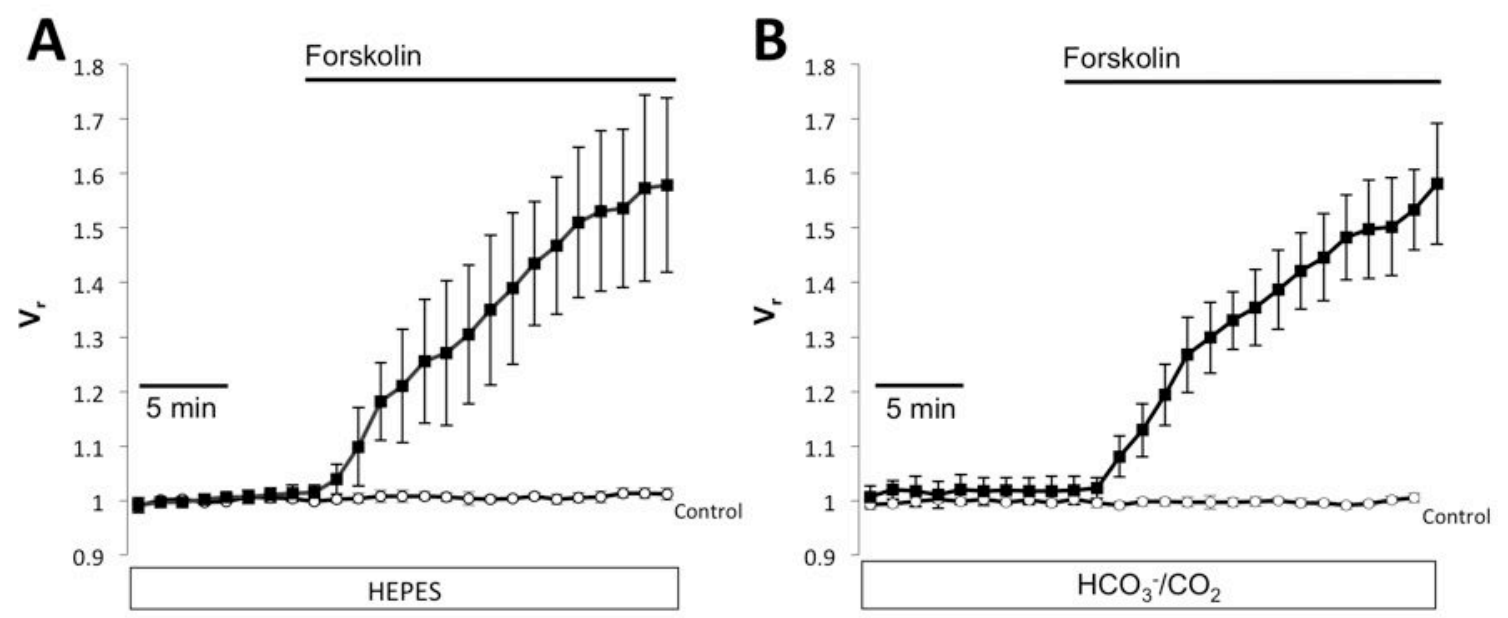

Figure 3. Effect of forskolin on ductal fluid secretion in rabbit LG interlobular ducts in the presence or in the absence of $\mathrm{HCO}_{3}^{-}$. (A) Ducts were superfused with HEPES-buffered solution throughout the experiments. From 10 minutes, ducts were exposed either to $10 \mathrm{lM}$ forskolin (filled square) or to no agonist (empty circle). (B) Ducts were superfused with HEPES-buffered solution for 10 minutes (data not shown) and then the perfusate was switched to $\mathrm{HCO}_{3}{ }^{-} / \mathrm{CO}_{2}$ buffered solution. After 10 minutes of superfusion with $\mathrm{HCO}_{3}{ }^{-} / \mathrm{CO}_{2}$ buffered solution, ducts were exposed either to $10 \mathrm{lM}$ forskolin (filled square) or to no agonist (empty circle). Changes in relative luminal volume (Vr) are shown. Data was obtained from five ducts isolated from at least three different animals in each series and is presented as the mean \pm SEM.

\subsubsection{Effects of different inhibitors on fluid secretion}

The above described results indicate that LG interlobular ducts are able to secrete fluid in response to forskolin stimulation in HEPES-buffered solution in the absence of extracellular $\mathrm{HCO}_{3}{ }^{-}$, another anion than $\mathrm{HCO}_{3}{ }^{-}$, most probably $\mathrm{Cl}^{-}$can be the driving force of fluid secretion. To study the source of basolateral $\mathrm{Cl}^{-}$uptake, we tested the role of $\mathrm{NKCC} 1$ by means of examination of the effect of cotransport inhibitor bumetanide. Bumetanide $(100 \mu \mathrm{mol} / \mathrm{l})$ completely blocked forskolin-evoked 
fluid secretion in HEPES-buffered, and also in $\mathrm{HCO}_{3}{ }^{-}$-buffered solutions (Figure 4A and 4B). Bumetanide was applied after 10 minutes of forskolin stimulation. Pretreatment with bumetanide completely inhibited forskolin evoked fluid secretion in $\mathrm{HCO}_{3}{ }^{-}$-buffered solution (Figure 4C) The complete inhibition of fluid secretion by bumetanide in $\mathrm{HCO}_{3}{ }^{-}$-buffered solution suggests the central role of $\mathrm{Cl}^{-}$transport and only the marginal role of $\mathrm{HCO}_{3}{ }^{-}$transport in this process.
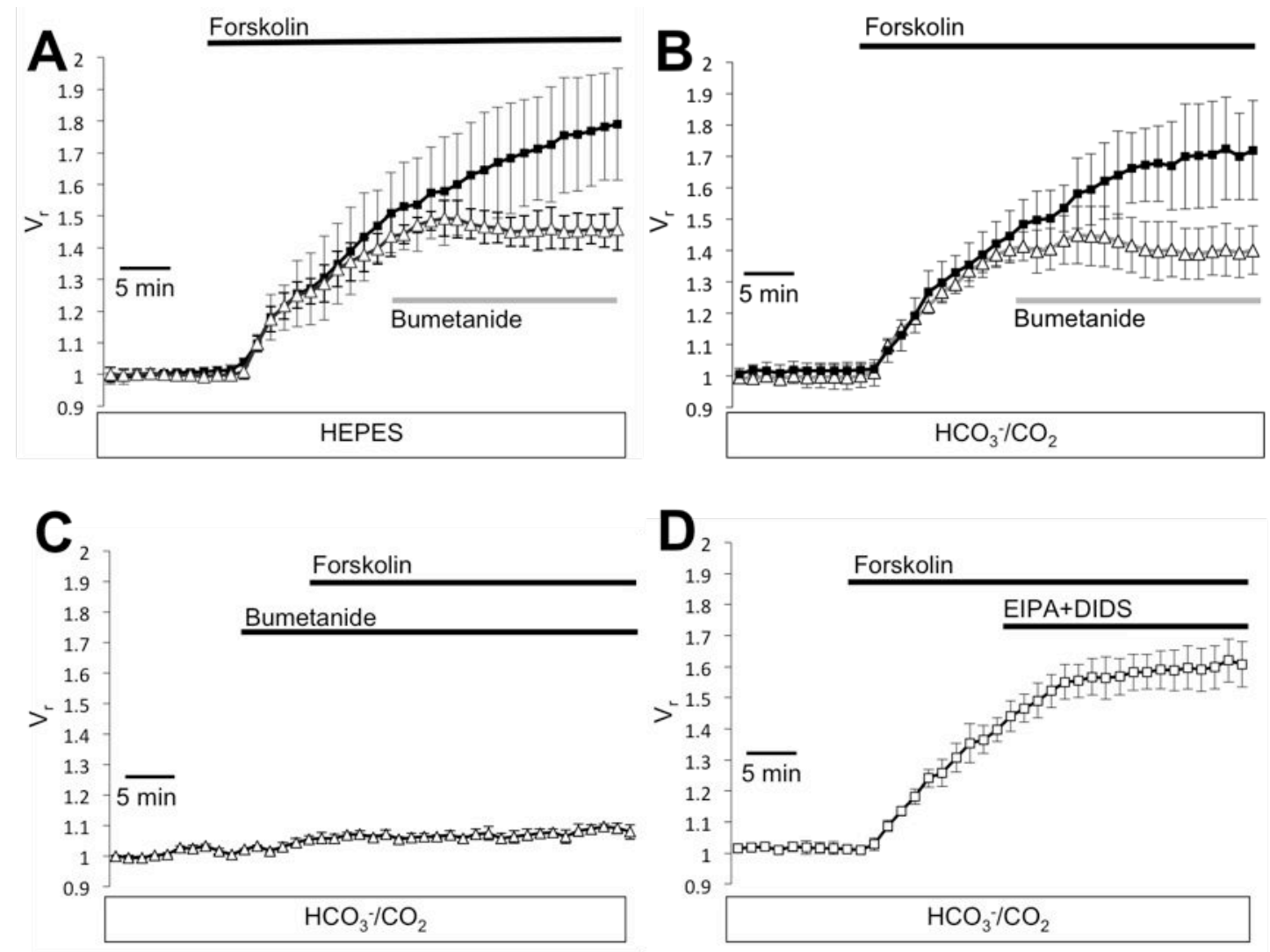

Figure 4. Effect of different inhibitors on forskolin-evoked ductal fluid secretion in rabbit LG interlobular ducts. (A) Ducts were superfused with HEPES buffered solution throughout the experiments. From 10 minutes, ducts were exposed to 10 $\mu \mathrm{mol} / 1$ forskolin, from 20 minutes, ducts were exposed either to no blocker (only forskolin stimulation, filled square) or to $100 \mu \mathrm{mol} / 1$ bumetanide (empty triangle). (B) Ducts were superfused with HEPES buffered solution for 10 minutes (data not shown) and then the perfusate was switched to $\mathrm{HCO}_{3}{ }^{-} / \mathrm{CO}_{2}$ buffered solution. After 10 minutes of superfusion with $\mathrm{HCO}_{3}{ }^{-} / \mathrm{CO}_{2}$ buffered solution, ducts were exposed to $10 \mu \mathrm{mol} / 1$ forskolin. From 20 minutes, ducts were exposed either to no blocker (only forskolin stimulation, filled square) or to $100 \mu \mathrm{mol} / 1$ bumetanide (empty triangle). (C) Ducts were superfused with HEPES buffered solution for 10 minutes (data not shown) and then the perfusate was switched to $\mathrm{HCO}_{3}{ }^{-} / \mathrm{CO}_{2}$ buffered solution. From 10 minutes, ducts were exposed either to $100 \mu \mathrm{mol} / \mathrm{l}$ bumetanide (empty triangle), or no blocker (filled square). From 20 minutes, all ducts were exposed to $10 \mu \mathrm{mol} / \mathrm{l}$ forskolin. (D) Ducts were superfused with HEPES buffered solution for 10 minutes (data not shown) and then the perfusate was switched to $\mathrm{HCO}_{3}{ }^{-} / \mathrm{CO}_{2}$ buffered solution. After 10 minutes of superfusion with $\mathrm{HCO}_{3}{ }^{-} / \mathrm{CO}_{2}$ buffered solution, ducts were exposed to $10 \mu \mathrm{mol} / 1$ forskolin. From 20 minutes ducts were exposed to $3 \mu \mathrm{mol} / \mathrm{l}$ 
EIPA and $100 \mu \mathrm{mol} / 1$ DIDS (empty square). Administration of EIPA and DIDS without bumetanide did not cause statistically significant reduction in forskolinevoked fluid secretion. Changes in relative luminal volume (Vr) are shown. Data was obtained from five ducts isolated from at least three different animals in each series and is presented as the mean \pm SEM.

\subsubsection{The role of basolateral $\mathrm{HCO}_{3}{ }^{-}$transporters in fluid secretion}

To study the contribution of basolateral $\mathrm{HCO}_{3}{ }^{-}$and $\mathrm{Cl}^{-}$transporters, we tested the role of inhibition of basolateral transporters potentially contributing to the $\mathrm{HCO}_{3}{ }^{-}$ transport. NHE was inhibited by $3 \mu \mathrm{mol} / 1 \mathrm{EIPA}$, and $\mathrm{Na}^{+}-\mathrm{HCO}_{3}{ }^{-}$cotransporter was inhibited by $500 \mu \mathrm{mol} / 1$ DIDS. In $\mathrm{HCO}_{3}^{-}$-buffered solution, administration of EIPA and DIDS had no effect on forskolin-evoked fluid secretion while simultaneous administration of $30 \mu \mathrm{mol} / 1$ bumetanide, $3 \mu \mathrm{mol} / 1$ EIPA and $500 \mu \mathrm{mol} / 1$ DIDS completely inhibited fluid secretion evoked by forskolin (Figure 4D).

These results suggest the key role of $\mathrm{Cl}^{-}$transport in fluid secretion in rabbit lacrimal gland interlobular ducts.

\subsubsection{Carbachol-stimulated fluid secretion of lacrimal gland interlobular ducts in the presence and in the absence of $\mathrm{HCO}_{3}^{-}$}

Carbachol were used in $10 \mu \mathrm{mol} / 1,100 \mu \mathrm{mol} / 1$, and $1 \mathrm{mmol} / 1$ doses to stimulate ductal fluid secretion. No secretory response was detected at $10 \mu \mathrm{mol} / 1$ concentration, while ductal swelling observed at the concentration of $1 \mathrm{mmol} / \mathrm{l}$ did not produce higher value compared to data obtained during $100 \mu \mathrm{mol} / 1$ dose stimulation (data are not shown). Carbachol in $100 \mu \mathrm{mol} / 1$ was used as the lowest concentration producing the maximal obtainable effect in the experiments described thereinafter.

Effect of carbachol treatment on secretion of lacrimal gland ducts was investigated both in HEPES-buffered and in $\mathrm{HCO}_{3}{ }^{-} / \mathrm{CO}_{2}$-buffered solutions. In the first series of experiments ducts were perfused with HEPES-buffered solutions for 10 min, followed by administration of $100 \mu \mathrm{mol} / \mathrm{l}$ carbachol to the bath solution. No secretion was observed in HEPES-buffered solution, while carbachol initiated ductal swelling representing the cholinergic effect-evoked ductal fluid secretion. Fluid secretion proved to be biphasic consisting of a continuous swelling in the first 5 minutes followed by a plateau phase (Figure 5A).

The role of $\mathrm{HCO}_{3}{ }^{-}$in carbachol evoked fluid secretion was investigated in the 
second series of experiments. Ducts were perfused with standard HEPES-buffered solution for $5 \mathrm{~min}$ (not shown in the figure $5 \mathrm{~B}$ ) followed by $10 \mathrm{~min}$ perfusion with $\mathrm{HCO}_{3}{ }^{-} / \mathrm{CO}_{2}$-buffered solution. One hundred $\mu \mathrm{mol} / 1$ carbachol was then administered to the bath and swelling response was detected. Figure 5B shows mean data for the change in relative volume. Ducts did not show spontaneous fluid secretion in $\mathrm{HCO}_{3}{ }^{-}$ $/ \mathrm{CO}_{2}$-buffered solution. The kinetics of carbachol stimulated ductal fluid secretion was very similar to those that observed in HEPES-buffered solution. The stimulatory effect of carbachol could be detected in the first 5 minutes, followed by a plateau phase. Administration of parasympatholytic atropine resulted in a complete abolishment of carbachol-evoked fluid secretion both in HEPES-buffered and in $\mathrm{HCO}_{3}{ }^{-} / \mathrm{CO}_{2}$-bufered solutions (Figure $5 \mathrm{~A}$ and $5 \mathrm{~B}$ ).
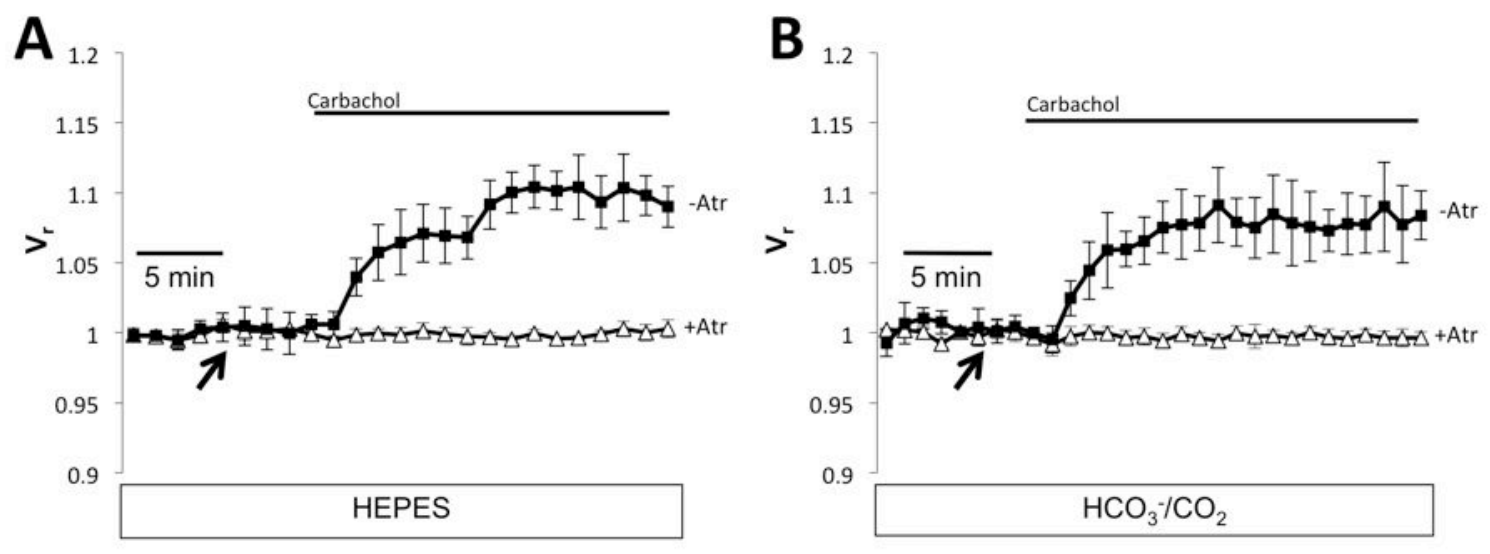

Figure 5. Effect of carbachol on ductal fluid secretion in LG gland interlobular ducts in the presence or in the absence of $\mathrm{HCO}_{3}^{-}$. (A) Ducts were superfused with HEPES buffered solution throughout the experiments. From 5 minutes ducts were exposed either to $100 \mu \mathrm{mol} / 1$ atropine (empty triangle, arrow indicates the initiation of atropine treatment) or no blocker (filled square). From 10 minutes all ducts were exposed to $100 \mu \mathrm{mol} / \mathrm{l}$ carbachol. (B) Ducts were superfused with HEPES buffered solution for 10 minutes (data not shown) and then the perfusate was switched to $\mathrm{HCO}_{3}{ }^{-} / \mathrm{CO}_{2}$ buffered solution. From 5 minutes, ducts were exposed either to $100 \mu \mathrm{mol} / 1$ atropine (empty triangle, arrow indicates the initiation of atropine treatment) or no blocker (filled square). From 10 minutes, all ducts were exposed to $100 \mu \mathrm{mol} / 1$ carbachol. Changes in the relative luminal volume $\left(\mathrm{V}_{\mathrm{r}}\right)$ are shown. Data was obtained from five ducts isolated from at least three different animals in each series and is presented as the mean \pm SEM.

Calculated secretory rates did not show a substantial difference measured in HEPES-buffered and $\mathrm{HCO}_{3}{ }^{-} / \mathrm{CO}_{2}$-buffered solutions (Figure 6). 


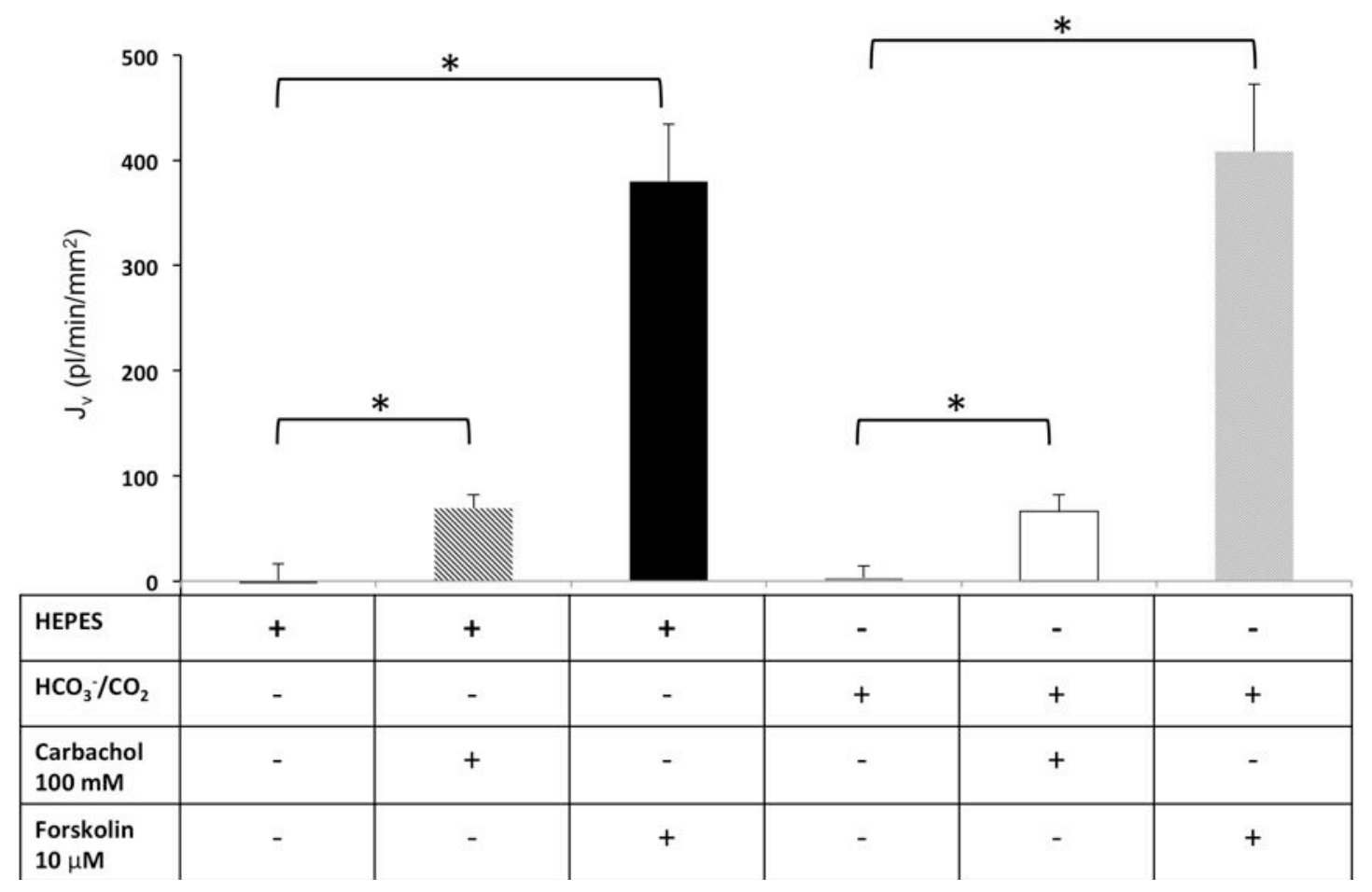

Figure 6. Calculated secretory rates of LG interlobular ducts evoked by forskolin and carbachol. Secretory rates $\left(J_{v}\right)$ were calculated from data shown in Figures 4 and 5 and are expressed in picoliter (pl) secreted fluid per minute per millimeter squared luminal epithelial surface. Secretory rates were calculated from the change in relative luminal volume in the first 10 minutes of carbachol or forskolin stimulation. Secretory rates evoked by carbachol or by forskolin both in HEPES buffered and $\mathrm{HCO}_{3}{ }^{-} / \mathrm{CO}_{2}$ buffered solutions were significantly higher, compared with controls (i.e., fluid secretion in the corresponding buffer solutions without stimulatory agent). $* \mathrm{P}<0.001$. 


\subsection{Effect of bile acids on pancreatic ductal cells}

\subsubsection{Effect of UDCA and CDCA on $\mathrm{pH}_{\mathrm{i}}$}

Several studies have shown that bile acids induce intracellular acidification in various cell types [68,95-97]. At first step, we have investigated the effect of CDCA and UDCA on basal $\mathrm{pH}_{\mathrm{i}}$ of pancreatic ducts. Administration of CDCA induced a dose-dependent intracellular acidification in Hepes-buffered solution (Figure 7A). The effect of CDCA on $\mathrm{pH}_{\mathrm{i}}$ was reversible, following the removal of bile acid from the external solution, the $\mathrm{pH}_{\mathrm{i}}$ completely returned to the basal level. UDCA also induced a dose-dependent decrease in $\mathrm{pH}_{\mathrm{i}}$, however the effect of UDCA was much smaller compared to CDCA (Figure 7B). We repeated these experiments in $\mathrm{HCO}_{3}{ }^{-}$ $/ \mathrm{CO}_{2}$-buffered solution, where the two bile acids induced similar degrees of $\mathrm{pH}_{\mathrm{i}}$ decrease (Figure $7 \mathrm{C}$ and $\mathrm{D}$ ). Summary of the changes of $\mathrm{pH}_{\mathrm{i}}$ is shown in Figure 7E and $\mathrm{F}$.
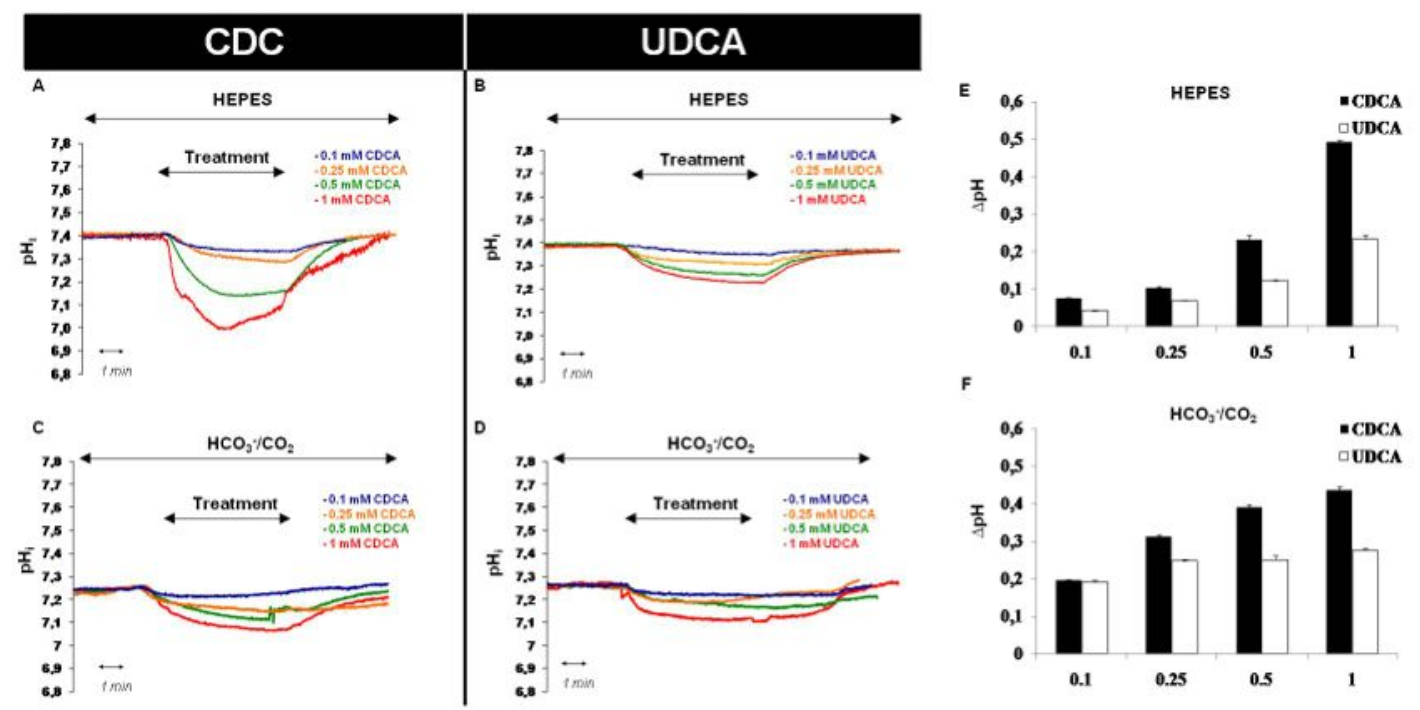

Figure 7. Effect of bile acids on the intracellular $\mathrm{pH}\left(\mathrm{pH}_{\mathrm{i}}\right)$ of pancreatic duct. Pancreatic duct epithelial cells (PDECs) were exposed to 0.1, 0.25, 0.5 and $1 \mathrm{mM}$ CDCA ( $\mathbf{A}$ and $\mathbf{C}$ ) and UDCA ( $\mathbf{B}$ and $\mathbf{D})$ in Hepes ( $\mathbf{A}$ and $\mathbf{B}$ ) and in $\mathrm{HCO}_{3}{ }^{-} / \mathrm{CO}_{2}{ }^{-}$ buffered $(\mathbf{C}$ and $\mathbf{D})$ solutions for 5 minutes. After the removal of bile acids the $\mathrm{pH}_{\mathrm{i}}$ spontaneously recovered. Summary data for the maximal $\mathrm{pH}_{\mathrm{i}}$ change $\left(\Delta \mathrm{pH} \mathrm{Hax}_{\max }\right)$ induced by bile acids in Hepes (E) and in $\mathrm{HCO}_{3}{ }^{-} / \mathrm{CO}_{2}$-buffered (F) solutions. The start point $\mathrm{pH}_{\mathrm{i}}$ for the measurment of $\Delta \mathrm{pH}$ was the $\mathrm{pH}_{\mathrm{i}}$ immediately before exposure to bile acids. Data are presented as means \pm SEM. $n=32-34$ regions of interest from 45 ducts. N.D.: not detectable. 


\subsubsection{Effect of UDCA pretreatment on the inhibitory effect of CDCA on the $\mathbf{a c i d} / \mathrm{base}$ transporters}

We used the ammonium pre-pulse technique to investigate the acid-base transporters of the pancreatic ducts. In $\mathrm{HCO}_{3}{ }^{-}$-free solution the initial recovery from the acid phase is due to the activity NHE (Figure 8A). In the presence of $\mathrm{HCO}_{3}{ }^{-}$the recovery from alkalosis reflects the activity of the AEs, whereas the recovery from acidosis results from the activity of both $\mathrm{NHE}$ and $\mathrm{NBC}$ (Figure 8B). Two $\mathrm{NH}_{4} \mathrm{Cl}$ pulses were applied, the first was the control and the second was the test. To estimate the effect of bile acids on the activity of acid-base transporters CDCA $(1 \mathrm{mM})$ and UDCA $(0.1,0.25,0.5$ and $1 \mathrm{mM})$ were administered 3 minutes before the pulse, during the pulse and 5 minutes after the pulse. Acute administration of UDCA did not affect the rate of recovery from the acid or alkali load neither in Hepes-buffered nor in $\mathrm{HCO}_{3}{ }^{-} / \mathrm{CO}_{2}$-buffered solutions (data not shown). In contrast, $1 \mathrm{mM} \mathrm{CDCA}$ strongly inhibited the activity of the acid/base transporters. (Figure 8A and B) Next we tested whether UDCA administration can influence the inhibitory effect of CDCA. When UDCA and CDCA were added simultaneously, UDCA was unable to prevent the inhibitory effect of CDCA on the ion transporters in all of the investigated concentration. (data not shown) Several studies have shown that prolonged incubation of the cells with UDCA is needed to exert its protective effect [85,98-100]. Therefore, in the next step, we pretreated the ducts with UDCA for various time periods ( $5 \mathrm{~h}$ and $24 \mathrm{~h}$ ) and the effect of CDCA on the ion transporters was examined. A $5 \mathrm{~h}$ preincubation of the ducts with $\operatorname{UDCA}(0.1,0.25,0.5$ and $1 \mathrm{mM})$ did not affect the response to CDCA. However, $24 \mathrm{~h}$ pretreatment with UDCA significantly decreased the toxic effect of CDCA both in Hepes (Figure 8A) and in $\mathrm{HCO}_{3}{ }^{-} / \mathrm{CO}_{2}{ }^{-}$ buffered (Figure 8B) solutions. The lowest concentration of UDCA which had a protective effect was $0.5 \mathrm{mM}$ (Figure $8 \mathrm{~A}$ and $\mathrm{B}$ ), whereas at higher concentrations (1 $\mathrm{mM}$ ) the protective effect of UDCA was significantly decreased. Therefore, we decided to use $0.5 \mathrm{mM}$ UDCA in the subsequent experiments. Summary data of the base fluxes $\left( \pm J\left(\mathrm{~B}^{-} / \mathrm{min}\right)\right)$ are shown on Figure $8 \mathrm{C}$-E. As shown, pretreatment of the ducts with $0.5 \mathrm{mM}$ UDCA prevented the inhibitory effect of CDCA on NHE (Figure $8 \mathrm{C}$ ), CBE (Figure 8D) and NBC (Figure 8E). 


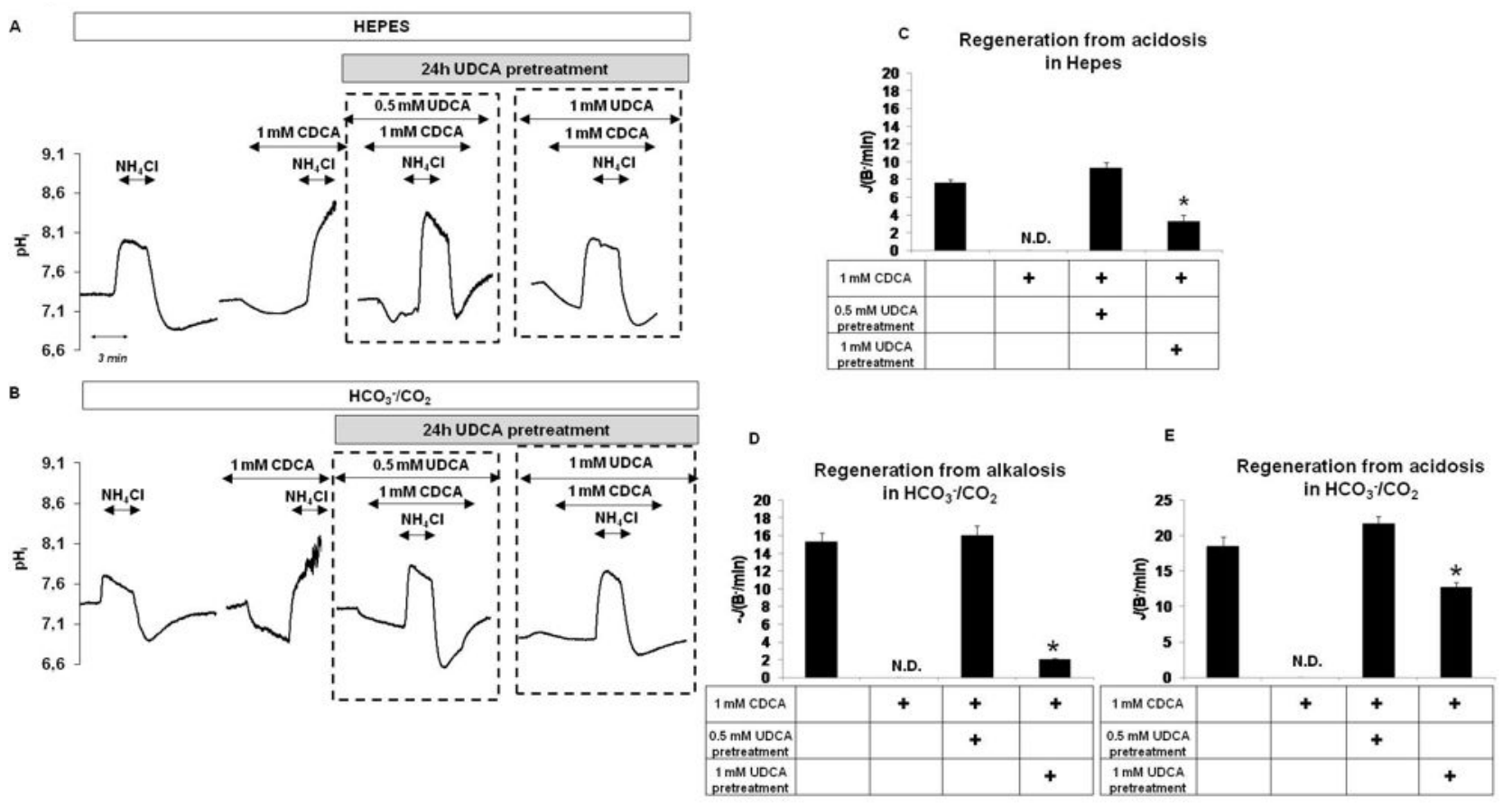

Figure 8. Effect of bile acids on the acid-base transporters of pancreatic duct. The activities of the ion transporters were investigated by the ammonium pre-pulse technique (see Materials and Methods). Administration of $1 \mathrm{mM} \mathrm{CDCA}$ was proved to be toxic on acid-base transporters both in standard HEPES (A) and $\mathrm{HCO}_{3}{ }^{-} / \mathrm{CO}_{2}{ }^{-}$ buffered (B) solutions. 0.5 and $1 \mathrm{mM}$ UDCA pretreatment ameliorated the CDCAinduced toxicity on the transporters both in HEPES (A) and $\mathrm{HCO}_{3}{ }^{-} / \mathrm{CO}_{2}$-buffered (B) solutions. Regeneration from acidosis in standard HEPES-buffered solution reflects the activity of NHE (C), whereas the recovery from acidosis (D) and alkalosis (E) in $\mathrm{HCO}_{3}{ }^{-} / \mathrm{CO}_{2}$ containing solutions reflects the activities of $\mathrm{Na}^{+} / \mathrm{HCO}_{3}{ }^{-}$cotransporter and $\mathrm{Cl}^{-} / \mathrm{HCO}_{3}{ }^{-}$exchanger, respectively. $-J\left(\mathrm{~B}^{-}\right)$and $J\left(\mathrm{~B}^{-}\right)$were calculated from the $\Delta \mathrm{pH} / \Delta \mathrm{t}$ obtained by linear regression analysis of $\mathrm{pH}_{\mathrm{i}}$ measurements made over the first 30 or $60 \mathrm{~s}$, respectively. Data are presented as means \pm SEM. ${ }^{*}=\mathrm{p} \leq 0.05$ vs. control, $\mathrm{n}=36-41$ regions of interest from 6-7 ducts. N.D.: not detectable.

\subsubsection{Effect of UDCA pretreatment on the CDCA-induced calcium signaling}

Numerous studies have indicated that bile-induced toxic calcium signalling is an initial step in the development of AP [101-104]. We have previously shown that high concentration of CDCA induces $\left(\mathrm{Ca}^{2+}\right)$ elevation in ductal cells [68]. So in the next step we have examined whether UDCA pretreatment has any effect on the CDCA-induced $\mathrm{Ca}^{2+}$ signalling. Administration of $0.5 \mathrm{mM}$ UDCA alone had no significant effect on $\left[\mathrm{Ca}^{2+}\right]_{\mathrm{i}}$ (data not shown). In contrast, $1 \mathrm{mM} \mathrm{CDCA}$ induced high and partially reversible $\mathrm{Ca}^{2+}$ signalling in pancreatic ducts. (Figure 9A) Preincubation of the ducts with $0.5 \mathrm{mM}$ UDCA for $24 \mathrm{~h}$ did not affect the CDCA-induced increase 
in $\left[\mathrm{Ca}^{2+}\right]_{\mathrm{i}}$, (Figure 9A and B) indicating that the protective effect of UDCA is unlikely to be caused be the prevention of the elevated $\left[\mathrm{Ca}^{2+}\right]_{\mathrm{i}}$.

\subsubsection{Effect of UDCA pretreatment on the CDCA-induced mitochondrial injury}

Injury of the mitochondra may lead to cell death [105,106]. Results from our laboratory shown that beside the elevated $\mathrm{Ca}^{2+}$ signalling, CDCA strongly damages mitochondria and causes $\mathrm{ATP}_{\mathrm{i}}$ depletion in pancreatic ducts which may contribute to the inhibitory effect of CDCA on ion transporters due to bioenergetic failure [74]. Therefore, in the next series of experiments we performed both functional and morphological studies to characterize the effect of UDCA pretreament on CDCAinduced mitochondrial injury.

The $\mathrm{ATP}_{\mathrm{i}}$ level is a good indicator of mitochondrial function; therefore in the first step we measured changes in $\mathrm{ATP}_{\mathrm{i}}$ in cells exposed to CDCA with or without UDCA pretreatment. As shown on Figure 9C, administration of $1 \mathrm{mM}$ CDCA caused a huge and irreversible $\mathrm{ATP}_{\mathrm{i}}$ loss in PDECs. (Figure 9C) In contrast, $24 \mathrm{~h}$ preincubation of the cells with $0.5 \mathrm{mM}$ UDCA reduced the rate of CDCA-induced $\mathrm{ATP}_{\mathrm{i}}$ decrease by $57.6 \pm 3.6 \%$ (Figure $9 \mathrm{C}$ and D). UDCA administration alone did not effect $\mathrm{ATP}_{\mathrm{i}}$.

To further analyse the protective effect of UDCA on ductal mitochondria, we also investigated $\Delta \Psi_{\mathrm{m}}$ and $\mathrm{mPTP}$ upon administration of bile acids. Ducts were incubated with $1 \mu \mathrm{M}$ TMRM in order to investigate the changes in $\Delta \Psi_{\mathrm{m}}$ (see Material and Methods section). After the stabilisation of the mitochondrial fluorescence, $1 \mathrm{mM}$ CDCA was applied and the fluorescence signal was monitored. As shown in Figure 9E, the administration of CDCA resulted in a huge increase in TMRM fluorescence intensity, indicating that this bile acid induced marked mitochondrial depolarization. Preincubation of the ducts with $0.5 \mathrm{mM}$ UDCA reduced the CDCA-induced depolarization by $69.4 \pm 4.6 \%$ (Figure $9 \mathrm{E}$ and $\mathrm{F}$ ).

Since ATP depletion and mitochondrial depolarization are caused by mPTP induction, next we investigated the effect of CDCA on the opening of MPTP using the calcein-cobalt technique. Treatment of the calcein-loaded pancreatic ducts with $1 \mathrm{mM}$ CDCA decreased the fluorescence excitation of calcein, approximately $1 \mathrm{~min}$ after the addition of the bile acid. (Figure 9G) Similarly to the $\Delta \Psi_{\mathrm{m}}$ experiments, $24 \mathrm{~h}$ 
pretreatment of the ducts with $0.5 \mathrm{mM}$ UDCA had a preventive role on mitochondria and decreased the CDCA-induced mPTP opening by $72.1 \pm 4 \%$. (Figure $9 \mathrm{G}$ and $\mathrm{H}$ ) Administration of UDCA alone did not affect mPTP.
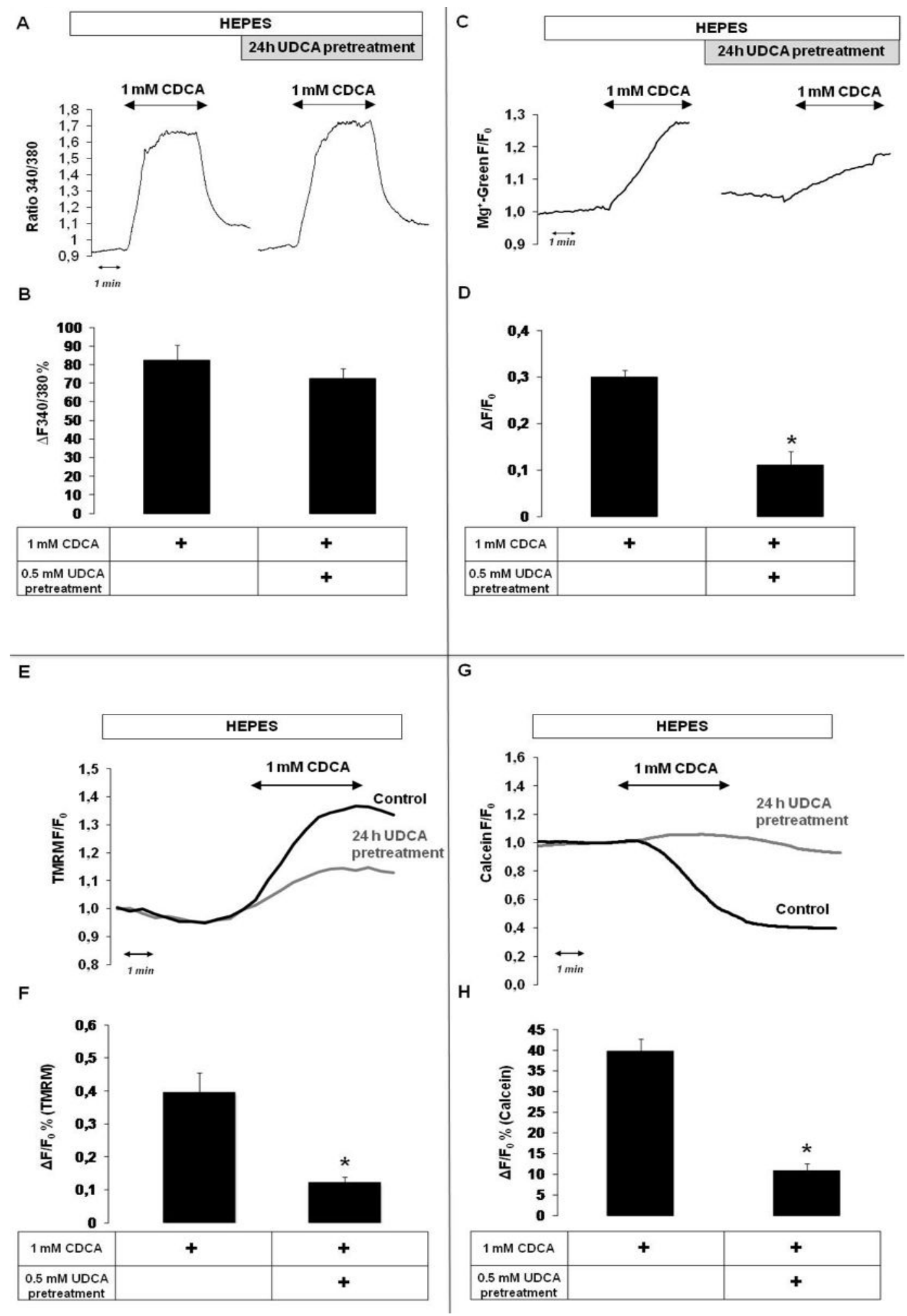

Figure 9. Effect of bile acids on intracellular $\mathrm{Ca}^{2+}$ concentration $\left(\left[\mathrm{Ca}^{2+}\right]_{\mathrm{i}}\right)$, ATP level $\left(A T P_{i}\right)$, mitochondrial membrane potential $\left(\Delta \Psi_{m}\right)$ and mitochondrial 
permeability transition pore (mPTP) of pancreatic duct. Representative experimental traces showing the effect of $1 \mathrm{mM} \mathrm{CDCA}$ on $\left[\mathrm{Ca}^{2+}\right]_{\mathrm{i}}(\mathbf{A}), \mathrm{ATP}_{\mathrm{i}}(\mathbf{C})$, $\Delta \Psi_{\mathrm{m}}(\mathbf{E})$ and $\mathrm{mPTP}$ opening $(\mathbf{G})$ in non pretreated and $24 \mathrm{~h}$ UDCA pretreated pancreatic ducts. (A) Acute administration of CDCA caused $\mathrm{Ca}^{2+}$ signalization in pancreatic ductal cells which was not affected by UDCA pretreatment. (C) Decrease in $\mathrm{ATP}_{\mathrm{i}}$ is shown by an increase in fluorescence intensity. As shown $24 \mathrm{~h}$ UDCA pretreatment markedly decreased the CDCA-induced ATP depletion. (E) Decrease in $\Delta \Psi_{\mathrm{m}}$ is shown by an increase in TMRM fluorescence intensity. Administration of 1 mM CDCA caused rapid depolarization of the mitochondrial membrane which was decreased by UDCA pretreatment. (G) mPTP opening is shown by a decrease in fluorescence intensity. CDCA-induced a marked mPTP opening which resulted in significant influx of $\mathrm{Co}^{2+}$ into the mitochondria causing a decrease in calcein fluorescence. $24 \mathrm{~h}$ UDCA pretreatment reduced CDCA-induced $\mathrm{mPTP}$ opening resulting in a milder decrease in calcein fluorescence. Summary data for the maximal fluorescence intensity changes are shown on Figure B, D, F and H. Data are presented as means \pm SEM. $*=p \leq 0.05$ vs. $1 \mathrm{mM} \mathrm{CDCA.} n=35-40$ regions of interest from 6-7 ducts.

Mitochondrial morphology of the ducts was also examined by electron microscopy (Figure 10A-D). The mean number of mitochondria in the section of the control, the CDCA, the UDCA and the CDCA+UDCA groups was nearly the same. No morphological alterations were observed in the control and UDCA-treated groups. (Figure 10A and B) In contrast, incubation of the ducts with $1 \mathrm{mM} \mathrm{CDCA}$ for $5 \mathrm{~min}$ resulted in mitochondrial swelling and the loss of the mitochondrial inner membrane (Figure 10C). This swelling could be prevented by UDCA pretreatment. Moreover, the integrity of the mitochondria was also maintained in the CDCA+UDCA-treated ducts compared to the ducts only treated with CDCA (Figure 10D). 

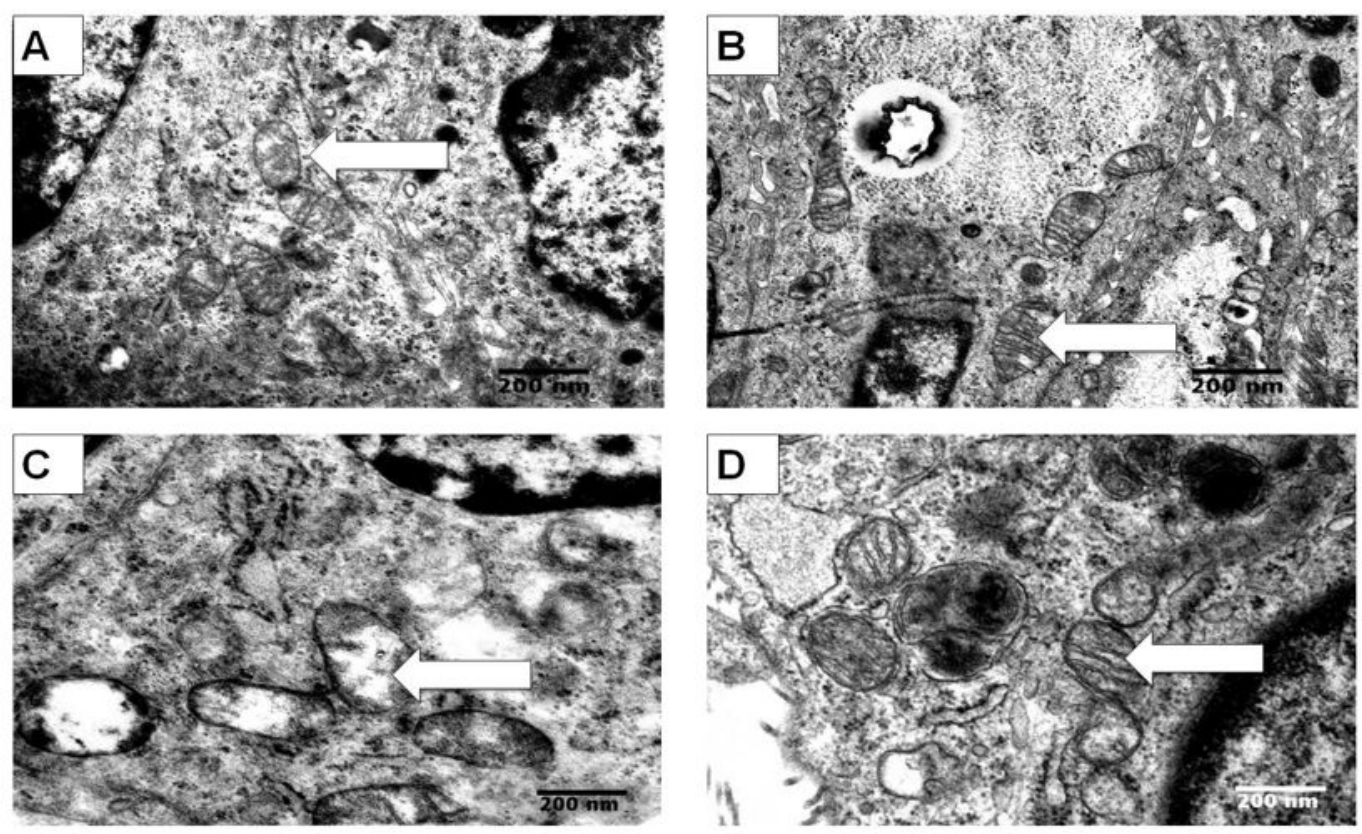

Figure 10. Effect of bile acids on the morphology of mitochondria. Representative electron micrograph images of pancreatic ductal mitochondria show normal mitochondria with intact inner membranes in the control and UDCA pretreated ducts (A and B). Treatment with $1 \mathrm{mM} \mathrm{CDCA}$ caused mitochondrial swelling after $5 \mathrm{~min}$ (C) which was completely prevented by $24 \mathrm{~h}$ UDCA pretreatment (D). Arrows show mitochondria.

\subsubsection{Effect of UDCA pretreatment on the CDCA-induced cell death}

In the next step, we tested whether the toxic effect of CDCA on the mitochondria is associated with cell death. Ducts were treated with $1 \mathrm{mM}$ CDCA for $5 \mathrm{~min}$, then were incubated in culture media for further $3 \mathrm{~h}$ in order to leave time for development of cell death. Cell death was assessed by TUNEL staining (Figure 11A and B). This method is based on the labelling of the 3'-OH ends of the fragmented DNA which are generated during cell death. Incubation of the pancreatic ducts with CDCA resulted in a significant increase in cell death compared to control, non-treated ducts. (Figure 11A and B) Although, both apoptosis and necrosis can be characterised by DNA fragmentation, the presence of intact cell organelles, cellular shrinkage and the lack of cellular content release indicate that CDCA rather induces apoptotic cell death than necrosis [107]. $24 \mathrm{~h}$ preincubation with UDCA $(0.5 \mathrm{mM})$ alone caused only a small degree of DNA fragmentation in the ductal cells, but significantly reduced the CDCA-induced apoptotic cell death by $63.3 \pm 5.7 \%$. (Figure $11 \mathrm{~A}$ and $\mathrm{B}$ ) 

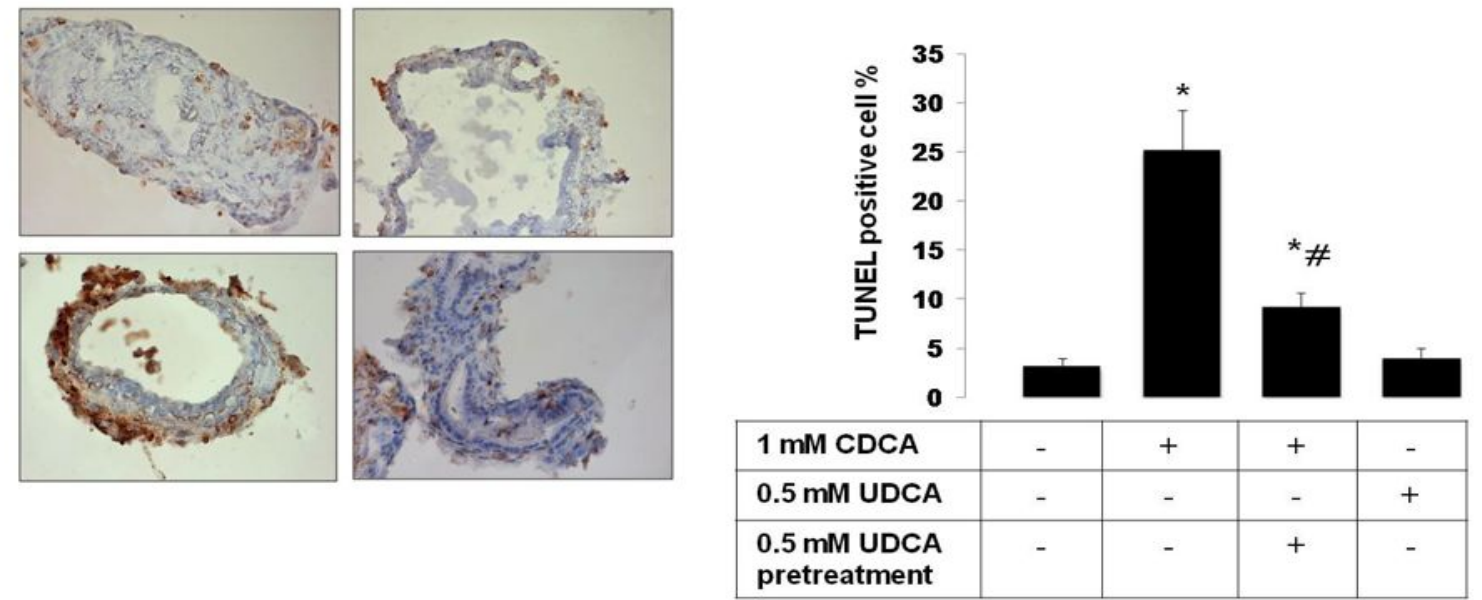

Figure 11. Effect of UDCA pretreatment on CDCA-induced cell death on pancreatic ductal epithelial cells (PDECs). (A) Representative pictures of TUNEL positive and hematoxylin-eosin stained pancreatic duct segments show that incubation of the pancreatic ducts with $1 \mathrm{mM}$ CDCA (left bottom) increased the rate of dead cells compared to control (left top) non-treated ducts. 5 min administration of UDCA $(0.5 \mathrm{mM})$ alone, had no significant effect on the cells (right top), whereas $24 \mathrm{~h}$ pretreatment of the ducts with $0.5 \mathrm{mM}$ UDCA (right, bottom) decreased the rate of dead cells in the CDCA-treated group. (B) Percentage of total cell counts that are TUNEL positive. Data are presented as means \pm SEM. ${ }^{*}=\mathrm{p} \leq 0.05$ vs. Control, $\#=\mathrm{p} \leq 0.05$ vs. $1 \mathrm{mM} \mathrm{CDCA}, \mathrm{n}=3-4$.

\subsubsection{In vivo investigation of the effect of UDCA pretreatment in CDC- induced AP model}

In order to investigate the protective effect of UDCA under in vivo conditions, we utilized a CDCA-induced pancreatitis model [108,109]. We used rats as the model animals because we were unable to administer CDCA intraductally in guinea pigs due to the anatomical topography of the main duct.

Serum amylase activities were significantly elevated after retrograde infusion of CDCA (CDCA group, $983 \pm 100 \mathrm{U} / 1$ ) compared to intraductally administered physiological saline (control group, 396 $\pm 50 \mathrm{U} / 1$ ). Pretreatment of UDCA for two weeks did not influence the serum amylase activities (UDCA group, $424.7 \pm 20$ ) in control animals; however, it was significantly decreased $(582 \pm 50 \mathrm{U} / \mathrm{l})$ in the UDCA+CDCA group versus the CDCA group (Figure 12A).

Pancreatic water content was significantly elevated after retrograde infusion of CDCA $(80 \pm 1 \%)$ compared to intraductally administered physiological saline $(60 \pm 1 \%)$. A two-week pretreatment with UDCA showed no influence on the 
pancreatic water content $(61 \pm 2 \%)$ in the UDCA group. However in the UDCA + CDCA group, it was significantly decreased (65 $2 \%)$ versus to the CDCA group (Figure 12B).

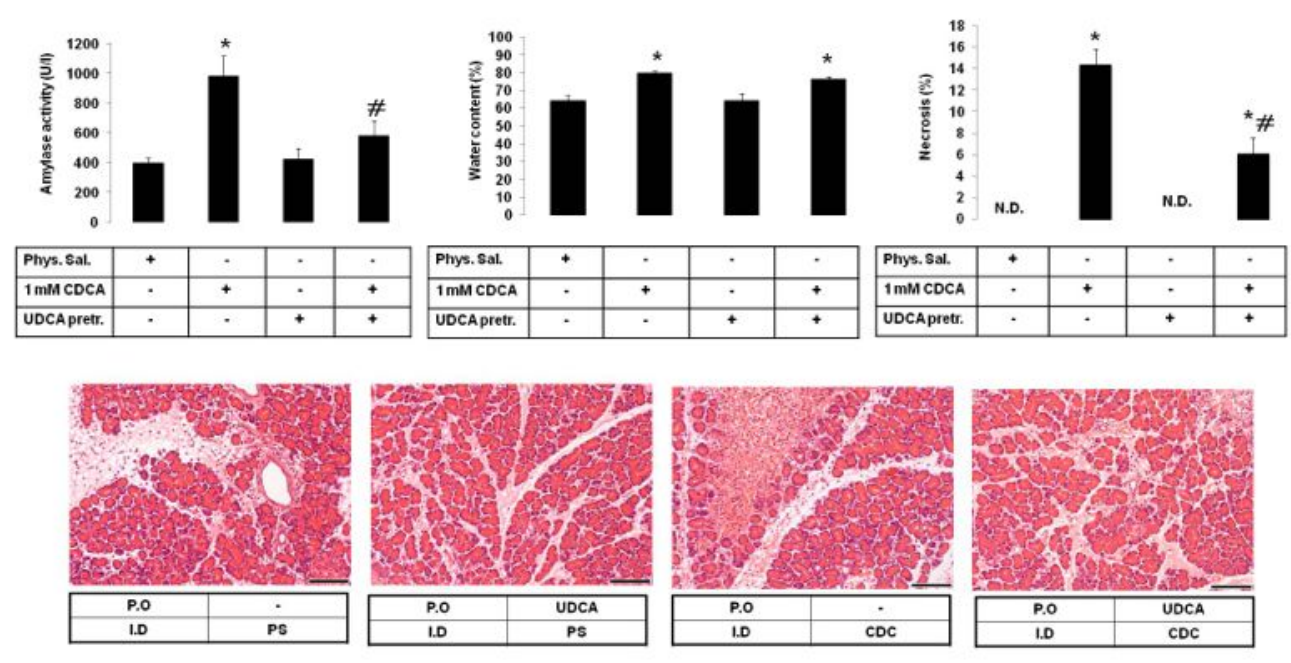

Figure 12. Effect of UDCA pretreatment on CDCA-induced pancreatitis model in rats. Serum amylase activity (U/1) (A) pancreatic oedema (B) and cell necrosis (\%) (C) increased by intraductal administration of CDCA, however 2 weeks UDCA pretreatment ameliorated each of these severity parameters. (D) Representative histological images of control, UDCA pretreated, CDCA-induced acute pancreatitis and UDCA pretreated CDCA-induced acute pancreatitis animals. Control rats were given physiological saline instead of CDCA. Scale bar $=100 \mu \mathrm{m}$. P.O.: per os, I.D.: intraductal. Data are presented as means \pm SEM. $*=p \leq 0.05$ vs. Control, $\#=p \leq 0.05$ vs. $1 \mathrm{mM}$ CDCA , $\mathrm{n}=6$ animals in each groups. Scale bar $100 \mu \mathrm{m}$. 


\section{DISCUSSION}

\subsection{Investigation of lacrimal gland ductal secretion}

The first part of this study provided the first experimental evidence of water permeability of LG ducts and the calculated values of osmotic permeability; and the first direct evidence of LG duct fluid secretion deriving from functional experiments evoked by forskolin and carbachol.

In contrast to many secretory epithelia, we are lacking of published calculations of the water permeability of the ductal epithelium, even through this parameter is essential in determining the ability of the fluid transport. It has been estimated that ductal cells may produce as much as $30 \%$ of the total volume of the lacrimal gland fluid, thus the relative contribution of ductal epithelial cells to water secretion cannot be neglected [42]. The summarized actions of basolaterally and apically located ion transporters, co-transporters and exchangers can produce an osmotic gradient which may determine the direction of water flow. Water passively follows secreted ions depending on the osmotic gradient and on the permeability of the epithelial structure.

Similarly to pancreatic ducts, the isolated lacrimal gland duct segments seal spontaneously during overnight culturing, forming closed sac-like structures. Secretory processes of ductal epithelium into the closed intraluminal space result in swelling of the ducts as the luminal space fills with the fluid secreted as seen in the case of isolated pancreatic ducts $[14,87,88,110]$. The ductal volume changes can be analyzed by videomicroscopy $[87,88]$.

We measured the initial rate of swelling of LG ducts after a sudden drop in bath osmolarity caused by a $\mathrm{Na}^{+}$-gradient in order to characterize the water permeability properties of the structure. There was only minimal connective tissue surrounding the basolateral surface of the epithelium thus the unstirred layer effect could be neglected [111]. According to our observations, the sealing of the ends of the ducts results in complete restoration of epithelial integrity and swelling of the ducts happens without leakage in the vast majority of cases. The value of $\mathrm{P}_{\mathrm{f}}$ proved to be $60,53 \mu \mathrm{m} / \mathrm{s}( \pm 19,76)$. This $\mathrm{P}_{\mathrm{f}}$ value is lower, than the highly water permeable pancreatic ductal epithelium $(160-170 \mu \mathrm{m} / \mathrm{s}$, measured in rat pancreatic ducts) or the kidney proximal tubule $(100-500 \mu \mathrm{m} / \mathrm{s}$, different species) and very similar to the 
distal airways of the guinea pig $(60 \mu \mathrm{m} / \mathrm{s})$, to the rat cholangiocytes $(50 \mu \mathrm{m} / \mathrm{s})$ or to the cultured corneal endothelium in mice $(74 \mu \mathrm{m} / \mathrm{s})[46,89,112-116]$. The $\mathrm{P}_{\mathrm{f}}$ value showed by our experiments is clearly sufficient to support fluid secretion, and proves that rabbit lacrimal gland ductal epithelium is be able to secrete fluid in response to secretagogues.

Until recently, limited number of studies has focused on lacrimal duct function $[14,45,47,48,117-119]$. All of these studies investigated the ion secretory profile of ductal cells, while fluid secretory properties of ductal system remained speculative. Dartt et al. published a landmark study in 1981 proposing that the electrolyte and water component of lacrimal gland fluid could be a mixture of plasmalike primary fluid secreted by the acinar cells and a potassium ion-rich fluid produced by the ductal cells [42]. They concluded that ductal cells may secrete a significant portion of lacrimal gland fluid. Using laser capture microdissection, Ding et al. anayzed the gene expression profile of various duct segments and the acinar cells with real-time RT-PCR in rabbit lacrimal gland. Predominant expression of CFTR was found in the duct cells along with the demonstration of the presence of certain transporters and aquaporins along the acinus-duct axis [117]. Another recent study found significant variations in the expression of different chloride channels in a rabbit model of Sjögren syndrome and in healthy animals [47]. The reduced levels of $\mathrm{Na}^{+}-$ $\mathrm{K}^{+}-2 \mathrm{Cl}^{-}$cotransporter and CFTR mRNA in ductal cells derived from diseased animals suggest the active contribution of these structures in altered lacrimal fluid secretion. In a recent paper Lu and Ding elegantly demonstrated that CFTR is functionally involved in $\mathrm{Cl}^{-}$transport in both acinar and duct cells in the rabbit LG and suggests that CFTR plays a significant role in LG function [119]. The presence of significant amounts of CFTR in the ducts along with the detection of other channels and transporters in the LG duct cells strongly suggests that LG ducts play a critical role in the maintenance of homeostasis of lacrimal fluid secretion.

Forskolin stimulation was initiated a brisk and continuous swelling response in rabbit lacrimal gland interlobular ducts. Forskolin is a potent direct activator CFTR through cAMP elevation. Fluid secretion was unaffected by inhibition of $\mathrm{HCO}_{3}{ }^{-}$ transport mechanisms, but completely abolished when basolateral $\mathrm{Cl}^{-}$uptake was blocked by bumetanide suggesting the predominant role of $\mathrm{Cl}^{-}$transport mechanisms over $\mathrm{HCO}_{3}^{-}$secreting processes in lacrimal duct fluid secretion in rabbit. As bumetanide is a well known inhibitor of the $\mathrm{Na}^{+}-\mathrm{K}^{+}-2 \mathrm{Cl}^{-}$cotransporter located on the 
basolateral membrane of the duct cells, this transport process can be the main route of cellular cloride uptake. Further studies are needed to determine the functional activity of this transporter.

LG secretion through M3 muscarinic receptors is well established [42,45,120125]. Cholinergic stimulation with carbachol resulted in a biphasic secretory response with a faster initial and a plateau second phase in our experiments. The kinetics of swelling response was in accordance with the carbachol-evoked changes of intracellular calcium levels of lacrimal ductal cells reported earlier by our laboratory [14]. Carbachol-evoked secretory pattern of lacrimal ducts was similar to those found in pancreatic ducts [87]. Parasympatholytic atropine abolished the stimulatory effect of carbachol, suggesting the involvement of muscarinic cholinoceptors. The secretory effects of forskolin were remarkably higher compared to the response to carbachol stimulation. We investigated the role of basolateral ion transport mechanisms only in case of forskolin stimulation. The relatively weak swelling response evoked by carbachol was a limitation to attempt to measure the effect of different transporters in case of carbachol stimulation.

In conclusion, besides water permeability, forskolin and carbachol induced fluid secretory capability of lacrimal gland ductal cells were demonstrated in the present work. Our results strongly support the hypothesis, that lacrimal gland ductal system is actively involved in lacrimal fluid secretion. Further studies are needed to clarify the effects of various stimulatory agents and the role of ion transport mechanisms in this process. Future results may contribute to the development of targeted pharmacological interventions in order to improve deteriorated lacrimal gland function in dry eye disease.

\subsection{Effect of bile acids on pancreatic ductal cells}

In the second part of this study, we have shown that the hydrophilic bile acid, UDCA is able to attenuate the toxic effect of CDCA on pancreatic ducts by preventing CDCA-induced mitochondrial injury.

The pathomechanism of biliary AP is not fully understood. Numerous studies indicated that bile reflux into the pancreas may lead to pancreatic injury and as a result can induce AP [63-65]. Therefore, a better understanding of the mechanisms underlying bile-induced pancreatic injury and its prevention may provide novel 
therapeutic tools for the treatment of AP.

To study the effect of CDCA and UDCA we used isolated intra-interlobular pancreatic ducts, which is a reliable in vitro model for investigating pancreatic ductal damage. The CDCA concentration used in this study was previously shown to induce intracellular $\mathrm{Ca}^{2+}$ signalling, mitochondrial injury and inhibition of the acid-base transporters, whereas the concentrations of UDCA were chosen on the basis of the literature data $[68,74,83,84]$. Examinations were performed using $0.5 \mathrm{mM}$ UDCA since the protective effect of UDCA was not increased by using higher concentrations $(1 \mathrm{mM})$, whereas lower concentrations of this bile acid $(0.1$ and $0.25 \mathrm{mM})$ had no detectable protective effect. This concentration of UDCA is one magnitude higher than the physiological concentration of bile acid in the blood and several orders of magnitude lower than the concentration of bile acids in the gall bladder or duodenum (10-100 mM) [126]. The optimal preincubation time of pancreatic ducts with UDCA was found to be $24 \mathrm{~h}$, indicating that the development of protective action is a complex mechanism which probably include changes at transcriptional level that modulate various signalling and apoptotic pathways [84,127,128].

Our results indicaded that $24 \mathrm{~h}$ pretreatment of pancreatic ducts with $0.5 \mathrm{mM}$ UDCA significantly reduced the inhibitory effect of CDCA on the acid/base transporters. Studies on pancreatic acinar cells have indicated that the toxic effect of hydrophobic bile acids is mediated by a sustained $\mathrm{Ca}^{2+}$ signalling $[66,66]$. We have previously shown that high concentration of CDCA induces a huge and long-lasting elevation of $\left[\mathrm{Ca}^{2+}\right]_{\mathrm{i}}$ in pancreatic ducts [68]. Therefore, we tested whether the protective effect of UDCA on the acid/base transporters is due to the prevention of CDCA-induced calcium signalling. When pancreatic ducts were exposed to UDCA for $24 \mathrm{~h}$ and CDCA was then added, the extent of calcium elevation did not change, indicating that the protective effect of UDCA is unlikely to be caused by the reduction of $\mathrm{Ca}^{2+}$ signalling. This finding is in accordance with our previous observation on pancreatic ducts, where preincubation of the cells with a specific calcium chelator, BAPTA-AM was unable to prevent the inhibitory effect of CDCA on acid-base transporters [68].

Numerous studies support the concept that mitochondrial damage plays a central role in the bile acid-induced cellular injury and that UDCA pretreatment is able to attenuate the toxic effect of hydrophobic bile acids on mitochondria $[81,83,84]$. Therefore, in the next step we investigated the protective effect of UDCA 
on the function and morphology of pancreatic ductal mitochondria. Administration of CDCA alone induced mPTP opening in the ductal cells. This is an early event in cell death which leads to mitochondrial swelling due to an increase in the mitochondrial inner membrane permeability. mPTP is also characterized by the loss of membrane potential which leads to mitochondrial dysfunction and consequently inhibition of ATP synthesis. Studies on rat hepatocytes demonstrated that in the presence of the specific mPTP inhibitor, cyclosporine A, the effect of CDCA was completely ameliorated indicating that CDCA selectively acts on mPTP [129]. It has been also demonstrated that CDCA induces mPTP due to increased membrane fluidity and cytochrome c release in calcium-loaded hepatic mitochondria [130]. In contrast to the effects of CDCA, UDCA alone caused no significant changes in mitochondrial function. However, UDCA pretreatment was able to prevent the CDCA-induced mPTP, mitochondrial membrane perturbation and the consequently formed decrease in membrane potential. Moreover, UDCA prevented the CDCA-induced ATP $_{i}$ loss, which provides further evidence that UDCA pretreatment is beneficial to avoid mitochondrial injury. This conclusion was confirmed by electron microscopic studies which showed normal appearance of mitochondria in the UDCA+CDCA group compared to the CDCA group, where mitochondrial swelling and disruption of the inner mitochondrial membrane were observed. The mechanism underlying the mitochondrial protective effect of UDCA is not clear. One of the main inducers of mPTP is $\mathrm{Ca}^{2+}$ overload and oxidative stress. Although, we have shown that UDCA pretreatment had no effect on the extent of CDCA-induced $\mathrm{Ca}^{2+}$ elevation, we did not investigate the effect of UDCA on the total $\mathrm{Ca}^{2+}$ load. It is possible that the protective effect of UDCA is due to the reduction of $\mathrm{Ca}^{2+}$ overload or by the inhibition of reactive oxygen species (ROS) production, however further studies are needed to confirm these hypotheses.

Mitochondrial dysfunction is often associated with cell death either by the reduction of $\mathrm{ATP}_{\mathrm{i}}$ levels or by irreversible alterations in the mitochondrial membrane permeability which induces the release of apoptotic signalling molecules from the mitochondria. Since mitochondria play a central role in cell survival, we wanted to determine if the CDCA-induced mitochondrial injury would result in cell death and to examine the possible protective role of UDCA in this process. Administration of CDCA induced marked DNA fragmentation in intact pancreatic ducts. We speculate that impairment of mitochondrial function plays a central role in this mechanism, but 
other signalling pathways may be involved. The apoptotic effect of CDCA and other hydrophobic bile acids have been examined in more detail in hepatocytes. ROS generation, mPTP induction, cytochrom c release and activation of downstream caspases have been shown to be associated with apoptosis $[131,132]$. It has been also demonstrated that the glycin-conjugated form of CDCA, directly stimulate Fasdependent cell death due to the activation of the Fas receptor which is independent from the mitochondrial pathway [133]. $24 \mathrm{~h}$ pretreatment with UDCA effectively reduced the CDCA-induced apoptosis as indicated by significantly decreased DNA fragmentation which further confirms the cytoprotective effect of UDCA. The exact mechanism by which UDCA exerts its protective effect was not investigated by our group; however, our results and previous studies on hepatocytes strongly indicate that mPTP inhibition by UDCA is one of the key mechanisms in the reduction of CDCAinduced cell death in PDECs.

In vivo experimental models are essential to confirm in vitro results. In order to extend our study, we also tested the protective effect of UDCA in animal models. There is no accepted bile acid-induced pancreatitis model in guinea pigs; therefore we induced AP in rats by intraductal injection of low concentration of CDCA $[108,109]$. Under these experimental conditions, CDCA induced acinar cell damage and also increased serum amylase activity. Previous studies on isolated rat and mouse acini demonstrated that the hydrophobic bile acid, TLC-S induces mitochondrial injury, pathological $\mathrm{Ca}^{2+}$ signalling and the generation of ROS $[69,72,73,134]$. We speculate that similar intracellular mechanisms may also have arisen in response to CDCA. The CDCA-induced acinar cell injury, hyperamylasemia and pancreatic edema was markedly reduced in the UDCA-treated group. The protective effect of UDCA can be attributed to its ability to reduce mitochondrial injury both in acinar and ductal cells. However, further in vitro experiments are needed to prove that UDCA pretreatment may exert a protective effect against the CDCA-induced acinar cell damage. Lastly, our results may have important clinical implication in patients with gallstone obstruction, where oral administration of UDCA or its metabolically stable form may reduce the risk of pancreatitis development. The beneficial effect of UDCA treatment has been demonstrated in idiopathic recurrent pancreatitis where long-term UDCA treatment reduced the rate of recurrence by prevention of the formation of gallstones [135-137]. The effect of orally administered UDCA is highly dependent on its metabolism. In rats, most of the UDCA is metabolized to TUDCA which also has 
cytoprotective effect as demonstrated in the liver [82,85,138,139]. In humans, one of the major metabolites of UDCA is isoursodeoxycholic acid (isoUDCA) which is the $3 \beta$-hydroxy epimer of UDCA and has been shown to be more effective than UDCA $[140,141]$. In the current study, we have not investigated the serum concentration of UDCA after oral administration. Notably, since UDCA was administered in an excess dose, we believe that sufficiently high concentration of UDCA (or TUDCA) was present in the serum to exert its protective effect.

Understanding the early injury mechanisms induced by hydrophobic bile acids is extremely important to find a therapeutic target to reduce pancreatic injury. In this study, we confirm and extend our previous observations that mitochondria is a key target in the CDCA-induced cellular injury in PDECs. The hydrophilic bile acid, UDCA inhibits CDCA-induced apoptosis probably by the stabilization of mitochondrial membrane via the block of membrane depolarization and MPTP and also by prevention of mitochondrial swelling (Figure 10). Several studies have focused on the inhibition of cellular injury during AP in order to stop or delay the progression of the disease. UDCA may represent a novel option against the bileinduced ductal injury, however issues for the therapeutic application of this bile acid in AP need further investigation.

\section{SUMMARY}

The investigation of epithelial functions under physiological and pathophysiologycal conditions is essential for the better understanding of their role in the body and their related diseases.

We have very limited information about the role of LG ducts in tear secretion. Pancreatic research provided useful tools to study the LG ductal functions and opened new potentials in $L G$ research .

Thanks to these tools, in the past decades our knowledge were increasing from the physiology and patophysiology of the exocrine pancreas, although there are still many open questions. One of this questions is the pathomechanism of the biliary AP. Better understanding of the disease may lead to the development of new therapeutical approaches.

Therefore this work was aimed to demonstrate the importance of physiological characterisation of epithelial cells and to study their function under 
pathophysiological conditions.

\subsection{Investigation of lacrimal gland ductal secretion}

In the first part of this study our AIM was to investigate the osmotic water permeability of LG duct epithelium by means of calculation of filtration permeability and to investigate LG ductal fluid secretion with the following METHODS: Experiments were performed on isolated rabbit LG duct segments maintained in short-term culture. Osmotically determined fluid movement or fluid secretion into the closed intraluminal space of cultured LG interlobular ducts was analyzed using video microscopic technique.

Therefore our RESULTS were:

- $\quad$ The end of the LG ducts sealed after overnight incubation forming a closed luminal space.

- For the calculation of osmotic water permeability, ducts were initially perfused with isotonic HEPES buffered solution, and then with hypotonic HEPES buffered solution. Filtration permeability was calculated from the initial slope of the relative volume increase.

- Secretory responses to carbachol or to forskolin stimulation were also investigated. Forskolin stimulation resulted in a rapid and sustained secretory response in both solutions. Forskolin- stimulated fluid secretion was completely inhibited by bumetanide both in HEPES buffered and in $\mathrm{HCO}_{3}{ }^{-} / \mathrm{CO}_{2}$ buffered solutions, suggesting the central role NKCC1.

- Administration of carbachol initiated a rapid but short secretory response in both HEPES buffered and in $\mathrm{HCO}_{3}{ }^{-} / \mathrm{CO}_{2}$ buffered solutions. Atropine completely abolished the carbachol-evoked fluid secretion.

CONCLUSIONS from the results:

(i) A new method was introduced to investigate LG duct function.

(ii) Water permeability of rabbit LG duct epithelium was measured by calculating filtration permeability.

(iii) Fluid secretion of LG duct cells induced by carbachol or forskolin was also demonstrated. These results provide calculated values of lacrimal duct osmotic permeability and direct experimental evidence of LG duct fluid secretion. 


\subsection{Effect of acids on pancreatic ductal cells}

Earlier studies showed that CDCA strongly inhibits pancreatic ductal $\mathrm{HCO}_{3}{ }^{-}$ secretion through the destruction of mitochondrial function, which may have significance in the pathomechanism of AP. UDCA is known to protect the mitochondria against hydrophobic bile acids and has ameliorating effect on cell death in heptocytes. Therefore, our AIM was to investigate whether UDCA pretreatment has any effect on CDCA-induced pancreatic ductal injury.

To study ductal functions under phatophysiological conditions we used the following METHODS:

- Guinea pig intra-interlobular pancreatic ducts were isolated by collagenase digestion. Ducts were treated with UDCA for 5 and $24 \mathrm{~h}$ and the effect of CDCA on intracellular $\mathrm{Ca}^{2+}$ concentration $\left(\left[\mathrm{Ca}^{2+}\right]_{\mathrm{i}}\right), \mathrm{pH}\left(\mathrm{pH}_{\mathrm{i}}\right)$, morphological and functional changes of mitochondria, and the rate of apoptosis were investigated.

- $\quad$ AP was induced in rat by retrograde intraductal injection of CDCA (0.5\%) and the disease severity of pancreatitis was assessed by measuring standard laboratory and histological parameters.

Using in vitro and in vivo approaches our RESULST showed that UDCA pretreatment:

- completely prevented the inhibitory effect of CDCA on ductal acid-base transporters,

- decreased the rate of CDCA-induced mitochondrial injury and cell death

- $\quad$ reduced the severity of experimental AP induced by CDCA.

Therefore our CONCLUSION is that these results clearly demonstrate that UDCA:

(i) suppresses the CDCA-induced pancreatic ductal injury by reducing apoptosis and mitochondrial damage

(ii) reduces the severity of CDCA-induced AP.

The protective effect of UDCA against hydrophobic bile acids may represent a novel therapeutical target in the treatment of biliary AP. 


\section{ACKNOWLEDGEMENTS}

I would like to thank all of the people who have helped and inspired me during my Ph.D studies. I am grateful to Prof. Dr. András Varró, the head of Department of Pharmacology and Pharmacotherapy, and to Prof. Dr. György Ábrahám and Prof. Dr. Tibor Wittmann, the current and former head of the First Department of Medicine who gave me opportunity to work at their Departments.

I would like express my deep and sincere gratitude to my supervisors Dr. Edit Tóth-Molnár and Dr. Viktória Venglovecz for their support, guidance and friendship. Their wide knowledge and logical way of thinking have been of great value for me. Without their outstanding supervision, this Ph.D project would not have been possible.

I also would like to say thank you for Prof. Dr. Péter Hegyi and Dr. Zoltán Rakonczay Jr. besides the opportunity to do my research in their laboratory, for their trust, help, support and constructive advices. In addition, I would like to thank my colleagues and friends, Zsolt Balla, Dr. Balázs Kui, Dr. Petra Pallagi, Dr. József Maléth, Dr. Klaudia Farkas, Dr. Anita Balázs, Dr. Éva Kunstár, Dr. Andrea Geisz, Dr. Andrea Schnúr, Dr. Dorottya Laczkó, Dr. Eszter Kormányos, Dr. Eszter Végh, Tamara Madácsy, Orsolya Berczeli, Vivien Szólik and Dr. Eszter Vizvári for all the help, entertainment and care they provided. This work would not have been possible to accomplish without the assistance and work of Fritz Rea, Edit Magyarné Pálfi, Tünde Pritz, Zsoltné Árva, Miklósné Árva, Zoltánné Fuksz and Etus Enyinginé. Our research was supported by the Hungarian National Development Agency grants (TÁMOP-4.2.2.A-11/1/KONV-2012-0035, TÁMOP4.2.2-A-11/1/KONV-2012-0052; $\quad$ TÁMOP-4.2.2.A-11/1/KONV-2012-0073; TÁMOP-4.2.4.A/2-11-1-2012-0001; TÁMOP- 4.2.4.A2-SZJÖ-TOK-13-0017), MTASZTE Momentum Grant (LP2014-10/2014) and the Hungarian Scientific Research Fund (K109756, NF105785, NF100677).

I have to say a special thanks to Lilla Rácz for her love and patience during my $\mathrm{PhD}$ studies.

Last, but not least I owe warm thanks to my parents, Andrea Pinke and László Katona, my sister Nóra Katona and my whole family for all their love, support, never-ending patience, encouragement and for always being there.

I dedicate this thesis to them! 


\section{REFERENCES}

1 Frizzell RA, Hanrahan JW. Physiology of epithelial chloride and fluid secretion. Cold Spring Harb Perspect Med 2012;2:a009563. doi:10.1101/cshperspect.a009563

2 Dartt DA. Neural regulation of lacrimal gland secretory processes: relevance in dry eye diseases. Prog Retin Eye Res 2009;28:155-77. doi:10.1016/j.preteyeres.2009.04.003

3 Pallagi P, Hegyi P, Rakonczay Z. The Physiology and Pathophysiology of Pancreatic Ductal Secretion: The Background for Clinicians. Pancreas 2015;44:1211-33. doi:10.1097/MPA.0000000000000421

4 Lee MG, Ohana E, Park HW, et al. Molecular mechanism of pancreatic and salivary gland fluid and HCO3 secretion. Physiol Rev 2012;92:39-74. doi:10.1152/physrev.00011.2011

5 Larsen EH. Hans H. Ussing--scientific work: contemporary significance and perspectives. Biochim Biophys Acta 2002;1566:2-15.

6 Jens Chr. Skou. Nobel Lecture. The identification of the sodium pump. Biosci Rep 1998;18:155-69. doi:10.1023/A:1020196612909

7 Kimberg DV, Field M, Johnson J, et al. Stimulation of intestinal mucosal adenyl cyclase by cholera enterotoxin and prostaglandins. J Clin Invest 1971;50:121830 .

8 Frizzell RA, Field M, Schultz SG. Sodium-coupled chloride transport by epithelial tissues. Am J Physiol - Ren Physiol 1979;236:F1-8.

9 Ishiguro H, Steward MC, Lindsay AR, et al. Accumulation of intracellular HCO3by $\mathrm{Na}(+)-\mathrm{HCO} 3$ - cotransport in interlobular ducts from guinea-pig pancreas. $J$ Physiol 1996;495 ( Pt 1):169-78.

10 Ishiguro H, Steward MC, Wilson RW, et al. Bicarbonate secretion in interlobular ducts from guinea-pig pancreas. $J$ Physiol 1996;495 ( Pt 1):179-91.

11 Quinton PM. The neglected ion: HCO3-. Nat Med 2001;7:292-3. doi:10.1038/85429

12 Bobulescu IA, Di Sole F, Moe OW. Na+/H+ exchangers: physiology and link to hypertension and organ ischemia. Curr Opin Nephrol Hypertens 2005;14:485-94.

13 Orlowski J, Grinstein S. Diversity of the mammalian sodium/proton exchanger SLC9 gene family. Pflüg Arch Eur J Physiol 2004;447:549-65. doi:10.1007/s00424-003-1110-3

14 Tóth-Molnár E, Venglovecz V, Ozsvári B, et al. New experimental method to study acid/base transporters and their regulation in lacrimal gland ductal epithelia. Invest Ophthalmol Vis Sci 2007;48:3746-55. doi:10.1167/iovs.06-1291 
15 Gross E, Hawkins K, Abuladze N, et al. The stoichiometry of the electrogenic sodium bicarbonate cotransporter NBC1 is cell-type dependent. J Physiol 2001;531:597-603.

16 Morth JP, Pedersen BP, Buch-Pedersen MJ, et al. A structural overview of the plasma membrane $\mathrm{Na}+, \mathrm{K}+-\mathrm{ATPase}$ and $\mathrm{H}+$-ATPase ion pumps. Nat Rev Mol Cell Biol 2011;12:60-70. doi:10.1038/nrm3031

17 Petersen $\mathrm{OH}$. Calcium-activated potassium channels and fluid secretion by exocrine glands. Am J Physiol 1986;251:G1-13.

18 Welsh MJ, McCann JD. Intracellular calcium regulates basolateral potassium channels in a chloride-secreting epithelium. Proc Natl Acad Sci U S A 1985;82:8823-6.

19 Gerlach U, Brendel J, Lang HJ, et al. Synthesis and activity of novel and selective I(Ks)-channel blockers. J Med Chem 2001;44:3831-7.

20 Bell SM, Schreiner CM, Schultheis PJ, et al. Targeted disruption of the murine Nhe1 locus induces ataxia, growth retardation, and seizures. Am J Physiol 1999;276:C788-95.

21 He X, Tse CM, Donowitz M, et al. Polarized distribution of key membrane transport proteins in the rat submandibular gland. Pflüg Arch Eur J Physiol 1997;433:260-8.

22 Lee MG, Ahn W, Choi JY, et al. $\mathrm{Na}(+)$-dependent transporters mediate $\mathrm{HCO}(3)(-$ ) salvage across the luminal membrane of the main pancreatic duct. $J$ Clin Invest 2000;105:1651-8. doi:10.1172/JCI9207

23 Zhao $\mathrm{H}$, Muallem S. Agonist-specific regulation of $[\mathrm{Na}+]$ i in pancreatic acinar cells. J Gen Physiol 1995;106:1243-63.

24 Zhao $\mathrm{H}$, Muallem S. Na+, $\mathrm{K}+$, and $\mathrm{Cl}$ - transport in resting pancreatic acinar cells. $J$ Gen Physiol 1995;106:1225-42.

25 Wizemann V, Schulz I. Influence of amphotericin, amiloride, ionophores, and 2,4-dinitrophenol on the secretion of the isolated cat's pancreas. Pflüg Arch Eur J Physiol 1973;339:317-38.

26 Veel T, Villanger $\mathrm{O}$, Holthe MR, et al. $\mathrm{Na}(+)-\mathrm{H}+$ exchange is not important for pancreatic HCO3- secretion in the pig. Acta Physiol Scand 1992;144:239-46. doi:10.1111/j.1748-1716.1992.tb09292.x

27 Melvin JE, Yule D, Shuttleworth T, et al. Regulation of fluid and electrolyte secretion in salivary gland acinar cells. Annu Rev Physiol 2005;67:445-69. doi:10.1146/annurev.physiol.67.041703.084745

28 Novak I, Young JA. Two independent anion transport systems in rabbit mandibular salivary glands. Pflüg Arch Eur J Physiol 1986;407:649-56.

29 Pirani D, Evans LA, Cook DI, et al. Intracellular $\mathrm{pH}$ in the rat mandibular salivary gland: the role of Na-H and Cl-HCO3 antiports in secretion. Pflüg Arch Eur J 
30 Shan J, Huang J, Liao J, et al. Anion secretion by a model epithelium: more lessons from Calu-3. Acta Physiol Oxf Engl 2011;202:523-31. doi:10.1111/j.1748-1716.2011.02253.x

31 Tessier GJ, Traynor TR, Kannan MS, et al. Mechanisms of sodium and chloride transport across equine tracheal epithelium. Am J Physiol 1990;259:L459-67.

32 Riordan JR, Rommens JM, Kerem B, et al. Identification of the cystic fibrosis gene: cloning and characterization of complementary DNA. Science

1989;245:1066-73. doi:10.1126/science.2475911

33 Evans MG, Marty A. Calcium-dependent chloride currents in isolated cells from rat lacrimal glands. $J$ Physiol 1986;378:437-60.

34 Marty A, Tan YP, Trautmann A. Three types of calcium-dependent channel in rat lacrimal glands. J Physiol 1984;357:293-325.

35 Maléth J, Hegyi P. Calcium signaling in pancreatic ductal epithelial cells: an old friend and a nasty enemy. Cell Calcium 2014;55:337-45.

doi:10.1016/j.ceca.2014.02.004

36 Caputo A, Caci E, Ferrera L, et al. TMEM16A, A Membrane Protein Associated with Calcium-Dependent Chloride Channel Activity. Science 2008;322:590-4. doi:10.1126/science. 1163518

37 Yang YD, Cho H, Koo JY, et al. TMEM16A confers receptor-activated calciumdependent chloride conductance. Nature 2008;455:1210-5. doi:10.1038/nature07313

38 Argent BE GM. Cell Physiology of Pancreatic Ducts. Johns. LR Ed. Physiol. Gastrointest. Tract 5th Ed Lond. Acad. Press 2012 P 1399-1423. 2012.https://www.escholar.manchester.ac.uk/uk-ac-man-scw:236647 (accessed 17 Nov2015).

39 Choi JY, Muallem D, Kiselyov K, et al. Aberrant CFTR-dependent HCO3transport in mutations associated with cystic fibrosis. Nature 2001;410:94-7. doi:10.1038/35065099

40 Park HW, Nam JH, Kim JY, et al. Dynamic regulation of CFTR bicarbonate permeability by [Cl-]i and its role in pancreatic bicarbonate secretion. Gastroenterology 2010;139:620-31. doi:10.1053/j.gastro.2010.04.004

41 Martin CL, Munnell J, Kaswan R. Normal ultrastructure and histochemical characteristics of canine lacrimal glands. Am J Vet Res 1988;49:1566-72.

42 Dartt DA, Møller M, Poulsen JH. Lacrimal gland electrolyte and water secretion in the rabbit: localization and role of $(\mathrm{Na}++\mathrm{K}+)$-activated ATPase. $J$ Physiol 1981;321:557-69.

43 Walcott B, Birzgalis A, Moore LC, et al. Fluid secretion and the $\mathrm{Na}+\mathrm{K}+-2 \mathrm{Cl}-$ cotransporter in mouse exorbital lacrimal gland. Am J Physiol Cell Physiol 
2005;289:C860-7. doi:10.1152/ajpcell.00526.2004

44 Dartt DA. Regulation of lacrimal gland secretion by neurotransmitters and the EGF family of growth factors. Exp Eye Res 2001;73:741-52.

doi:10.1006/exer.2001.1076

45 Ubels JL, Hoffman HM, Srikanth S, et al. Gene expression in rat lacrimal gland duct cells collected using laser capture microdissection: evidence for $\mathrm{K}+$ secretion by duct cells. Invest Ophthalmol Vis Sci 2006;47:1876-85. doi:10.1167/iovs.050363

46 Ding C, Parsa L, Nandoskar P, et al. Duct system of the rabbit lacrimal gland: structural characteristics and role in lacrimal secretion. Invest Ophthalmol Vis Sci 2010;51:2960-7. doi:10.1167/iovs.09-4687

47 Nandoskar P, Wang Y, Wei R, et al. Changes of chloride channels in the lacrimal glands of a rabbit model of Sjögren syndrome. Cornea 2012;31:273-9. doi:10.1097/ICO.0b013e3182254b42

$48 \mathrm{Lu} \mathrm{M}$, Ding C. CFTR-mediated Cl(-) transport in the acinar and duct cells of rabbit lacrimal gland. Curr Eye Res 2012;37:671-7.

doi:10.3109/02713683.2012.675613

49 Hemady R, Chu W, Foster CS. Keratoconjunctivitis sicca and corneal ulcers. Cornea 1990;9:170-3.

50 The definition and classification of dry eye disease: report of the Definition and Classification Subcommittee of the International Dry Eye WorkShop (2007). Ocul Surf 2007;5:75-92.

51 Paulsen F, Langer G, Hoffmann W, et al. Human lacrimal gland mucins. Cell Tissue Res 2004;316:167-77. doi:10.1007/s00441-004-0877-7

52 Shcheynikov N, Wang Y, Park M, et al. Coupling modes and stoichiometry of Cl/HCO3- exchange by slc26a3 and slc26a6. J Gen Physiol 2006;127:511-24. doi:10.1085/jgp.200509392

53 Zeng W, Lee MG, Yan M, et al. Immuno and functional characterization of CFTR in submandibular and pancreatic acinar and duct cells. Am J Physiol 1997;273:C442-55.

54 Freedman SD, Kern HF, Scheele GA. Pancreatic acinar cell dysfunction in CFTR(-/-) mice is associated with impairments in luminal $\mathrm{pH}$ and endocytosis. Gastroenterology 2001;121:950-7.

55 Bhoomagoud M, Jung T, Atladottir J, et al. Reducing extracellular pH sensitizes the acinar cell to secretagogue-induced pancreatitis responses in rats. Gastroenterology 2009;137:1083-92. doi:10.1053/j.gastro.2009.05.041

56 Behrendorff N, Floetenmeyer M, Schwiening C, et al. Protons released during pancreatic acinar cell secretion acidify the lumen and contribute to pancreatitis in mice. Gastroenterology 2010;139:1711-20, 1720.e1-5. 
doi:10.1053/j.gastro.2010.07.051

57 Yadav D, Lowenfels AB. The epidemiology of pancreatitis and pancreatic cancer. Gastroenterology 2013;144:1252-61. doi:10.1053/j.gastro.2013.01.068

58 Sadr-Azodi O, Andrén-Sandberg Å, Orsini N, et al. Cigarette smoking, smoking cessation and acute pancreatitis: a prospective population-based study. Gut 2012;61:262-7. doi:10.1136/gutjnl-2011-300566

59 Hegyi P, Ordog B, Rakonczai Z, et al. Effect of herpesvirus infection on pancreatic duct cell secretion. World J Gastroenterol 2005;11:5997-6002.

60 Lerch MM, Aghdassi AA. The role of bile acids in gallstone-induced pancreatitis. Gastroenterology 2010;138:429-33. doi:10.1053/j.gastro.2009.12.012

61 Maléth J, Balázs A, Pallagi P, et al. Alcohol disrupts levels and function of the cystic fibrosis transmembrane conductance regulator to promote development of pancreatitis. Gastroenterology 2015;148:427-39.e16.

doi:10.1053/j.gastro.2014.11.002

62 Acosta JM, Ledesma CL. Gallstone migration as a cause of acute pancreatitis. $N$ Engl J Med 1974;290:484-7. doi:10.1056/NEJM197402282900904

63 Pandol SJ, Saluja AK, Imrie CW, et al. Acute pancreatitis: bench to the bedside. Gastroenterology 2007;132:1127-51. doi:10.1053/j.gastro.2007.01.055

64 Perides G, van Acker GJD, Laukkarinen JM, et al. Experimental acute biliary pancreatitis induced by retrograde infusion of bile acids into the mouse pancreatic duct. Nat Protoc 2010;5:335-41. doi:10.1038/nprot.2009.243

65 Wan MH, Huang W, Latawiec D, et al. Review of experimental animal models of biliary acute pancreatitis and recent advances in basic research. HPB 2012;14:7381. doi:10.1111/j.1477-2574.2011.00408.x

66 Gerasimenko JV, Flowerdew SE, Voronina SG, et al. Bile acids induce Ca2+ release from both the endoplasmic reticulum and acidic intracellular calcium stores through activation of inositol trisphosphate receptors and ryanodine receptors. J Biol Chem 2006;281:40154-63. doi:10.1074/jbc.M606402200

$67 \mathrm{Kim}$ JY, Kim KH, Lee JA, et al. Transporter-mediated bile acid uptake causes $\mathrm{Ca} 2+-$ dependent cell death in rat pancreatic acinar cells. Gastroenterology 2002;122:1941-53.

68 Venglovecz V, Rakonczay Z, Ozsvári B, et al. Effects of bile acids on pancreatic ductal bicarbonate secretion in guinea pig. Gut 2008;57:1102-12. doi:10.1136/gut.2007.134361

69 Voronina S, Longbottom R, Sutton R, et al. Bile acids induce calcium signals in mouse pancreatic acinar cells: implications for bile-induced pancreatic pathology. J Physiol 2002;540:49-55.

70 Reber HA, Mosley JG. The effect of bile salts on the pancreatic duct mucosal barrier. Br J Surg 1980;67:59-62. 
71 Farmer RC, Tweedie J, Maslin S, et al. Effects of bile salts on permeability and morphology of main pancreatic duct in cats. Dig Dis Sci 1984;29:740-51.

72 Voronina SG, Barrow SL, Gerasimenko OV, et al. Effects of secretagogues and bile acids on mitochondrial membrane potential of pancreatic acinar cells: comparison of different modes of evaluating DeltaPsim. $J$ Biol Chem 2004;279:27327-38. doi:10.1074/jbc.M311698200

73 Voronina SG, Barrow SL, Simpson AWM, et al. Dynamic changes in cytosolic and mitochondrial ATP levels in pancreatic acinar cells. Gastroenterology 2010;138:1976-87. doi:10.1053/j.gastro.2010.01.037

74 Maléth J, Venglovecz V, Rázga Z, et al. Non-conjugated chenodeoxycholate induces severe mitochondrial damage and inhibits bicarbonate transport in pancreatic duct cells. Gut 2011;60:136-8. doi:10.1136/gut.2009.192153

75 Kowal JM, Haanes KA, Christensen NM, et al. Bile acid effects are mediated by ATP release and purinergic signalling in exocrine pancreatic cells. Cell Commun Signal CCS 2015;13:28. doi:10.1186/s12964-015-0107-9

76 Scheele GA, Fukuoka SI, Kern HF, et al. Pancreatic dysfunction in cystic fibrosis occurs as a result of impairments in luminal $\mathrm{pH}$, apical trafficking of zymogen granule membranes, and solubilization of secretory enzymes. Pancreas 1996;12:1-9.

77 de Caestecker JS, Jazrawi RP, Petroni ML, et al. Ursodeoxycholic acid in chronic liver disease. Gut 1991;32:1061-5.

78 Festi D, Montagnani M, Azzaroli F, et al. Clinical efficacy and effectiveness of ursodeoxycholic acid in cholestatic liver diseases. Curr Clin Pharmacol 2007;2:155-77.

79 Poupon RE, Poupon R, Balkau B. Ursodiol for the long-term treatment of primary biliary cirrhosis. The UDCA-PBC Study Group. N Engl J Med 1994;330:1342-7. doi:10.1056/NEJM199405123301903

80 Rust C, Beuers U. Medical treatment of primary biliary cirrhosis and primary sclerosing cholangitis. Clin Rev Allergy Immunol 2005;28:135-45. doi:10.1385/CRIAI:28:2:135

81 Botla R, Spivey JR, Aguilar H, et al. Ursodeoxycholate (UDCA) inhibits the mitochondrial membrane permeability transition induced by glycochenodeoxycholate: a mechanism of UDCA cytoprotection. $J$ Pharmacol Exp Ther 1995;272:930-8.

82 Pusl T, Vennegeerts T, Wimmer R, et al. Tauroursodeoxycholic acid reduces bile acid-induced apoptosis by modulation of AP-1. Biochem Biophys Res Commun 2008;367:208-12. doi:10.1016/j.bbrc.2007.12.122

83 Rodrigues CM, Fan G, Ma X, et al. A novel role for ursodeoxycholic acid in inhibiting apoptosis by modulating mitochondrial membrane perturbation. J Clin Invest 1998;101:2790-9. doi:10.1172/JCI1325 
84 Rodrigues CM, Ma X, Linehan-Stieers C, et al. Ursodeoxycholic acid prevents cytochrome c release in apoptosis by inhibiting mitochondrial membrane depolarization and channel formation. Cell Death Differ 1999;6:842-54. doi:10.1038/sj.cdd.4400560

85 Schoemaker MH, Conde de la Rosa L, Buist-Homan M, et al. Tauroursodeoxycholic acid protects rat hepatocytes from bile acid-induced apoptosis via activation of survival pathways. Hepatol Baltim Md 2004;39:156373. doi: $10.1002 /$ hep. 20246

86 Argent BE, Arkle S, Cullen MJ, et al. Morphological, biochemical and secretory studies on rat pancreatic ducts maintained in tissue culture. QJ Exp Physiol Camb Engl 1986;71:633-48.

87 Fernández-Salazar MP, Pascua P, Calvo JJ, et al. Basolateral anion transport mechanisms underlying fluid secretion by mouse, rat and guinea-pig pancreatic ducts. J Physiol 2004;556:415-28. doi:10.1113/jphysiol.2004.061762

88 Pascua P, García M, Fernández-Salazar MP, et al. Ducts isolated from the pancreas of CFTR-null mice secrete fluid. Pflüg Arch Eur J Physiol 2009;459:203-14. doi:10.1007/s00424-009-0704-9

89 Ko SBH, Naruse S, Kitagawa M, et al. Aquaporins in rat pancreatic interlobular ducts. Am J Physiol Gastrointest Liver Physiol 2002;282:G324-31. doi:10.1152/ajpgi.00198.2001

90 Mlekoday HJ, Moore R, Levitt DG. Osmotic water permeability of the human red cell. Dependence on direction of water flow and cell volume. J Gen Physiol 1983;81:213-20.

91 Thomas JA, Buchsbaum RN, Zimniak A, et al. Intracellular $\mathrm{pH}$ measurements in Ehrlich ascites tumor cells utilizing spectroscopic probes generated in situ. Biochemistry (Mosc) 1979;18:2210-8.

92 Hegyi P, Rakonczay Z, Gray MA, et al. Measurement of intracellular $\mathrm{pH}$ in pancreatic duct cells: a new method for calibrating the fluorescence data.

Pancreas 2004;28:427-34.

93 Hegyi P, Gray MA, Argent BE. Substance P inhibits bicarbonate secretion from guinea pig pancreatic ducts by modulating an anion exchanger. Am J Physiol Cell Physiol 2003;285:C268-76. doi:10.1152/ajpcell.00574.2002

94 Hegyi P, Rakonczay Z, Tiszlavicz L, et al. Protein kinase C mediates the inhibitory effect of substance $\mathrm{P}$ on $\mathrm{HCO} 3$ - secretion from guinea pig pancreatic ducts. Am J Physiol Cell Physiol 2005;288:C1030-41. doi:10.1152/ajpcell.00430.2003

95 Alvaro D, Mennone A, Boyer JL. Effect of ursodeoxycholic acid on intracellular $\mathrm{pH}$ regulation in isolated rat bile duct epithelial cells. Am J Physiol 1993;265:G783-91.

96 Goldman A, Shahidullah M, Goldman D, et al. A novel mechanism of acid and 
bile acid-induced DNA damage involving $\mathrm{Na}+/ \mathrm{H}+$ exchanger: implication for Barrett's oesophagus. Gut 2010;59:1606-16. doi:10.1136/gut.2010.213686

97 Pallagi-Kunstár É, Farkas K, Maléth J, et al. Bile acids inhibit $\mathrm{Na}^{+} / \mathrm{H}^{+}$exchanger and $\mathrm{Cl}^{-} / \mathrm{HCO}_{3}{ }^{-}$exchanger activities via cellular energy breakdown and $\mathrm{Ca}^{2+}$ overload in human colonic crypts. Pflüg Arch Eur J Physiol 2015;467:1277-90. doi:10.1007/s00424-014-1560-9

98 Ikegami T, Matsuzaki Y, Fukushima S, et al. Suppressive effect of ursodeoxycholic acid on type IIA phospholipase A2 expression in HepG2 cells. Hepatol Baltim Md 2005;41:896-905. doi:10.1002/hep.20630

99 Im E, Akare S, Powell A, et al. Ursodeoxycholic acid can suppress deoxycholic acid-induced apoptosis by stimulating Akt/PKB-dependent survival signaling. Nutr Cancer 2005;51:110-6. doi:10.1207/s15327914nc5101_15

100 Saeki T, Yui S, Hirai T, et al. Ursodeoxycholic acid protects colon cancer HCT116 cells from deoxycholic acid-induced apoptosis by inhibiting apoptosome formation. Nutr Cancer 2012;64:617-26. doi:10.1080/01635581.2012.669876

101 Krüger B, Albrecht E, Lerch MM. The role of intracellular calcium signaling in premature protease activation and the onset of pancreatitis. Am J Pathol 2000;157:43-50. doi:10.1016/S0002-9440(10)64515-4

102 Mithöfer K, Fernández-del Castillo C, Frick TW, et al. Acute hypercalcemia causes acute pancreatitis and ectopic trypsinogen activation in the rat. Gastroenterology 1995;109:239-46.

103 Raraty M, Ward J, Erdemli G, et al. Calcium-dependent enzyme activation and vacuole formation in the apical granular region of pancreatic acinar cells. Proc Natl Acad Sci U S A 2000;97:13126-31. doi:10.1073/pnas.97.24.13126

104 Thorn P, Lawrie AM, Smith PM, et al. Ca2+ oscillations in pancreatic acinar cells: spatiotemporal relationships and functional implications. Cell Calcium 1993;14:746-57.

105 Lemasters JJ, Nieminen AL, Qian T, et al. The mitochondrial permeability transition in cell death: a common mechanism in necrosis, apoptosis and autophagy. Biochim Biophys Acta 1998;1366:177-96.

106 Lemasters JJ, Qian T, Bradham CA, et al. Mitochondrial dysfunction in the pathogenesis of necrotic and apoptotic cell death. J Bioenerg Biomembr 1999;31:305-19.

107 Grasl-Kraupp B, Ruttkay-Nedecky B, Koudelka H, et al. In situ detection of fragmented DNA (TUNEL assay) fails to discriminate among apoptosis, necrosis, and autolytic cell death: a cautionary note. Hepatol Baltim Md 1995;21:1465-8.

108 Sun W, Watanabe Y, Toki A, et al. Beneficial effects of hydrocortisone in induced acute pancreatitis of rats. Chin Med J (Engl) 2007;120:1757-61.

109 Sun W, Watanabe Y, Wang Z-Q. Expression and significance of ICAM-1 and its 
counter receptors LFA-1 and Mac-1 in experimental acute pancreatitis of rats. World J Gastroenterol 2006;12:5005-9.

110 Szalmay G, Varga G, Kajiyama F, et al. Bicarbonate and fluid secretion evoked by cholecystokinin, bombesin and acetylcholine in isolated guinea-pig pancreatic ducts. J Physiol 2001;535:795-807.

111 Burghardt B, Nielsen S, Steward MC. The role of aquaporin water channels in fluid secretion by the exocrine pancreas. J Membr Biol 2006;210:143-53. doi:10.1007/s00232-005-0852-6

112 Berry CA. Water permeability and pathways in the proximal tubule. Am J Physiol 1983;245:F279-94.

113 Berry CA, Verkman AS. Osmotic gradient dependence of osmotic water permeability in rabbit proximal convoluted tubule. J Membr Biol 1988;105:3343.

114 Folkesson HG, Matthay MA, Frigeri A, et al. Transepithelial water permeability in microperfused distal airways. Evidence for channel-mediated water transport. $J$ Clin Invest 1996;97:664-71. doi:10.1172/JCI118463

115 Roberts SK, Yano M, Ueno Y, et al. Cholangiocytes express the aquaporin CHIP and transport water via a channel-mediated mechanism. Proc Natl Acad Sci U S A 1994;91:13009-13.

116 Kuang K, Yiming M, Wen Q, et al. Fluid transport across cultured layers of corneal endothelium from aquaporin-1 null mice. Exp Eye Res 2004;78:791-8. doi:10.1016/j.exer.2003.11.017

117 Ding C, Nandoskar P, Lu M, et al. Changes of aquaporins in the lacrimal glands of a rabbit model of Sjögren's syndrome. Curr Eye Res 2011;36:571-8. doi:10.3109/02713683.2011.574330

118 Ding C, Lu M, Huang J. Changes of the ocular surface and aquaporins in the lacrimal glands of rabbits during pregnancy. Mol Vis 2011;17:2847-55.

119 Herzog V, Sies H, Miller F. Exocytosis in secretory cells of rat lacrimal gland. Peroxidase release from lobules and isolated cells upon cholinergic stimulation. $J$ Cell Biol 1976;70:692-706.

120 Dartt DA, Botelho SY. Protein in rabbit lacrimal gland fluid. Invest Ophthalmol Vis Sci 1979;18:1207-9.

121 Ubels JL, Foley KM, Rismondo V. Retinol secretion by the lacrimal gland. Invest Ophthalmol Vis Sci 1986;27:1261-8.

122 Dartt DA, Hodges RR. Cholinergic agonists activate P2X7 receptors to stimulate protein secretion by the rat lacrimal gland. Invest Ophthalmol Vis Sci 2011;52:3381-90. doi:10.1167/iovs.11-7210

123 Hootman SR, Picado-Leonard TM, Burnham DB. Muscarinic acetylcholine receptor structure in acinar cells of mammalian exocrine glands. $J$ Biol Chem 
1985;260:4186-94.

124 Mauduit P, Jammes H, Rossignol B. M3 muscarinic acetylcholine receptor coupling to PLC in rat exorbital lacrimal acinar cells. Am J Physiol 1993;264:C1550-60.

125 Ding C, Walcott B, Keyser KT. Neuronal nitric oxide synthase and the autonomic innervation of the mouse lacrimal gland. Invest Ophthalmol Vis Sci 2001;42:2789-94.

126 Boyer JL. New concepts of mechanisms of hepatocyte bile formation. Physiol Rev 1980;60:303-26.

127 Solá S, Castro RE, Kren BT, et al. Modulation of nuclear steroid receptors by ursodeoxycholic acid inhibits TGF-beta1-induced E2F-1/p53-mediated apoptosis of rat hepatocytes. Biochemistry (Mosc) 2004;43:8429-38. doi:10.1021/bi049781x

128 Sola S, Ma X, Castro RE, et al. Ursodeoxycholic acid modulates E2F-1 and p53 expression through a caspase-independent mechanism in transforming growth factor beta1-induced apoptosis of rat hepatocytes. J Biol Chem 2003;278:488318. doi:10.1074/jbc.M300468200

129 Rolo AP, Oliveira PJ, Moreno AJ, et al. Chenodeoxycholate is a potent inducer of the permeability transition pore in rat liver mitochondria. Biosci Rep 2001;21:73-80.

130 Rolo AP, Oliveira PJ, Moreno AJ, et al. Chenodeoxycholate induction of mitochondrial permeability transition pore is associated with increased membrane fluidity and cytochrome c release: protective role of carvedilol. Mitochondrion 2003;2:305-11. doi:10.1016/S1567-7249(03)00007-2

131 Woolbright BL, Jaeschke H. Novel insight into mechanisms of cholestatic liver injury. World J Gastroenterol 2012;18:4985-93. doi:10.3748/wjg.v18.i36.4985

132 Yerushalmi B, Dahl R, Devereaux MW, et al. Bile acid-induced rat hepatocyte apoptosis is inhibited by antioxidants and blockers of the mitochondrial permeability transition. Hepatol Baltim Md 2001;33:616-26.

doi:10.1053/jhep.2001.22702

133 Faubion WA, Guicciardi ME, Miyoshi H, et al. Toxic bile salts induce rodent hepatocyte apoptosis via direct activation of Fas. J Clin Invest 1999;103:137-45. doi:10.1172/JCI4765

134 Booth DM, Murphy JA, Mukherjee R, et al. Reactive oxygen species induced by bile acid induce apoptosis and protect against necrosis in pancreatic acinar cells. Gastroenterology 2011;140:2116-25. doi:10.1053/j.gastro.2011.02.054

135 Ros E, Navarro S, Bru C, et al. Occult microlithiasis in "idiopathic" acute pancreatitis: prevention of relapses by cholecystectomy or ursodeoxycholic acid therapy. Gastroenterology 1991;101:1701-9. 
136 Testoni PA, Caporuscio S, Bagnolo F, et al. Idiopathic recurrent pancreatitis: long-term results after ERCP, endoscopic sphincterotomy, or ursodeoxycholic acid treatment. Am J Gastroenterol 2000;95:1702-7. doi:10.1111/j.15720241.2000.02292.x

137 Venneman NG, vanBerge-Henegouwen GP, van Erpecum KJ. Pharmacological manipulation of biliary water and lipids: potential consequences for prevention of acute biliary pancreatitis. Curr Drug Targets Immune Endocr Metab Disord 2005;5:193-8.

138 Benz C, Angermüller S, Otto G, et al. Effect of tauroursodeoxycholic acid on bile acid-induced apoptosis in primary human hepatocytes. Eur J Clin Invest 2000;30:203-9.

139 Benz C, Angermüller S, Töx U, et al. Effect of tauroursodeoxycholic acid on bile-acid-induced apoptosis and cytolysis in rat hepatocytes. $J$ Hepatol 1998;28:99-106.

140 Beuers U, Fischer S, Spengler U, et al. Formation of iso-ursodeoxycholic acid during administration of ursodeoxycholic acid in man. J Hepatol 1991;13:97-103.

141 Marschall HU, Roeb E, Yildiz Y, et al. Study of human isoursodeoxycholic acid metabolism. J Hepatol 1997;26:863-70. 
I. 


\section{Experimental Evidence of Fluid Secretion of Rabbit Lacrimal Gland Duct Epithelium}

\section{Chuanqing Ding}

Pharmacology \& Pharmaceutical Sciences, Ophthalmology, University of Southern California, Los Angeles, California, United States; cding®usc.edu

The lacrimal gland (LG) is the major source of tears that lubricate, nourish, and protect the integrity and function of the eye, most notably the ocular surface. Dysfunction of the LG may cause dry eye, the most common disease in eye clinics. While most of the research has focused on the acinar cells, little is known about the ductal cells, although these cells long have been suggested to have a role in LG fluids secretion and absorption.

In the current issue of Investigative Opbthalmology and Visual Science, Katona et al. ${ }^{1}$ employed the novel technique they developed several years ago, clarified the myth and gave us an unequiveal answer that ductal cells, indect, can secrete on their developed sever own. By a core forming closelin, ducts, which was blocked completely by atropine. These studies showed, for the first time, direct observation of the LG duct's ability to secrete by themselves. This is critical information as it confirmed earlier notions of functional role of these ducts in LG secretion, and paved the way for future drug information as it confirmed earlier notions of functional role of these ducts in LG secretion, and paved the way for future drug
development to treat dry eye by targeting these ducts. development to treat dry eye by targeting these ducts.

Artificial tears currently are the major approach to manage dry eye, but only alleviate the symptoms on a temporary basis, without treating the root cause of the disease. While the etiology of dry eye is hugely diverse and largely unknown, most of the previous efforts have focused on acinar cells, without adequate consideration of these ducts. The LG ducts clearly are underinvestigated, and, therefore, the data presented are especially valuable.

\section{References}

1. Katona M, Vizvári E, Németh L, et al. Experimental evidence of fluid secretion of rabbit lacrimal gland duct epithelium. Invest Opbtbalmol Vis Sci. 2014;55:4360-4367. 


\section{Experimental Evidence of Fluid Secretion of Rabbit Lacrimal Gland Duct Epithelium}

Máté Katona,,${ }^{1,2}$ Eszter Vizvári, ${ }^{3}$ Lukács Németh, ${ }^{4}$ Andrea Facskó, ${ }^{3}$ Viktória Venglovecz, ${ }^{2}$ Zoltán Rakonczay Jr, ${ }^{1}$ Péter Hegyi, ${ }^{1}$ and Edit Tóth-Molnár ${ }^{2,3}$

'1st Department of Internal Medicine, University of Szeged, Szeged, Hungary

${ }^{2}$ Department of Pharmacology and Pharmacotherapy, University of Szeged, Szeged, Hungary

${ }^{3}$ Department of Ophthalmology, University of Szeged, Szeged, Hungary

Department of Medicinal Chemistry, University of Szeged, Szeged, Hungary

Correspondence: Edit Tóth-Molnár

University of Szeged, 6720 Szeged,

Koranyi fasor 10-11, Hungary;

tmes tmedit.hu.

Submitted: January 24, 2014

Accepted: May 12, 2014

Citation: Katona M, Vizvári E, Németh

L. et al. Experimental evidence of fluid

epithelium Invest Opbibinit vis

cpithelium. 2014:55:4360-4367. DOI:

10.1167/iovs. 14-14025
Purpose. To investigate the osmotic water permeability of lacrimal gland (LG) duct epithelium by means of calculation of filtration permeability and to investigate LG ductal fluid secretion. METHODS. Experiments were performed on isolated rabbit LG duct segments maintained in short-term culture. Osmotically determined fluid movement or fluid secretion into the closed intraluminal space of cultured LG interlobular ducts was analyzed using video microscopic technique.

Resurs. The end of the LG ducts sealed after overnight incubation forming a closed luminal space. For the calculation of osmotic water permeability, ducts were initially perfused with

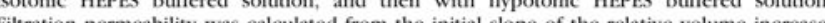
Hectration perme secretory responses to carbachol or to Forskolin stimulaton were also investigated. Forskolin stimulation resulted in a rapid and sustained secretory response in both solutions. Forskolinstimulated hlid secretion was completely inhibited by bumetanide both in HEPES buffered and in $\mathrm{HCO}_{3}-\mathrm{CO}_{2}$ buffered solutions, suggesting the central role of $\mathrm{Na}+\mathrm{K}^{-}-2 \mathrm{Cl}$ cotransporter type 1 (NKCC1). Administration of carbachol initiated a rapid but short secretory response in both $\mathrm{HEF}$. completely abolished the carbachol-evoked fluid secretion.

Concussions. A new method was introduced to investigate LG duct function. Water permeability of rabbit LG duct epithelium was measured by calculating filtration permeability Fluid secretion of LG duct cells induced by carbachol or forskolin was also demonstrated. These results provide calculated values of lacrimal duct osmotic permeability and direct experimental evidence of LG duct fluid secretion.

Keywords: lacrimal gland, epithelial cells, lacrimal gland duct, fluid secretion
$\mathbf{B}^{\text {oth the balanced electrolyte, and mucin protein composi- }}$ $\mathbf{B}_{\text {tion, as well as the appropriate amount of fluid secreted by }}$ the lacrimal gland (LG) are essential for maintaining preocular tear film integrity. Dysfunction of the lacrimal functional unit can lead to the development of dry eye causing a wide spectrum of ocular surface damage. ${ }^{1-3}$ Dry eye disease has become an emerging health problem in industrialized countries worldwide. A more detailed understanding of the LG function can lead to the development of specific therapeutic modalities. Similarly to other exocrine tubuloacinar glands, LG is mainly composed of three types of cells: acinar, duct, and myoepithelial cells. ${ }^{4.5}$ Functions of acinar cells are widely studied, resulting in a broad spectrum of information. ${ }^{6-9}$ Contrarily, much less is known about the possible secretory function of duct cells. It has been proposed that primary acinar fluid is modified by ductal secretory processes: an elevated $\mathrm{K}^{\prime}$ and $\mathrm{Cr}$ content of the final product evolves during passage of fluid through the ductal tree $6,7,10$ However, the role of LG duct epithelium on fluid clectrolyte, and protein secretion is not well understood.

Copyright 2014 The Association for Research in Vision and Ophthalmology, In wwwiovs. org | ISSN: 1552.5783
New methods have been published to study LG duct epithelium during the past few years, Ubels and colleagues ${ }^{11}$ epithelium during the past few years. Ubels and colleagues
collected duct cells from frozen rat LG sections using a laser capture microdissection technique. Numerous genes coding basolateral-to-apical $K$ secretion-related transport proteins were found in duct cells. Another experimental method to study LG function was described by our laboratory. ${ }^{12}$ The new isolation technique resulted in viable duct segments for functional studies. The role and regulation of various ion ransporters in the lacrimal duct can be studied with the use of isolated, short-term cultured duct segments. Our results showed the functional presence of a $\mathrm{Na}^{+}$-dependent proton efflux mechanism $\left(\mathrm{Na}^{+} / \mathrm{H}^{+}\right.$exchanger; NHE) and a $\mathrm{Cl}^{-}$ dependent $\mathrm{HCO}_{3}^{-}$efflux mechanism (anion exchanger; $\mathrm{AE}$ ) using pH-sensitive fluorescent dye in LG duct cells. Overal actions of basolaterally- and apically- located ion transporter produce an osmotic gradient, which determine the direction of water flow. Water passively follows secreted ions depending on the osmotic gradient.

The underrepresentation of studies concerning lacrimal duct epithelial cells is in striking contrast to the information 
that has been gathered from the duct system of the pancreas or salivary glands. The role of duct system in different glands varies on a wide scale. Pancreatic ducts have an important role in secretion of $\mathrm{HCO}_{3}{ }^{-}$-rich fluid. ${ }^{13-17}$ The duct cells in salivary glands seem to secrete $\mathrm{K}^{+}$and $\mathrm{HCO}_{3}{ }^{-}$and reabsorb $\mathrm{Na}^{+}$and $\mathrm{Cl}^{-}$without water movement. ${ }^{18-21}$ Although LG duct epithelial cells supposedly participate in ion transport processes, there is no data supported by experimental results regarding the contribution of duct cells in fluid secretion of the gland. In addition, there is no data available about water permeability of LG duct epithelium.

The aims of the present work were to determine the osmotic water permeability of duct epithelium by means of calculation of filtration permeability $\left(P_{\gamma}\right)$, and to investigate LG duct fluid secretion by means of measurement of fluid secretion evoked by potential agonists (forskolin and carbachol).

\section{Materials and Methods}

\section{Animals}

Adult male New Zealand white rabbits weighing 2 to $2.5 \mathrm{~kg}$ were used (Devai Farm, Kondoros, Hungary). The animals were narcotized with a mixture of ketamine $(10 \mathrm{mg} / \mathrm{kg}$, intravenously) and xylazine ( $3 \mathrm{mg} / \mathrm{kg}$, intravenously) and were euthanized with pentobarbital overdose $(80 \mathrm{mg} / \mathrm{kg}$, intravenously). All experiments were conducted in compliance with the ARVO Statement for the Use of Anit Ophthalmic and Vision Research. The protocot has been Ophered by the ethicat com Anim in Researly of the University of Syeged, syeged,

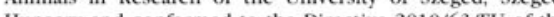
to the Directive $2010 / 63 / \mathrm{EU}$ of the European Parliament.

Solutions and Chemicals for Isolation, Culture, and Superfusion of LG Ducts

Isolation solution contained Dulbecco's modified Eagle's medium (DMEM) supplemented with $100 \mathrm{U} / \mathrm{mL}$. collagenase (Worthington, Lakewood, NJ, USA) and $1 \mathrm{mg} / \mathrm{mL}$. BSA. Storage solution contained DMEM and 3\% (wt/vol) BSA. Culture solution contained McCoy's $5 \mathrm{~A}$ tissue culture medium, $10^{\circ}$ (vol/vol) fetal calf serum, and $2 \mathrm{mM}$ glutamine Media supplements (DMEM MeCoy, fetal calf serum, glutamine, and BSA) were purchased from Sigma-Aldrich (Budapest, Hungary).

Standard HEPE buffered solution contained (mM): $140 \mathrm{NaC}$ (67.5 $\mathrm{NaCl}$ in case of hypotonic solution: $145 \operatorname{mos} \mathrm{M}$ ), $5 \mathrm{KCl}$, $\mathrm{CaCl}_{2}, 1 \mathrm{MgCl}_{2}, 10 \mathrm{D}$-glucose, and $10 \mathrm{Na}$-HEPES and $\mathrm{pH}$ was set to 7.4 with $\mathrm{HCl}$ at $37^{\circ} \mathrm{C}(290 \mathrm{mos} \mathrm{M})$

of The standard $\mathrm{HCO}_{3}^{-} / \mathrm{CO}_{2}^{-}$buffered solution contained (mM): $115 \mathrm{NaCl}_{2} 25 \mathrm{NaHCO}_{3}, 5 \mathrm{KCl}, 1 \mathrm{CaCl}_{2}, 1 \mathrm{MgCl}_{2}, 10 \mathrm{D}$ glucose and was gassed with $95 \% \mathrm{O}_{2} / 5 \% \mathrm{CO}_{2}$ at $37^{\circ} \mathrm{C}$.

Carbamoylcholine chloride (Carbachol), forskolin, bumetanide, DIDS, and 5-(N-ethyl-N-isopropylamiloride (EIPA) were obtained from Sigma-Aldrich.

\section{Isolation and Culture of Lacrimal Duct Segments}

Rabbit LG interlobular ducts were isolated as previously described by our laboratory. ${ }^{12}$ Briefly LGs were dissected and transferred to a sterile small flatbottom glass flask containing a cold $\left(+4^{\circ} \mathrm{C}\right)$ storage solution. Isolation solution was injected inte the interstitum of the gands and the tissue piec

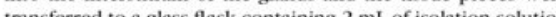
for incubation in a shaking water bath at 37 solution was removed after incubating for 25 minutes and $5 \mathrm{~mL}$ of fresh cold storage $\left(+4^{\circ} \mathrm{C}\right)$ solution was added to the flask Lacrimal gland tissue samples were transferred to a glass microscope slide and viewed under stereo microscope Interlobular ducts were microdissected and after microdissection, intact LG ducts were transferred to the culture solution in a petri dish. Ducts were cultured overnight in a $37^{\circ} \mathrm{C}$ incubator gassed with $5 \% \mathrm{CO}_{2} / 95 \% \mathrm{O}_{2}$.

Measurement of Osmotic Water Permeability and Fluid Secretion of LG Interlobular Duct Epithelium

The ends of LG ducts seal during overnight incubation forming a closed luminal space. Secretory processes (or osmoticallydetermined fluid movement) of duct epithelium into the closed intraluminal space result in swelling of the ducts as the luminat space fllts with the secreted fluid as seen in the ase of lunise of isolated pancreatic duct. The change in duct volume can be a LG duct segments were careflly transerred to a coverslip pretreated with dilued poly-lysine (diluted in distilled water ratio $=1: 9 ;$ Sigma-Aldrich). The coverslip formed the base of a perfusion chamber mounted on an inverted microscope (Olympus Ltd., Budapest, Hungary). The chamber was perfused with solutions via an infusion pump at approximately $2.5 \mathrm{~mL} / \mathrm{min}$ at $37^{\circ} \mathrm{C}$. Ducts were visualized at high magnification $(\times 20$ objective). Bright-field images were acquired at set time intervals ( 5 seconds in the case of osmotic permeability measurements and 1 minute in the case of ductal fluid secretion experiments) using a charge-coupled digital camera device coupled to a personal computer. Both the duration of experiments and the time intervals between images were defined in Xcellence (Olympus Lud.) imaging software. An image series in taged image file format was generated image series in tagged image file format was generated containing all of the images collected from the same experiment, Scion Image (Scion Corporation, Frederick, MD, USA) software was used to obtain values and analyze changes in the area corresponding to the luminal space in each image The initial lumen length $\left(L_{0}\right)$ and the lumen area $\left(A_{0}\right)$ were measured directly from the pixel intensities on the first image. The lumen diameter was calculated assuming the cylindrical setup of the duct, from the formula $2 \mathrm{R}=A_{0} / L_{0}$. The lumina surface area was calculated as $2 \pi R_{0} L_{0}$, also assuming cylindrical geometry. Measurements from subsequent individual image were normalized to the first lumen area in the series $\left(\mathrm{A}_{0}\right)$ thus giving values for the relative area $\left(A_{\mathrm{R}}=A / A_{0}\right)$. Relative luminal volume $\left(V_{\mathrm{R}}=V / V_{\mathrm{o}}\right)$ of the ducts was then calculated from the relative image area. These calculations were done using Scion Image and Microsoft Excel software (Microsoft, Redmond, WA USA).

Luminal volume change after exposure to hypotonic solution was measured for the calculation of osmotic permeatilys mostic permeabily as follows. ducts were perfused with isotonic HEPES buffered solution ( 290 mosM) for 5 minutes afte equilibration, then the perfusate was changed to hypotonic
HEPES buffered solution $(145 \text { mos } M)^{24}$

The osmotic water permeability constant $\left(\left[P_{i}\right]=\mu \mathrm{m} / \mathrm{s}\right)$ was calculated using the initial volume $\left(V_{0}=\pi R_{0}^{2} L_{0}\right)$, the initial slope of the relative volume increase $\left(d\left(V / V_{0}\right) / d t\right)$, the initial luminal surface area $\left(S_{0}=2 \pi R_{0} L_{0}\right)$, and the molar volume of water $\left(V_{\mathrm{w}}=18 \times 10^{12} \mu \mathrm{M}\right)$ as follows ${ }^{25}$ :

$$
P_{\mathrm{f}}=\left[V_{0} d\left(V / V_{0}\right) / d t\right] /\left[S_{0} V_{\mathrm{w}}\left(o s m_{\text {in }}-o s m_{\text {out }}\right)\right]
$$

where $o s m_{\text {in }}-o s m_{\text {out }}$ is the difference between inner and outer 


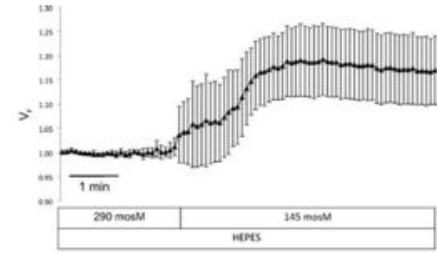

Figuke 1. Osmotic permeability of rabbit interlobular duct epitheli( the relative luminal volume $\left(V_{r}\right)$ induced by a $50 \%$ reduction in the osmolarity of the perfusate are shown. Measurements were performed by video microscopy. Bright field images were captured at 5-second intervals. Data was obtained from nine ducts isolated from three

mediums osmolarity. In this case $o s m_{\text {in }}=290 \mathrm{mOsm}$ and $o s m_{\text {out }}=145 \mathrm{mOsm}$

In the case of fluid secretion measurements, carbachol or forskolin was added to the perfusate after 10-minutes superfusion with HEPES buffered or $\mathrm{HCO}_{3}-/ \mathrm{CO}_{2}$ buffered solution At the end of each experiment, perfision was solutiond At he experion was changed to hithe end in conin epilling of the duets as a sesping was proved by rapid swelling or the dicts as a response to hypotonic challenge. Data obtained fro response was discarded.

\section{Statistical Analysis}

Data is presented as means \pm SEM, where the value of $n$ is the number of ducts. One-way ANOVA followed by Bonferroni post hoc test was used for statistical comparison of data, $P$ less than 0.05 was chosen as the limit for statistical significance.

\section{Results}

\section{Osmotic Water Permeability of LG Interlobular}

\section{Duct Epithelium}

The luminal area increased after exposure to the hypotonic solution indicating that the $\mathrm{NaCl}$ gradient caused rapid water flux into the closed luminal space. $P_{\mathrm{f}}$ was $60.53 \pm 19.76 \mu \mathrm{m} / \mathrm{s}$ ( $n=9$, from three different animals). Figure 1 shows the changes in the luminal volume after the change in bath osmolarity.

\section{Forskolin-Stimulated Fluid Secretion of} Interlobular Ducts

Effects of forskolin stimulation on secretion of LG ducts were investigated both in HEPES buffered and in $\mathrm{HCO}_{3}^{-} / \mathrm{CO}_{2}$ buffered solutions. In the first series of the experiments, ducts were superfused with HEPES buffered solution for 10 minutes and then $10 \mu \mathrm{M}$ forskolin was added to the bath. Ducts remained unchanged in HEPES buffered solution (secretory rate: $-2.2 \pm 18.7 \mathrm{pL} / \mathrm{min} / \mathrm{mm}^{2}$ ), while during forskolin stimulation, rapid, sustained swelling response was observed (secretory rate in the first 10 minutes of stimulation: $379.9 \pm$ $54.4 \mathrm{pL} / \mathrm{min} / \mathrm{mm}^{2}$, in the first 15 minutes of stimulation: 327.4 $\pm 41.6 \mathrm{pL} / \mathrm{min} / \mathrm{mm}^{2}$; Fig. $2 \mathrm{~A}$ ).

In order to evaluate the potential role of $\mathrm{HCO}_{3}^{-}$transporters in forskolin-evoked fluid secretion, ducts were superfused with $\mathrm{HCO}_{3}^{-} / \mathrm{CO}_{2}$ buffered solutions for 10 minutes, and then forskolin was added to the bath. There was no detectable -

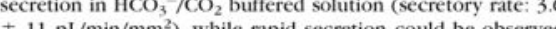
\pm 11 pl/m 10 ents first 15 min of stinution: $408.3=69.5 \mathrm{pL} / \mathrm{min} / \mathrm{mm}^{2}$, in the first 15 minutes of stimulation. $355.1 \pm 64 \mathrm{pL} / \mathrm{min} / \mathrm{mm}^{2}$; Fig. 2B). See Supplementary Video $\mathrm{S} 1$ for the effect of forskolin stimulation on ductal fluid secretion in $\mathrm{HCO}_{3}{ }^{-} / \mathrm{CO}_{2}$ buffered solution. Figure 3 shows photo series of swelling duct deriving from the video.

The secretory effect of forskolin did not differ in HEPES or $\mathrm{HCO}_{3}-\mathrm{CO}_{2}$ buffered solution. The sensitivity of forskolinevoked secretion to inhibitors of known basolateral ion transporters was then investigated in the presence and in the absence of $\mathrm{HCO}_{3}^{-}$.

\section{Effects of Bumetanide on Fluid Secretion}

since rabbit LG interlobular ducts are able to secrete fluid in response to forskolin stimulation in HEPES buffered (nominally response to for kolin stin $\mathrm{HCO}_{3}$ - $\mathrm{rec}$ ) $\mathrm{HCO}_{3}, \mathrm{mos}$ probably $\mathrm{CT}$ can be the anionic driving force of fluid secretion. To inestigate the transporter responsible for basolateral CI uptake, we tested the role of NKCC1 by administration of the cotransport inhibitor bumetanide Bumetanide $(100 \mu \mathrm{M})$ completely blocked forskolin-evoked fluid secretion in HEPES buffered $\left(\mathrm{HCO}_{3}^{-}\right.$free), and also in $\mathrm{HCO}_{3}-\mathrm{CO}_{2}$ buffered solutions (Figs, $4 \mathrm{~A}, 4 \mathrm{~B}$ ). Bumetanide was applied after 10 minutes of stimulation with forskolin in these experiments. Effect of preincubation with bumetanide on forskolin-evoked fluid secretion in $\mathrm{HCO}_{3}^{-} / \mathrm{CO}_{2}^{-}$buffered solution can be seen on Figure $4 \mathrm{C}$.

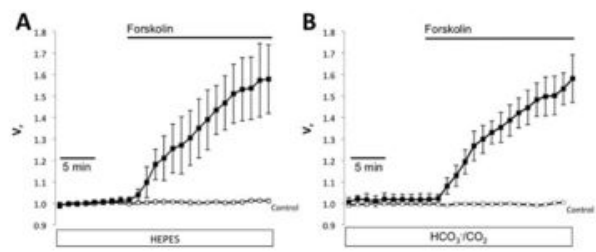

Fuctue 2. Effect of forskolin on ductal fluid secretion in rabbit LG interlobular ducts in the presence or in the absence of $\mathrm{HCO}_{3}^{-}$. (A) Ducts were superfused with HEPES-buffered solution throughout the experiments. From 10 minutes, ducts were exposed either to $10 \mu \mathrm{M}$ forskolin (filled square) or to no agonist (empty circle). (B) Ducts were superfused with HEPES-buffered solution for 10 minutes (data not shown) and then the pither $10 \mu \mathrm{V}$ for five ducts isolated from at least three different animals in each series and is presented as the mean $+5 E M$ 


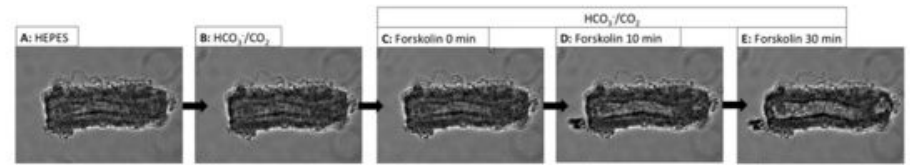

FiGtike 3. Photo series of secreting isolated rabbit LG duct segment in response to forskolin stimulation. (A) Isolated LG duct segment in HEPES buffered solution. (B) Isolated LG duct segment in $\mathrm{HCO}_{3}-/ \mathrm{CO}_{2}$ buffered solution. (C) The beginning of $10 \mu \mathrm{M}$ forskolin stimulation in $\mathrm{HCO}_{5}-/ \mathrm{CO}_{2}$ response of duct segment after 30 minutes of forskolin stimulation in $\mathrm{HCO}_{3}^{-} / \mathrm{CO}_{2}$ buffered solution.

\section{Role of Basolateral $\mathrm{HCO}_{3}{ }^{-}$Transporters in Fluid} Secretion

To further investigate the contribution of basolateral $\mathrm{HCO}_{3}$ and $\mathrm{Cl}^{-}$transporters, we tested the effects of basolater transport inhibitors EIPA $(3 \mu \mathrm{M})$ and DIDS $(100 \mu \mathrm{M})$. In $\mathrm{HCO}_{3}$ buffered solution, administration of EIPA and DIDS did not significantly alter the secretory rates (Fig. 4D).

These results suggest the key role of $\mathrm{Cl}^{-}$transport in fluid secretion in rabbit LG interlobular ducts.
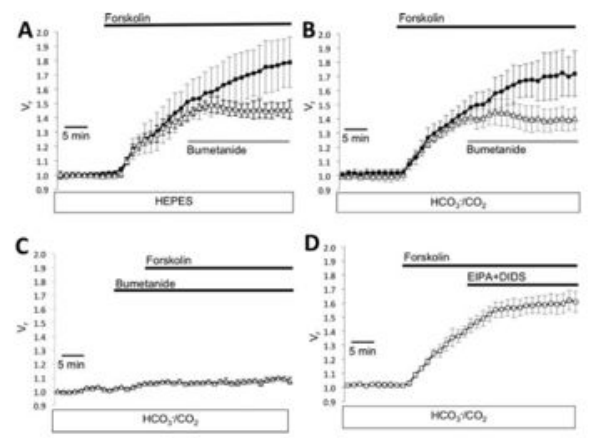

FigtRe 4. Effects of bumetanide, EIPA, and DIDS on forskolin-evoked ductal fluid secretion in rabbit LG interlobular ducts. (A) Ducts were superfused with HEPES buffered solution throughout the experiments. From 10 minutes, ducts were exposed to $10 \mu \mathrm{M}$ forskolin, from 20 minutes, ducts were exposed either to no blocker (only forskolin stimulation, filled square) or to $100 \mu \mathrm{M}$ bumctanide (empty triangle). (B) Ducts were superfused with HEPES buffered solution for minutes (data not shown) and then the perfusate was switched to $\mathrm{HCO}_{3} / \mathrm{CO}_{2}$ buffered solution. After 10 minutes of superfusion with $\mathrm{HCO}_{3}-1 \mathrm{CO}_{2}$ buffered solution, ducts were exposed to $10 \mu \mathrm{M}$ forskolin From 20 minutes, ducts were exposed either to no blocker (only

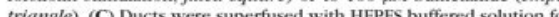

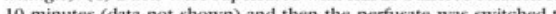
HCO- $-1 \mathrm{CO}_{2}$ buffered solution. From 10 minutes, ducts were exposed cither to 100 M bumetanide (empty triangle), or no blocker (filled square) From 20 minutes, all ducts were exposed to $10 \mu \mathrm{V}$ forskolin. (D) Ducts were superfused with HEPES buffered solution for 10 minutes (data not shown) and then the perfusate was swirched to $\mathrm{HCO}_{3}-/ \mathrm{CO}_{2}$ buffered solution. After 10 minutes of superfusion with $\mathrm{HCO}_{3} / \mathrm{CO}_{2}$ buffered solution, ducts were exposed to $10 \mu \mathrm{M}$ forkoing From 20 minutes ducts were exposed to $3 \mu \mathrm{M}$ EIPA and $100 \mu \mathrm{M}$ DIDS (empty square). Administration of $\mathrm{EPA}$ and $\mathrm{DIDS}$ without bumetanicle did not cause statistically significant reduction in forskotin-voked fluid secretion. Changes in relative luminal volame $(V)$ are shown. Bata W. each series and is presented as the mean \pm SEM

\section{Carbachol-Stimulated Fluid Secretion of LG} Interlobular Ducts

The effect of carbachol treatment on fluid secretion of LG ducts was investigated both in HEPES buffered and in $\mathrm{HCO}_{3}^{-1}$ $\mathrm{CO}_{2}$ buffered solutions. In the first series of experiments, ducts were perfused with HEPES buffered solutions for 10 minutes, followed by administration of $100 \mu \mathrm{M}$ carbachol to the bath solution. No secretion was observed in HEPES buffered solution, whereas carbachol initiated ductal swelling representing cholinergic-evoked ductal fluid secretion. Fluid secre tion proved to be biphasic consisting of a continuous swelling in the first 5 minutes followed by a plateau phase (secretory rate in the first 5 minutes of stimulation: $122.3 \pm 29.6 \mathrm{pL} / \mathrm{min} /$ $\mathrm{mm}^{2}$, in the first 10 minutes of stimulation: $69.2 \pm 12.9 \mathrm{pL}$ $\mathrm{min} / \mathrm{mm}^{2}$; Fig. $5 \mathrm{~A}$ )

The role of $\mathrm{HCO}_{3}^{-}$in carbachol-evoked fluid secretion was investigated in the second series of experiments. Ducts were perfused with $\mathrm{HCO}_{3}^{-} / \mathrm{CO}_{2}$ buffered solution. Ducts did not show fluid secretion in $\mathrm{HCO}_{3}^{-} / \mathrm{CO}_{2}$ buffered solution. One hundred micromols of carbachol was then administered to the bath and the swelling response was detected. Figure $\mathrm{BB}$ shows bath a d hean mean carbacholstimuled dictallition secretion was very similar to those the observed in tory effect of carbachol could be detected in the first 5 5 minutes, followed by a plateau phase (secretory rate in the first 5 minutes of stimatation. $106.3-26.7 \mathrm{pL} / \mathrm{min} / \mathrm{mm}^{2}$, in the first 10 minutes of stimulation: $66.3 \pm 15.6 \mathrm{pL} / \mathrm{min} / \mathrm{mm}^{2}$; Fig. 5B).

Administration of parasympatholytic atropine $(10 \mu \mathrm{M})$ resulted in a complete abolishment of carbachol-evoked fluic secretion both in HEPES buffered and in $\mathrm{HCO}_{3}^{-} / \mathrm{CO}_{2}$ buffered solutions (Figs. 5A, 5B). Secretory rates did not show a significant difference between measurements in HEPES buffered and $\mathrm{HCO}_{3}-/ \mathrm{CO}_{2}$ buffered solutions. Secretory rates evoked by forskolin and carbachol in the presence and in the absence of $\mathrm{HCO}_{3}{ }^{-}$are summarized in Figure 6.

\section{Discussion}

In the present work, we provide the quantification of water permeability of lacrimal ducts, as well as the experimental evidence of lacrimal duct fluid secretion evoked by forskolin or carbachol.

Until recently, neither experimental methods, nor results deriving from functional experiments have been published concerning the fluid secreting capability of the LG duct epithelium. In contrast to many secretory epithelia, there is a lack of published calculation of the water permeability of the duct epithelium, even thoug this paremeter is essentin determining the even though this parameter is essential in determining the fluid transport. It has been estimated that duct cells may produce up to $30 \%$ of the total volume of the LC 
$\mathbf{A}_{120}$

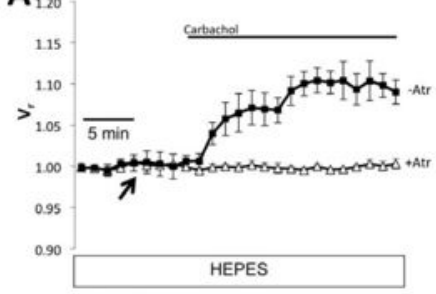

$\mathbf{B}_{120}$

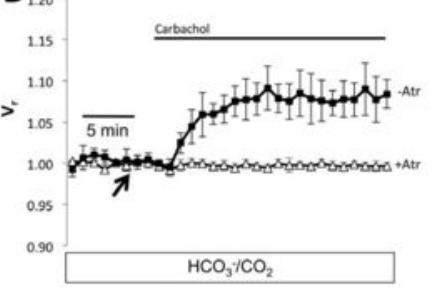

FigurE 5. Effect of carbachol on ductal fluid secretion in LG gland interlobular ducts in the presence or in the absence of $\mathrm{HCO}_{5}^{-}$. (A) Ducts were superfused with HEPES buffered solution throughout the experiments. From 5 minutes ducts were exposed either to $100 \mu \mathrm{M}$ atropine (empty triangle, arrow indicates the initiation of atropine treatment) or no blocker (filled square). From 10 minutes all ducts were exposed to $100 \mu \mathrm{M}$ carbachol. (B) Ducts were superfused with HEPEs buffered solution for 10 , atropine teas in each seres and presented as be ment volum

water secretion cannot be neglected. ${ }^{6.7}$ However the relative inaccessibility of the LG duct structure makes it difficult to obtain information from viable duct segments

The LG isolation technique described earlier by our laboratory results in viable duct segments maintained in short-term culture, which are suitable for functional studies. According to our observations, the sealing of the ends of the ducts results in complete restoration of epithelial integrity and swelling of the ducts happens without leakage in the vast majority of cases. For the first time, video microscopic method was applied to investigate the osmotic permeability and secretory properties of LG duct epithelium in the present work.

The value of $P_{\mathrm{f}}$ proved to be $60.53 \pm 19.76 \mu \mathrm{m} / \mathrm{s}$. This $P_{\mathrm{r}}$ value is lower than the highly water permeable pancreatic duct epithelium $(160-170 \mu \mathrm{m} / \mathrm{s}$, measured in rat pancreatic ducts $^{24.26}$ or the kidney proximal tubule $(100-500 \mu \mathrm{m} / \mathrm{s}$, different species ${ }^{27,28}$ and very similar to the distal airways of the guinea pig $(60 \mu \mathrm{m} / \mathrm{s})^{29}$ to the rat cholangiocytes $(50 \mu \mathrm{m} /$

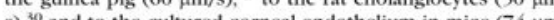
s). 31 The $P_{i}$ value showed by our experiments is cle

5). ${ }^{31}$ The $P_{f}$ value showed by our experiments is clearly

sufficient to support the process of fluid secretion, and proves that rabbit LG duct epithelium can be able to secrete fluid. Until recently, limited number of studies has focused on LG duct epithelium. ${ }^{11,12,32-36}$ All of these studies investigated the on secretory profile of duct cells, while fluid secretory properties of duct system remained speculative. Dartt et al. published a landmark study in 1981 proposing that the electrolyte and water component of LG fluid could be a mixture of plasma-like primary fluid secreted by the acinar cells and a potassium ion-rich fluid produced by the duct cells. They concluded that duct cells may secrete a significan portion of LG fluid. Ding et al. ${ }^{32}$ recently established nomenclature for the lacrimal duct system in the mabit. According to their description, lacrimal duct system can be divided into intralobular interlobular intralobar, and can be ducts. The gene expression profile of hese and interlobar ducts. The garious duct segments microdissetion difference could be iffer segments suggesting thei differing fole in tear secretion. In general, predominan

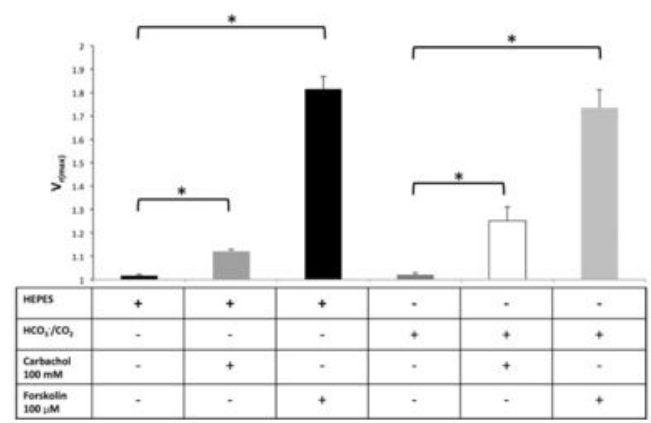

FigukE 6. Calculated secretory rates of LG interlobular ducts evoked by forskolin and carbachol. Secretory rates $\left(U_{v}\right)$ were calculated from data shown in Figures 2 and 4 and are expressed in picoliter secreted fluid per minute per millimeter squared luminal epithelial surface. Secretory rate cartalot or by forkelin be

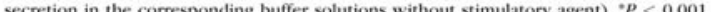




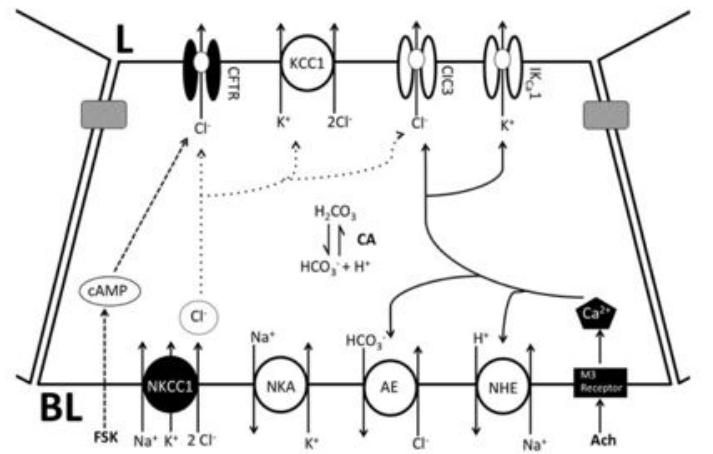

FiGLRE 7. Schematic model of electrolyte secretion underlying fluid secretion in LG interlobular duct epithelial cells. The model is based on the channels and transporters identified by Dartt et al., ${ }^{6}$ Ubels et al., ${ }^{11}$ Ding et al.. ${ }^{32}$ our earlier investigations, ${ }^{12}$ and by the present study. Forskolinstimulation results in elevated cytosolic CAMP levels which activate C secretion through CFTR. Summarized actions of Cl selective channels determinant of lumen-negative transepithelial voltage difference, which is the driving force of ductal fluid secretion. Coupled influxes of $\mathrm{Na}^{+} \mathrm{K}^{+}$ and $\mathrm{Cl}$ are mediated by bumetanidesensitive NKCC1 located on the basolateral membrane. Parasympathomimetic carbachol stimulates NHE activity, followed by the activation of $\mathrm{AE}$ on the basolateral membrane through $\mathrm{Ca}^{2+}$ signaling. The elevated intracellular $\mathrm{Ca}^{2+}$ concentration ${ }^{2}$ activate IKCa1, a $\mathrm{Ca}^{2+}$-activated potassium channel and $\mathrm{CIC} 3$, an apically located $\mathrm{Cl}$ channel. L, luminal side; BI, basolateral side; $\mathrm{KCCl}^{-} \mathrm{K}^{+} / 2 \mathrm{Cl}$ cotransporter; CIC, Chloride channel; IKCal, intermediate conductance calcium-activated $\mathrm{K}^{+}$channel; $\mathrm{NKA}^{-} \mathrm{Na}^{+} / \mathrm{K}^{+} \cdot \mathrm{ATP}^{-}$

regulator (CFTR) was found in the duct cells. ${ }^{32}$ Another recent study ${ }^{33}$ found significant variations in the expression of different $\mathrm{Cl}^{-}$channels in a rabbit model of Sjögren syndrome and in healthy animals. The reduced levels of NKCC1 and CFTR mRNA in duct cells derived from diseased animal suggest the active contribution of these structures in altere lacrimal fluid secretion. In a recent paper, Lu and Ding elegantly demonstrated that CFTR is functionally involved in $\mathrm{Cl}^{-}$transport in both acinar and duct cells in the rabbit LG and suggests that CFTR plays a significant role in LG function. The presence of significant amounts of CFTR and other channels and transporters in the LG duct cells strongly suggests that LG ducts play a critical role in the maintenance of homeostasis of lacrimal fluid secretion.

In the present work, we found that forskolin initiated a brisk and eontinuous swelling responne in mabit LG interlobular ducts. Find secretion was anost unaffected by inhibition of $\mathrm{HCO}_{3}^{-} \mathrm{tran}$. or men basolateral cl uptak

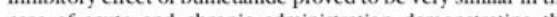

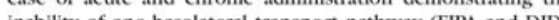
inability of one basolateral transport pathway (EIPA and DIDS sensitive) to increase its activity when another (bumetanidesensitive) is chronically inhibited. A model summarizing the channels, transporters, and intracellutar messengers is show in Figure 7. Both elevated cytosolic caMp levels an intracellular $\mathrm{Ca}^{2}$ signaling can activate $\mathrm{Cl}^{2}$ secretion throug different CI selective channels located on the apical menbrane. Summarized actions of these Cl channels result in intraluminal flux of chloride. Elevation of intraluminal $\mathrm{CI}$ concentration can be the main determinant of lumen-negative transepithelial voltage difference, which is the driving force of ductal fluid secretion.

The complete inhibition of fluid secretion by bumetanide in $\mathrm{HCO}_{-}^{-} / \mathrm{CO}_{2}$ buffered solution suggests the predominant role of $\mathrm{Cl}^{-}$tansport mechanisms over $\mathrm{HCO}^{-}$secreting processes in Cr crimal duct fluid secretion in rabbit as bumetacesses in lacrim inhibior of the $\mathrm{NKCCl}$ beated on the baster membrane of the duct cells, this transport process can be the main route of cellular chloride uptake. Further studies are needed to determine the functional activity of this transporter Our findings strongly sugest the importance of CFTR in ductal fuid secretion as forskolin, well-known activator of CFTR via the elevation of cytosolic cAMP levels, resulted in a significant (he elesich swelling response in our experiments. We were unable to carry out direct investigation of the apically located CFTR since the luminal space cannot be reached in sealed ducts. Cannulation of these narrow and fragile structure

Cholinergic control of LG secretion through M3 muscarinic receptors is well known. ${ }^{6,10,11,37-43}$ Cholinergic stimulation with carbachol resulted in a biphasic secretory response with faster initial and a plateau second phase in our experiments. The caloch the carbachol-evoked secretory pattern of lacrimal ducts was similar to those found in pancreatic ducts. ${ }^{22}$ Parasympatholytic atropine abolished the stimulatory effect of carbachol, suggesting the involvement of muscarinic cholinoceptors The secretory effects of forskolin were remarkably higher compared with the response to carbachol stimulation.

Interlobular ducts are the smallest segments, which can be isolated with our technique. Considering the presumably different function of various duct segments suggested by earlier investigations it must be emphasized that data obtained from one specified section of the duct system can only be translated to other parts of the ductal tree with great precaution.

In conclusion, calculated values of filtration permeability and forskolin- and carbachol-induced fluid secretory capabilities of LG duct cells were demonstrated in the present work. These results were achieved by an experimental technique used by the first time in lacrimal duct research. Our results strongly support the hypothesis that the LG duct system is actively involved in lacrimal fluid secretion. Our nove experimental technique opens a new horizon in the investige tion of acrim luct function and can help to clarify investigathect. 
mechanisms in tear secretion. Effects of potential secretagouge compounds can also be tested with this method. These future results may contribute to the development of targeted pharmacological interventions in order to improve deteriorat ed LG functions in dry eye disease.

\section{Acknowledgments}

This work was supported by Grants TÁMOP-4.2.2./B-10/1-20100012, TAMOP-4.2.2A-11/1/KONV-2012-0035, and TAYOP 4.2.4A A2-SZJÖ-TOK-13-0017 (TÁMOP, Hungary).

Disclosure: M. Katona, None; E. Vizvári, None; L. Németh None; A. Facskó, None; V. Venglovecz, None; Z. Rakonczay Jr None; A. Facskó, None; V. Venglovecz, None;
None; P. Hegyi, None; E. Tóth-Molnăr, None

\section{References}

1. Hemady R, Chu W, Foster CS, Keratoconjunctivitis sicca and corneal ulcers. Cornea 1990:9:170-173.

2. The definition and classification of dry eye disease: report of the Definition and Classification Subcommittee of the International Dry Eye WorkShop. Ocul Surf. 2007;5:75-92.

3. Paulsen F, Langer G, Hoffmann W, Berry M. Human lacrimal gland mucins. Cell Tissue Res. 2004:316:167-177.

4. Millar TJ, Herok G, Koutavas H, Martin DK, Anderton PJ. Immunohistochemical and histochemical characterisation of epithelial cells of rabbit lacrimal glands in tissue sections and cell cultures. Tissue Cell. 1996;28:301-312.

5. Martin CL. Munnell J, Kaswan R. Normal ultrastructure and histochemical characteristics of canine lacrimal glands. $\mathrm{Am}$ Vet Res. 1988;49:1566-1572.

6. Dart DA Moller M, Poulsen JH. Lacrimal gland electrolyte and ind role of $\mathrm{Na}^{+}+$ $K^{\prime}$ )activated ATPase. J Pbysiol. 1981:321:557-569.

7. Mircheff AK. Control of lacrimal gland function: water and electrolyte secretion and fluid modification. In: DM electrolyre secretion and find Jakobicc FA, eds. Principles and Practice in 0 Philadelphia, PA: WB Saunders; 1994:466-472.

8. Walcott B, Birzgalis A, Moore LC, Brink PR. Fluid secretion and Walcott B, Birzgalis A, Moore LC, Brink PR. Fluid secretion and the $\mathrm{Na}$. Am J Pbysiol Cell Plysiol. 2005;289:C860-C867.

9. Dart DA. Regulation of lacrimal gland secretion by neurotransmitters and the EGF family of growth factors. $\operatorname{Exp} E$

10. Dartt DA. Neural regulation of tacrimal gland secretory processes: relevance in dry eye diseases. Prog Retin Eje Res. 2009:28: 155-177.

11. Ubels JL, Hoffman HM, Srikanth S, Resau JH, Webb CP. Gene expression in rat lacrimal gland duct cells collected using lase capture microdissection. evidence for $\mathrm{K}+$ secretion by the duct cells. Invest Ophtbalmol Vis Sci. 2006;47:1876-1885.

12. Toth-Molnar E, Venglovecz V, Ozsvari B, et al. New experimental method to study acid/base transporters and their regulation in lacrimal gland ductal epithelia. Invest Opbthamol Vis Sci. 2007;48:3746-3755.

13. Argent BE, Arkle S, Cullen MJ, Green R. Morphological, biochemical and secretory studies on rat pancreatic ducts maintained in tissue culture. Q J Exp Pbysiol. 1986:71:633648.

14. Ishiguro H, Steward MC, Wilson RW, Case RM. Bicarbonate secretion in interlobular ducts

15. Ishigure H, Naruse S, Steward MC, et al Fluid secretion in interlobular duets isolat from guineapis pancreas. $J$ Ptyon 1998:511:407-422.

16. Hegyi P. Rakonczay Z Jr. The inhibitory pathways of pancreatic ductal bicarbonate secretion. Int J Biochem Cell Biol. 2007; 39:25-30.
17. Szalmay G, Varga G, Kajiyama F, et al. Bicarbonate and fluid secretion evoked by cholecystokinin, bombesin and acetyl. 2001:535.3:795-807.

18. Martinez JR. Cellular mechanisms underlying the production of primary secretory fluid in salivary glands. Critic Rev Oral
Biol Med. 1990;1:67-78.

19. Tandler B, Pinkstaff CA, Phillips CJ. Interlobular excretory ducts of mammalian salivary glands: structural and histochemical review.

20. Roussa E. Channels and transporters in salivary glands. Cell Tissue Res. 2011;343:263-287.

21. Bandyopadhyay BC, Swaim WD, Sarkar A, Liu X, Ambudkar is Extracellular $\mathrm{Ca}^{2+}$ sensing in salivary ductal cells. $J$ Biol Chem 2012;287:30305-30316.

22. Fernández-Salazar MP, Pascua P, Calvo J, et al. Basolateral anion transport mechanisms underlying fluid secretion by mouse, rat and guinea-pig pancreatic ducts. $J$ Pbysiol. 2004:556.2:415428

23. Pascua P, Garcia M, Fernández-Salazar MP, et al. Ducts isolated rom the pancreas of CFTR-null mice secrete fluid. Pflugers Arcb. 2009:459:203-214.

24. Ko SBH, Naruse S, Kitagawa M, et al. Aquaporins in rat pancreatic interlobular ducts. Am J Pbysiol Gastrointest Liver Pbysiol. 2002;282:G324-G331.

25. Mlekoday HJ, Moore R, Levitt DG. Osmotic water permeability the human red cell. Dependence on direction of wirer flow and cell volume. J Gen Physiol. 1983:81:213-220.

26. Burghardt B, Nielsen S, Steward MC. The role of aquaporin water channels in fluid secretion by the exocrine pancreas. $J$
Membr Biol. 2006;210:143-153.

27. Berry CA. Water permeability and pathways in the proximal tubule. Am J Plysiol Renal Pbysiol. 1983;245:F279-F294.

28. Berry CA, Verkman AS. Osmotic gradient dependence of osmotic permeability in rabbit proximal convoluted tubule. $J$ Membr Biol, 1988;105:33-43.

29. Folkesson HG, Matthay MA, Frigeri A, Verkman AS. Transepithelial water permeability in microperfused distal airuyays. Evidence for channel-mediated water transport. J Clin Invest. 1996:97:664-671.

30. Roberts SK, Yano M, Ueno $\mathrm{Y}$, et al. Cholangiocytes express the aquaporin CHIP and transport water via a channel-mediated mechanism. Proc Natl Acad Sci U S A. 1994:91:13009-13013.

31. Kuang $K$, Yiming $M$, Wen Q, et al. Fluid transport across cultured layers of corneal endothelium from aquaporin-1 null cultured layers of corneal endotheliur
mice, Exp Fje Res. 2004; $78: 791-798$.

32. Ding C, Parsa L, Nandoskar P, Zhao P, Wu K, Wang Y. Duct system of the rabbit lacrimal gland: structural characteristic and role in lacrimal secretion. Intest Opbthalmol Vis Sci

33. Nandoskar P, Wang Y, Wei R, et al. Changes of chloride channels in the lacrimal glands of a rabbit model of Sjögren syndrome. Cornea. 2012;31:273-279.

34. Ding C, Nandoskar P, Lu M, Thomas P, Trousdale MD, Wang Y Changes of aquaporins in the lacrimal glands of a rabbit mode of Sjogren's syndrome. Curr Eye Res. 2011:36:571-578.

35. Ding C, Lu M, Huang J. Changes of the ocular surface and aquaporins in the lacrimal glands of rabbits during pregnancy. Mol Vis. 2011;17:2847-2855.

36. Lu M, Ding C. CFTR-mediated $\mathrm{Cl}^{-}$transport in the acinar and duct cells of rabbit lacrimal gland. Curr Eye Res. 2012;37:671677.

37. Herzog V, Sies H, Miller F Exocytosis in secretory cells of rat lacrimal gland. Peroxidase release from lobules and isolated clls upon cholinergic stimulation. J Cell Biol. 1976;70-692 
38. Dartt DA, Botelho SY. Protein in rabbit lacrimal gland secretion. Invest Opbthalmol Vis Sci. 1979:18:1207-1209.

39. Ubels JL, Foley KM, Rismondo V. Retinol secretion by the lacrimal gland. Invest Opbthalmol Vis Sci. 1986;27:1261 1268.

40. Dartt DA, Hodges RR. Cholinergic agonists activate P2X receptors to stimulate protein secretion by the rat lacrimal receptors to stimulate protein secretion by the rat lacing
gland. Imest Opbthalmol Vis Sci. 2011:52:3381-3390.
41. Hootmann SR, Picardo-Leonard TM, Burnham DB. Muscarinic acetylcholine receptor structure in acinar cells of mammalian exocrine glands. J Biol Cbem. 1985:260:4186-4194.

42. Mauduit P, Jammes H, Rossignol B. M3 muscarinic acetylcholine receptor coupling to PLC in rat exorbital lacrimal acinar line receptor coupling to PLC in rat exorbital lacim
cells. Am J Pbysiol. 1993;264(6 Pt 1);1550-1560.

43. Ding C, Walcott B, Keyser KT. Neuronal nitric oxide synthase and
and the autonomic innervations of the mouse lacrimal gland. Invest Opbtbalmol Vis Sci. 2001:42:2789-2794. 


\section{II.}




\section{Decision made for GI-00317-2015R2}

1 üzenet

jjones@the-aps.org <jjones@the-aps.org>

Válaszcim: jjones@the-aps.org

Cimzett: mate.katona@gmail.com

Dear Dr. Katona:

A decision for GI-00317-2015R2, "A novel, protective role of ursodeoxycholate in bile-induced pancreatic ductal injury" for which you are listed as co-author, has been sent to the corresponding author. That letter is below. Contributing authors are: Máté Katona, Péter Hegyi, Balázs Kui, Zsolt Balla, Zoltan Rakonczay Jr., Zsolt Rázga, Laszlo Tiszlavicz, József Maléth, and Viktoria Venglovecz

\section{Subject: GI-00317-2015R2 Accept for publication}

Dear Dr. Venglovecz:

I am pleased to inform you that your manuscript "A novel, protective role of ursodeoxycholate in bile-induced pancreatic ductal injury" (GI-00317-2015R2)

has been accepted and will be published online as an Article in Press within approximately two weeks, assuming all files are in order.

PLEASE NOTE THAT YOUR MANUSCRIPT WILL BE PUBLISHED IN AIPS EXACTLY AS SUBMITTED, INCLUDING SPELLING OF AUTHOR NAMES AS PROVIDED IN THE METADATA OF THE MANUSCRIPT RECORD.

Thank you for your continued interest in the journal and

congratulations to you and your colleagues on such an excellent

study.

Regards,

Stephen Pandol

Associate Editor

American Journal of Physiology - Gastrointestinal and Liver Physiology

Open Access Author Choice

Traditionally, articles published online in this journal are available through subscription or pay per view for one year, and are then made free to all, or open access, 12 months after publication. Now you can choose to allow immediate open access for your research article by paying a fee $(\$ 2000)$. The fee is $\$ 3000$ for review articles. The payment form can be found at $h$ ttp://www.the-aps.org/authorchoice/pdf/form.pdf . For more information, please see: http://www.authorchoice.org .

Important Information about the NIH Public Access Requirement and Your Manuscript Under the NIH Public Access Policy, NIH is requiring that its funded investigators submit to PubMed Central (PMC) all manuscripts accepted after April 7, 2008, resulting from research supported in whole or in part with direct costs from $\mathrm{NIH}$.

If you are NIH funded, APS will upload the final published article to PMC for you; you do not need to do anything more to meet this requirement. APS will have PMC make the article free 12 months after final 
publication. This period of time is consistent with our existing policy to make all content publicly available through HighWire Press 12 months after print publication, and keeps you in compliance with your copyright agreement with APS.

Other Funding Agencies that require posting to PMC

If you are funded by a different funding agency, such as the Wellcome Trust, that requires posting to PMC APS will submit your article to PMC for you. If that agency also requires that access be made free before 12 months, you are required to pay an AuthorChoice fee, which will allow your article to be made free on the Journal site and in PMC immediately upon receipt of payment. Please click on the AuthorChoice link for the payment form:

http://www.the-aps.org/authorchoice/pdf/form.pdf

If you have any questions with respect to the NIH Public Access Policy or other funding agencies' policies and the publication of your article in an APS journal, please see:

http://www.the-aps.org/mm/Publications/Funding-Agencies

Confidentiality Notice: This e-mail message, including any attachments, is for the sole use of the intended recipient(s) and may contain confidential and privileged information. Any unauthorized review, copy, use, disclosure, or distribution is prohibited. If you are not the intended recipient, please contact the sender by reply e-mail and destroy all copies of the original message.

Confidentiality Notice: This e-mail message, including any attachments, is for the sole use of the intended recipient(s) and may contain confidential and privileged information. Any unauthorized review, copy, use, disclosure, or distribution is prohibited. If you are not the intended recipient, please contact the sender by reply e-mail and destroy all copies of the original message. 
A novel, protective role of ursodeoxycholate in bile-induced pancreatic ductal injury

Máté Katona ${ }^{l}$, Péter Hegyi, ${ }^{2,3}$, Balázs Kui ${ }^{2}$, Zsolt Balla ${ }^{2,4}$, Zoltán Rakonczay Jr. ${ }^{2,4}$, Zsolt Rázga ${ }^{5}$, László Tiszlavicz $^{5}$, József Maléth ${ }^{2}$, Viktória Venglovecz ${ }^{I}$

${ }^{1}$ Department of Pharmacology and Pharmacotherapy, ${ }^{2}$ First Department of Medicine, ${ }^{3}$ MTASZTE Translational Gastroenterology Research Group, ${ }^{4}$ Department of Pathophysiology, ${ }^{5}$ Department of Pathology, University of Szeged, Szeged, Hungary

Running title: Ursodeoxycholic acid in acute pancreatitis

Corresponding author:

Viktória Vengloyecz, Ph.D.

Department of Pharmacology and Pharmacotherapy

University of Szeged

Szeged

HUNGARY

Telephone: +36 62545682

Fax: +36 62545680

Email: venglovecz.viktoria@med.u-szeged.hu 


\section{ACCEPTED MANUSCRIPT}

Abbreviations: $\mathrm{ATP}_{\mathrm{i}}$ : intracellular ATP; $\left[\mathrm{Ca}^{2+}\right]_{\mathrm{i}}$ : intracellular $\mathrm{Ca}^{2+}$ concentration; $\mathrm{CBE}: \mathrm{Cl}$ $/ \mathrm{HCO}_{3}{ }^{-}$exchanger; $\mathrm{CDCA}$ : chenodeoxycholic acid; $\Delta \Psi_{\mathrm{m}}$ : mitochondrial membrane potential; mPTP: mitochondrial permeability transition pore; NHE1: $\mathrm{Na}^{+} / \mathrm{H}^{+}$exchanger; $\mathrm{NBC}$ : $\mathrm{Na}^{+} / \mathrm{HCO}_{3}{ }^{-}$cotransporter; PDECs: pancreatic ductal epithelial cells; $\mathrm{pH}_{\mathrm{i}}$ : intracellular $\mathrm{pH}$; UDCA: ursodeoxycholic acid

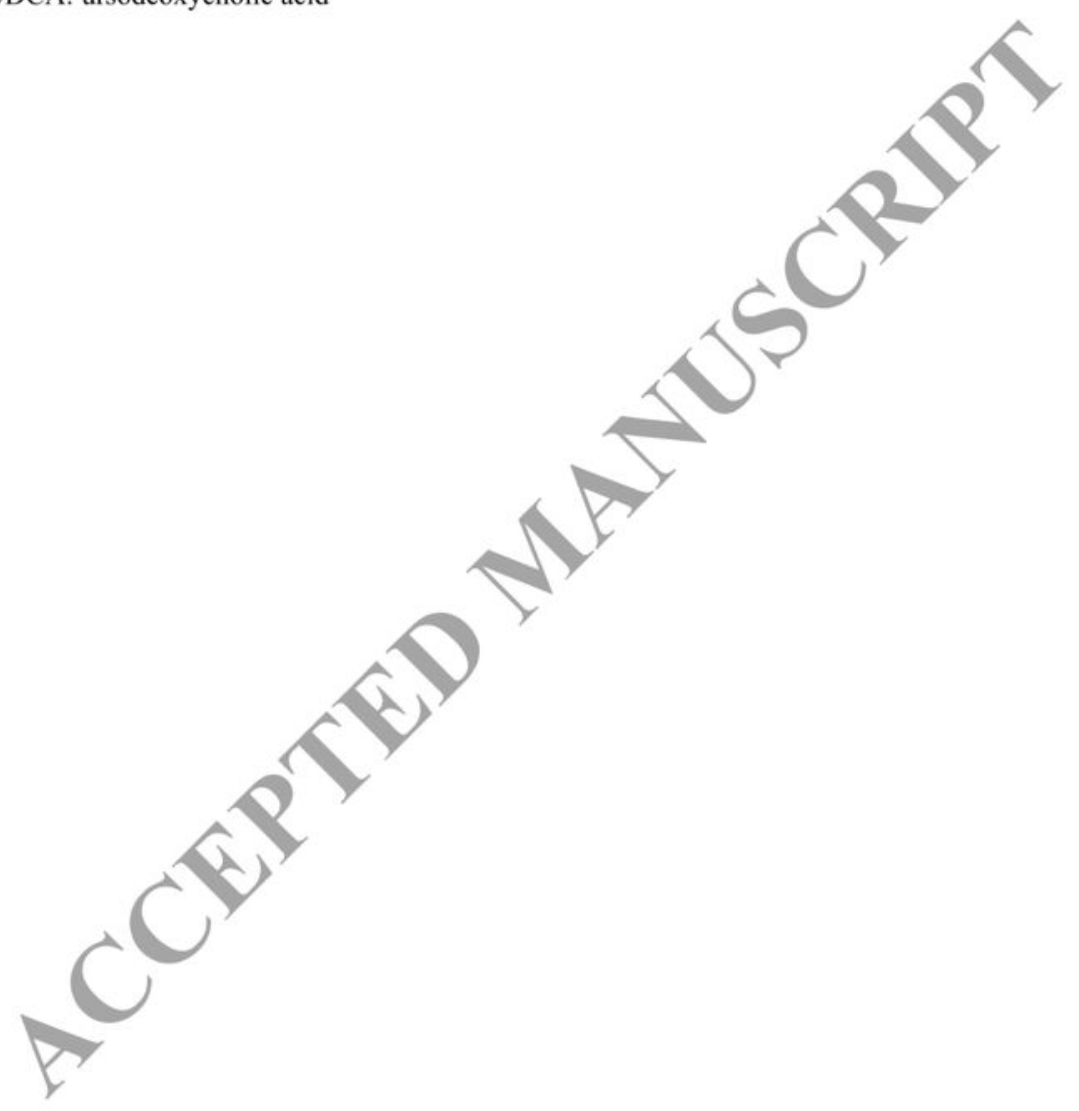




\section{ACCEPTED MANUSCRIPT}

ABSTRACT

Introduction. We have previously shown that chenodeoxycholic acid (CDCA) strongly inhibits pancreatic ductal $\mathrm{HCO}_{3}{ }^{\circ}$ secretion through the destruction of mitochondrial function, which may have significance in the pathomechanism of acute pancreatitis (AP). Ursodeoxycholic acid (UDCA) is known to protect the mitochondria against hydrophobic bile acids and has ameliorating effect on cell death. Therefore, our aim was to investigate the effect of UDCA pretreatment on CDCA-induced pancreatic ductal injury,

Methods. Guinea pig intra-interlobular pancreatic ducts were isolated by collagenase digestion. Ducts were treated with UDCA for 5 and $24 \mathrm{~h}$ and the effect of CDCA on intracellular $\mathrm{Ca}^{2+}$ concentration $\left(\left[\mathrm{Ca}^{2+}\right]_{\mathrm{i}}\right), \mathrm{pH}\left(\mathrm{pH}_{\mathrm{i}}\right)$, morphological and functional changes of mitochondria, and the rate of apoptosis were investigated. AP was induced in rat by retrograde intraductal injection of CDCA $(0.5 \%)$ and the disease severity of pancreatitis was assessed by measuring standard laboratory and histological parameters.

Results. 24 h pretreatment of pancreatic ducts with $0.5 \mathrm{mM}$ UDCA significantly reduced the rate of ATP depletion, mitochondrial injury and cell death induced by $1 \mathrm{mM} \mathrm{CDCA}$ and completely prevented the inhibitory effect of CDCA on acid-base transporters. UDCA pretreatment had no effect on CDCA-induced $\mathrm{Ca}^{2+}$ signalling. Oral administration of UDCA (250 $\mathrm{mg} / \mathrm{kg}$ ) markedly reduced the severity of CDCA-induced AP.

Conclusion. Our results clearly demonstrate that UDCA (i) suppresses the CDCA-induced pancreatic ductal injury by reducing apoptosis and mitochondrial damage and (ii) reduces the severity of CDCA-induced AP. The protective effect of UDCA against hydrophobic bile acids may represent a novel therapeutical target in the treatment of biliary AP. 


\section{ACCEPTED MANUSCRIPT}

Keywords: acute pancreatitis, chenodeoxycholic acid, ursodeoxycholic acid, epithelial cells, mitochondria

\section{INTRODUCTION}

Acute pancreatitis (AP) is a sudden and severe disease in which no specific therapy or medication is being currently available. Obstruction of the common biliopancreatic duct by a gallstone is a frequent cause of AP, however, the exact mechanism is not completely known.(1, 34) A number of theories have been proposed to explain how'gallstones cause pancreatitis. One of the most accepted views is that bile reflux into the pancreatic ductal system leads to AP. This "bile reflux" theory is largely based on animal studies where retrograde infusion of bile acids into the pancreatic duct triggers pancreatitis.(33, 35, 64) Therefore the cytotoxic effects of bile acids have been widely investigated in the pancreas.(15, 23, 59, 61) Initial studies, in which the main pancreatic duct was perfused with various bile acids, demonstrated that in the $\mathrm{mM}$ range hydrophobic bile acids cause mucosal damage and increase the permeability of the pancreatic ducts to different ions. $(12,39)$

The cytotoxic effect of $\mathrm{CDCA}$ is basically attributed to its detergent characteristic, which is responsible for the disruption of the membrane integrity and consequently the release of intracellular constituents. However, increasing number of studies suggest that nondetergent effects of bile acids are also involved in the bile-induced cellular injury. The monohydroxy bile acid, taurolithocholic acid-3-sulphate (TLC-S) causes acinar injury through the induction of long-term elevation of intracellular calcium concentration $\left(\left[\mathrm{Ca}^{2+}\right]\right.$ i $)$, mitochondrial membrane depolarization and consequently intracellular ATP $\left(\operatorname{ATP}_{i}\right)$ depletion. $(15,61,63)$ 


\section{ACCEPTED MANUSCRIPT}

The specific effects of bile acids have been also demonstrated in the pancreatic ductal epithelial cells (PDECs). Recent studies from our lab showed that the dihydroxy bile acid, chenodeoxycholic acid (CDCA), dose-dependently decreased the intracellular $\mathrm{pH}\left(\mathrm{pH}_{\mathrm{i}}\right)$ and caused elevation of $\left[\mathrm{Ca}^{2+}\right]_{i}$ in guinea pig pancreatic ducts.(59) In addition, we showed that high concentration of this bile acid $(1 \mathrm{mM})$ strongly inhibited both oxidative and glycolytic metabolism of the ductal cells and caused an irreversible depletion of ATP..(29) Moreover, it has been recently demonstrated that CDCA induces ATP release from both ductal and acinar cells, which probably play a role in the CDCA-induced $\left[\mathrm{Ca}^{2+}\right]_{i}$ elevation by the activation of P2 receptors.(24) In the absence of $\mathrm{ATP}_{\mathrm{i}}$, the acid/base transporters fail to function properly, which finally causes decreased fluid and $\mathrm{HCO}_{3}{ }^{-}$secretion.(29) Impaired fluid secretion can lead to pancreatic injury and likely contributes to the development of pancreatitis. $(11,33,49)$ We speculate that restoration of pancreatic ductal fluid and $\mathrm{HCO}_{3}{ }^{-}$secretion could be beneficial in the early phase of biliary pancreatitis.

Ursodeoxycholic acid (UDCA) is a secondary, hydrophilic bile acid, which is currently used for gallstone dissolution and considered as first-choice therapy for various liver diseases, such as cholelithiasis, primary biliary cirrhosis or sclerosing cholangitis.(10, 14, 36, 47) The mechanism by which UDCA increases liver function is not completely understood. Basically, there are three concepts for the action of UDCA: (i) stimulation of hepatobiliary secretion (ii) displacement of the hydrophobic, toxic bile acids from the liver and (iii) direct cytoprotection against toxic bile acids. The cytoprotective effects of UDCA or its taurinconjugated form, tauroursodeoxycholic acid (TUDCA) have been widely investigated in the liver. Studies on hepatocytes have shown that UDCA pretreatment significantly reduces bile acid-induced opening of the mitochondrial permeability transition pore (mPTP) and consequently apoptosis, $(8,37,41-43,50)$ indicating that stabilization of the mitochondrial membrane, at least in part, plays an important role in the cytoprotective action of UDCA. 


\section{ACCEPTED MANUSCRIPT}

Since the CDCA-induced failure in pancreatic ductal function is also strongly associated with mitochondrial damage, we wondered if UDCA pre-treatment is able to prevent the CDCAinduced ductal injury. Therefore, we tested whether the toxic effect of CDCA on pancreatic ducts can be attenuated by the hydrophilic bile acid, UDCA.

Using in vitro and in vivo approaches, we demonstrated for the first time that UDCA (1) completely prevented the inhibitory effect of CDCA on ductal acid-base transporters, (2) decreased the rate of CDCA-induced mitochondrial injury (3) and cell death (4) and reduced the severity of experimental AP induced by CDCA. 


\section{ACCEPTED MANUSCRIPT}

\section{MATERIALS AND METHODS}

\section{Ethics}

All experiments were conducted in compliance with the Guide for the Care and Use of Laboratory Animals (National Academies Press, Eight Edition, 2011), with the 2010/63/EU guideline and the Hungarian 40/2013 (II.14.) government decree. The experiments were approved by Committees on investigations involving animals at the University of Szeged and also by independent committees assembled by local authorities (XII./3773/2012.).

\section{Solutions and chemicals}

The standard Na-Hepes solution contained (in $\mathrm{mM}$ ): $130 \mathrm{NaCl}, 5 \mathrm{KCl}, 1 \mathrm{CaCl}_{2}, 1$ $\mathrm{MgCl}_{2}, 10 \mathrm{D}$-glucose and $10 \mathrm{Na}$-HEPES. $\mathrm{NH}_{4} \mathrm{Cl}$-HEPES solution was supplemented with 20 $\mathrm{mM} \mathrm{NH} \mathrm{H}_{4} \mathrm{Cl}$ while $\mathrm{NaCl}$ concentration was lowered to $110 \mathrm{mM}$. HEPES-buffered solutions were gassed with $100 \% \mathrm{O}_{2}$ and their $\mathrm{pH}$ was set to 7.4 with $\mathrm{HCl}$. The standard $\mathrm{HCO}_{3}{ }^{\circ} / \mathrm{CO}_{2}$ buffered solution contained (in $\mathrm{mM}$ ): $115 \mathrm{NaCl}, 25 \mathrm{NaHCO}_{3}, 5 \mathrm{KCl}, 1 \mathrm{CaCl}_{2}, 1 \mathrm{MgCl}_{2}$ and 10 D-glucose. $\mathrm{NH}_{4} \mathrm{Cl}-\mathrm{HCO}_{3} / \mathrm{CO}_{2}$ solution was supplemented with $20 \mathrm{mM} \mathrm{NH}_{4} \mathrm{Cl}$ while $\mathrm{NaCl}$ concentration was lawered to $95 \mathrm{mM}$. $\mathrm{HCO}_{3}{ }^{\circ} / \mathrm{CO}_{2}$-buffered solutions were gassed with $95 \%$ $\mathrm{O}_{2} / 5 \% \mathrm{CO}_{2}$ and their $\mathrm{pH}$ was set to 7.4 with $\mathrm{NaOH}$.

Chromatographically pure collagenase was purchased from Worthington (Lakewood, New Jersey, USA). 2,7-Bis-(2-carboxyethyl)- 5-(and-6-)carboxyfluorescein, acetoxymethyl ester (BCECF-AM), 5-oxazolecarboxylic, 2-(6-(bis(carboxymethyl) amino)-5-(2-(2(bis(carboxymethyl)amino)-5-methylphenoxy)- ethoxy)-2-benzofuranyl)-5-oxazolecarboxylic acetoxymethyl ester (FURA 2-AM), calcein acetoxymethyl ester (calcein-AM), tetramethylrhodamine methyl ester (TMRM) and Magnesium Green acetoxymethyl ester (MgGreen-AM) were from Life Technologies (Grand Island, NY). Apoptotic cells were 


\section{ACCEPTED MANUSCRIPT}

quantified by using an In Situ Cell Death Detection Kit from Roche Diagnostics (Mannheim, Germany). Bile acids and all other chemicals were obtained from Sigma-Aldrich (Budapest, Hungary)

\section{Isolation and culture of the ducts}

Small intra-interlobular ducts were isolated from the pancreas of guinea pigs weighing $150-250 \mathrm{~g}$. The guinea pig was humanely killed by cervical dislocation, the pancreas was removed and intra-interlobular ducts were isolated as described previously.(3) The ducts were cultured overnight in a $37^{\circ} \mathrm{C}$ incubator gassed with $5 \% \mathrm{CO}_{2} / 95 \%$ air

\section{Bile acid treatments}

Isolated pancreatic ducts were treated with bile acids as follows: no treatment (control group), $5 \mathrm{~min}$ CDCA $(1 \mathrm{mM})$ treatment (CDCA group), $24 \mathrm{~h}$ UDCA $(0.5 \mathrm{mM})$ treatment (UDCA group) and $24 \mathrm{~h}$ pre-incubation with $0.5 \mathrm{mM}$ UDCA and then parallel incubation for further $5 \mathrm{~min}$ with $1 \mathrm{mM} \mathrm{CDCA}$ (UDCA+CDCA group).

\section{Measurement of intracellular $\mathrm{Ca}^{2+}$ concentration, $\mathrm{pH}$ and ATP level}

Intracellular $\mathrm{Ca}^{2+}$ concentration $\left(\left[\mathrm{Ca}^{2+}\right]_{\mathrm{i}}\right)$, intracellular $\mathrm{pH}\left(\mathrm{pH}_{\mathrm{i}}\right)$ and intracellular ATP level (ATP) were measured by loading the pancreatic ducts with the $\mathrm{Ca}^{2+}$-sensitive fluorescent dye, FURA 2-AM ( $5 \mu \mathrm{M}, 60 \mathrm{~min}$, in the presence of $0.05 \%$ pluronic $\mathrm{F}-127)$, the $\mathrm{pH}$-sensitive fluorescent dye, BCECF-AM $(2 \mu \mathrm{M}, 30 \mathrm{~min})$ and the $\mathrm{Mg}^{2+}$-sensitive fluorescent dye, MgGreen-AM ( $5 \mu \mathrm{M}, 60 \mathrm{~min}$, in the presence of $0.05 \%$ pluronic F-127), respectively. Ducts were attached to a poly-l-lysine-coated cover slip $(24 \mathrm{~mm})$ forming the base of a perfusion chamber and were mounted on the stage of an inverted fluorescence microscope linked to an Xcellence imaging system (Olympus, Budapest, Hungary). Ducts were then 


\section{ACCEPTED MANUSCRIPT}

bathed with different solutions at $37^{\circ} \mathrm{C}$ at the perfusion rate of $5-6 \mathrm{ml} / \mathrm{min}$. 6-7 region of interests (ROIs) were examined in each experiments and one measurement per second was obtained.

To determine the changes of $\left[\mathrm{Ca}^{2+}\right]_{i}$, cells were excited with 340 and $380 \mathrm{~nm}$ wavelength and the changes in $\left[\mathrm{Ca}^{2+}\right]_{i}$ were calculated from the $340 / 380$ fluorescence ratio measured at $510 \mathrm{~nm}$. In order to estimate $\mathrm{pH}_{\mathrm{i}}$, cells were excited with 490 and $440 \mathrm{~nm}$ wavelength, and the $490 / 440$ fluorescence emission ratio was measured at $535 \mathrm{~nm}$. The calibration of the fluorescent emission ratio to $\mathrm{pH}_{\mathrm{i}}$ was performed with the high- $\mathrm{K}^{2}$-nigericin technique, as previously described. $(19,56)$ Changes in $[\mathrm{ATP}]_{\mathrm{i}}$ was determined by exciting the cells at a wavelength of $490 \mathrm{~nm}$, with emitted light monitored at $535 \mathrm{~nm}$. Fluorescence signals were normalised to initial fluorescence intensity $\left(\mathrm{F} / \mathrm{F}_{0}\right)$ and expressed as relative fluorescence.

\section{Measurement of acid/base transporter activity}

In order to estimate the activity of $\mathrm{Na}^{+} / \mathrm{H}^{+}$exchanger (NHE), the $\mathrm{Na}^{+} / \mathrm{HCO}_{3}$ cotransporter $(\mathrm{NBC})$ and $\mathrm{Cl}^{-} / \mathrm{HCO}_{3}$ exchanger $(\mathrm{CBE})$ the $\mathrm{NH}_{4} \mathrm{Cl}$ prepulse technique was used. Briefly, exposure of pancreatie ducts to $20 \mathrm{mM} \mathrm{NH}_{4} \mathrm{Cl}$ for 3 min induced an immediate rise in $\mathrm{pH}_{\mathrm{i}}$ due to the rapid entry of lipophilic, basic $\mathrm{NH}_{3}$ into the cells. After the removal of $\mathrm{NH}_{4} \mathrm{Cl}, \mathrm{pH}_{\mathrm{i}}$ rapidly decreased. This acidification is caused by the dissociation of intracellular $\mathrm{NH}_{4}{ }^{+}$to $\mathrm{H}^{+}$and $\mathrm{NH}_{3}$, followed by the diffusion of $\mathrm{NH}_{3}$ out of the cell. In standard Hepesbuffered solution, the initial rate of $\mathrm{pH}_{\mathrm{i}}(\Delta \mathrm{pH} / \Delta \mathrm{t})$ recovery from the acid load (over the first $60 \mathrm{sec}$ ) reflects the activities of NHEs, whereas in $\mathrm{HCO}_{3} / \mathrm{CO}_{2}$-buffered solutions represents the activities of both NHEs and NBC.(18,20) In order to estimate CBE activity the initial rate of $\mathrm{pH}_{\mathrm{i}}$ recovery from alkalosis in $\mathrm{HCO}_{3}{ }^{-} / \mathrm{CO}_{2}$-buffered solutions was analyzed. Previous data have indicated that under these conditions the recovery over the first $30 \mathrm{sec}$ reflects the activity of CBE.(18, 20) 


\section{ACCEPTED MANUSCRIPT}

In order to evaluate transmembrane base flux $\left(J\left(\mathrm{~B}^{-}\right)\right)$the following equation was used: $J\left(\mathrm{~B}^{-}\right)=\Delta \mathrm{pH} / \Delta \mathrm{t} X \beta_{\text {total, }}$, where $\Delta \mathrm{pH} / \Delta \mathrm{t}$ was calculated by linear regression analysis, whereas the total buffering capacity $\left(\beta_{\text {total }}\right)$ was estimated by the Henderson-Hasselbach equation using the following formula: $\beta_{\text {total }}=\beta_{\mathrm{i}}+\beta_{\mathrm{HCO}_{-}-}=\beta_{\mathrm{i}}+2.3 \times\left[\mathrm{HCO}_{3}{ }^{-}\right]_{\mathrm{i}}$. We denote base influx as $J(\mathrm{~B})$ and base efflux (secretion) as $-J\left(\mathrm{~B}^{-}\right)$.

\section{Measurement of mitochondrial membrane potential}

Mitochondrial membrane potential $\left(\Delta \Psi_{\mathrm{m}}\right)$ was measured using the lipophilic, mitochondria-selective fluorescence dye, TMRM. Accumulation of TMRM in the mitochondria depends on the $\Delta \Psi_{\mathrm{m}}$. Pancreatic ducts were pre-jincubated with TMRM $(1 \mu \mathrm{M})$ for $30 \mathrm{~min}$ at $37^{\circ} \mathrm{C}$ and transferred to a poly-1-lysine-coated cover slip (24 mm) forming the base of a perfusion chamber. Ducts were then perfused continuously with solutions at $37^{\circ} \mathrm{C}$ at a rate of $2-2.5 \mathrm{ml} / \mathrm{min}$. The perfusion solutions were complemented with $100 \mathrm{nM}$ TMRM to avoid dye leakage. Changes in $\Delta \Psi_{\mathrm{m}}$ were monitored using a Fluoview 10i-W confocal microscope (Olympus, Budapest, Hungary). 5-10 ROIs (mitochondria) of 5-10 cells were excited with light at $543 \mathrm{~nm}$ and the emitted light was captured between $560-650 \mathrm{~nm}$. We have employed the dequench method for the estimation of $\Delta \Psi_{\mathrm{m}}$. At the applied concentration of TMRM, depolarisation of the mitochondria causes release of the dye and its dequenching in the cytosol. Thus increase in fluorescence intensity reflects a decrease in $\Delta \Psi_{\mathrm{m}}$ Fluorescence signals were normalised to initial fluorescence intensity $\left(\mathrm{F} / \mathrm{F}_{0}\right)$ and expressed as relative fluorescence.

\section{Measurement of mitochondrial permeability transition pore opening}

To measure mitochondrial inner membrane permeabilization and/or the opening of the mitochondrial permeability transition pore (mPTP), we used the calcein-cobalt dequenching 


\section{ACCEPTED MANUSCRIPT}

technique. Calcein-AM is a lipid-soluble fluorescent dye which diffuses into all subcellular components including mitochondria. $\mathrm{Co}^{2+}$ is a quencher of calcein which can enter to the cytoplasm but cannot pass through the mitochondrial membrane. Upon transient opening of $\mathrm{mPTP}, \mathrm{Co}^{2+}$ diffuses into the mitochondria and quenches the mitochondrial calcein fluorescence which results in a decrease of fluorescence intensity. Pancreatic ducts were loaded with calcein- $\mathrm{AM}(1 \mu \mathrm{M})$ for $30 \mathrm{~min}$ then with $\mathrm{CoCl}_{2}(1 \mathrm{mM})$ for further $10 \mathrm{mim}$. Ducts were then washed at $37^{\circ} \mathrm{C}$ at the perfusion rate of $5-6 \mathrm{ml} / \mathrm{min}$ and imaged using an Olympus IX71 fluorescence microscope (Olympus, Budapest, Hungary). 5-6 ROIs were excited with light at $495 \mathrm{~nm}$ and the emitted light was captured at $515 \mathrm{~nm}$. Fluorescence signals were normalised to initial fluorescence intensity $\left(\mathrm{F} / \mathrm{F}_{0}\right)$ and expressed as relative fluorescence.

\section{TUNEL cell death assay}

For detection of cell death we used the terminal deoxyribonucleotidyl transferase (TDT)-mediated dUTP-digoxigenin nick end labelling (TUNEL) assay (Roche Diagnostics, Mannheim, Germany). Intra-interlobular pancreatic ducts were treated with bile acids as previously described. Contrô and bile acid-treated isolated duct segments were fixed with $4 \%$ paraformaldehyde oyernight and then cryosectioning and staining of the samples were performed according to the manufacturer's protocol. The CDCA-treated groups were incubated for $3 \mathrm{~h}$ in culture media before fixation. Pictures were taken with the use of a Zeiss AxioImager fluorescent light microscope (Carl Zeiss MicroImaging, Thornwood, NY, USA) fitted with a PixeLINK CCD camera (PixeLINK, Ottawa, ON, Canada)

\section{Transmission electron microscopy}

For electron microscopic studies, ducts were fixed in $2.5 \%$ glutaraldehyde immediately after isolation. Samples were then postfixed in $1 \%$ osmium tetroxide, dehydrated 


\section{ACCEPTED MANUSCRIPT}

in a series of graded ethanols, and subsequently embedded in epoxy resin. Ultrathin sections were contrasted with uranyl acetate and lead citrate. Tissue sections were analyzed under a transmission electron microscope (CM10; Philips, Eindhoven, The Netherlands).

\section{Induction of acute pancreatitis}

Male Sprague Dawley (SPRD) rats weighing 200-250 g were used for all experiments. Rats were kept at constant room temperature of $24^{\circ} \mathrm{C}$ with a $12 \mathrm{~h}$ light and dark cycle and were allowed free access to tap water and standard laboratory chow (Biofarm, Zagyvaszaántó, Hungary). Animal were fasted $12 \mathrm{~h}$ before the surgical procedure, All experiments were approved by the Institutional Animal Care and Use Committee of the University of Szeged (I74-3/2012 MÁB) and also by an independent committee assembled by national authorities (XII./3773/2012.). Rats were randomly allocated into four groups $(n=6)$ as follows: (1) control (intraductal administration of physiological saline), (2) UDCA (rats were treated with oral UDCA without induction of pancreatitis), (3) CDCA (pancreatitis was induced by intraductal administration of CDCA) and (4) $\mathrm{EDCA}+\mathrm{CDCA}$ (rats were treated with oral UDCA and pancreatitis was induced with intraductal administration of CDCA). Ursodeoxycholic acid (Ursofalk) was purchased from Dr Falk Pharma Ltd. UDCA was dissolved in $2 \mathrm{~mL}$ of tap water and $250 \mathrm{mg} / \mathrm{kg}$ of body weight was administered orally (gavage) daily, for two weeks. The pretreatment period was chosen on the basis of studies investigating cholestatic diseases. $(26,57)$ Control animals were only treated with the same amount of tap water. The last UDCA treatment was performed one day before the AP induction.

Rats were anesthetized with intraperitoneal injection of a cocktail containing of 50 $\mathrm{mg} / \mathrm{kg}$ Ketamine and $10 \mathrm{mg} / \mathrm{kg}$ Xylazine. After the anesthesia, rats were shaved and the abdominal cavity was opened with median laparotomy. The common bile duct was temporary occluded with a vessel clip. The duodenum was punctured with a $0.4 \mathrm{~mm}$ diameter needle connected to polyethylene tubing, then it was placed into the pancreatic duct and $1 \mathrm{ml} / \mathrm{kg} 1 \%$ 


\section{ACCEPTED MANUSCRIPT}

sodium-CDCA (dissolved in physiologic saline) was administered via retrograde ductal infusion with $1 \mathrm{ml} / \mathrm{min}$ speed with an infusion pump (TSE System GmbH, Bad Homburg, Germany). Control animals received intraductal physiological saline instead of bile acid. After bile acid or physiological saline infusion, the vessel clip and the polyethylene tube were removed and the abdominal wall and skin were closed. Rats were sacrificed $24 \mathrm{~h}$ after the surgical procedure.

\section{Histologic examination and laboratory parameter measurements}

Terminal anesthesia was performed with $50 \mathrm{mg} / \mathrm{kg}$ sodium pentobarbital. The abdominal and thoracic cavities were opened with a median laparotomy and thoracotomy and blood was collected with cardiac puncture. The pancreas was removed immediately after the blood collection and it was trimmed from fat and lymphatic tissues on ice. Pancreata were dissected and only parts of the head and body were used for histological analysis and for laboratorial measurements. Sections from the pancreatic tail didn't show any signs of necrosis or inflammation, therefore it was not used later. The pancreatic head and body were longitudinally dissected and one part of pancreas was put into $6 \%$ neutral formaldehyde solution, however other part was immediately frozen in liquid nitrogen. These parts of pancreata were stored at $-80^{\circ} \mathrm{C}$ until further use. The collected blood was centrifuged at $4{ }^{\circ} \mathrm{C}$ with $2500 \mathrm{RCF}$ for $15 \mathrm{~min}$. Sera were eventually stored at $-20^{\circ} \mathrm{C}$ until use.

Serum amylase activity was measured with a commercial colorimetric kit (Diagnostikum, Budapest, Hungary) with a FLUOstar OPTIMA (BMG Labtech, IronMaas Consulting Kft., Budapest Hungary) microplate reader at $405 \mathrm{~nm}$. Wet pancreatic tissues were measured and they were dried for $24 \mathrm{~h}$ at $100{ }^{\circ} \mathrm{C}$. The dry weight-wet weight ratio was calculated. Pancreatic samples were prepared for hematoxylin and eosin staining. Pancreatic histological samples were scanned. Necrotic areas were detected and analyzed with Image $\mathbf{J}$ 


\section{ACCEPTED MANUSCRIPT}

(National Institutes of Health, Bethesda, MD, USA) software. Necrotic areas were compared to the total analyzed pancreatic area.

\section{Statistical Analysis}

Data are expressed as means \pm SEM. Significant difference between groups was determined by analysis of variance (ANOVA). Statistical analysis of the immunohistochemical data was performed using the Mann-Whitney U test. Probability values of $\mathrm{p}<0.05$ were accepted as being significant.

In vivo experiments were evaluated by using ANOVA followed by Bonferroni or Dunnett's multiple comparison post hoc test. 


\section{ACCEPTED MANUSCRIPT}

\section{RESULTS}

\section{Effect of UDCA and CDCA on intracellular $\mathrm{pH}\left(\mathrm{pH}_{\mathrm{i}}\right)$}

Previous studies have shown that bile acids induce intracellular acidification in several cell types. $(2,16,32,59)$ Therefore, first we have investigated the effect of CDCA and UDCA on basal $\mathrm{pH}_{\mathrm{i}}$ of pancreatic ducts. Administration of $\mathrm{CDCA}$ induced a dose-dependent intracellular acidification in Hepes-buffered solution (Fig. 1A). The effect of CDCA on $\mathrm{pH}_{\mathrm{i}}$ was reversible, following the removal of bile acid from the externa solution, the $\mathrm{pH}$ completely returned to the basal level. UDCA also induced a dose-dependent decrease in $\mathrm{pH}_{\mathrm{i}}$, however the effect of UDCA was much smaller compared to CDCA(Fig. 1B). We repeated these experiments in $\mathrm{HCO}_{3}{ }^{-} / \mathrm{CO}_{2}$-buffered solution, where the two bile acids induced similar degrees of $\mathrm{pH}_{\mathrm{i}}$ decrease (Fig. $1 \mathrm{C}$ and D). Summary of the changes of $\mathrm{pH}_{\mathrm{i}}$ is shown in Fig. 1E and $\mathrm{F}$.

\section{UDCA pre-treatment prevents the inhibitory effect of CDCA on acid-base transporters}

To investigate the acid-base transporters of pancreatic ducts, we used the ammonium pre-pulse technique. In the absence of $\mathrm{HCO}_{3}{ }^{-}$the initial recovery from the acid phase is due to the activity of the $\mathrm{Na}^{+} / \mathrm{H}^{+}$exchanger (NHE) (Fig. 2A). In the presence of $\mathrm{HCO}_{3}{ }^{-}$the recovery from alkalosis reflects the activity of the $\mathrm{Cl}^{2} / \mathrm{HCO}_{3}{ }^{\circ}$ exchanger (CBE), whereas the recovery from acidosis results from the activity of both $\mathrm{NHE}$ and $\mathrm{Na}^{+} / \mathrm{HCO}_{3}{ }^{-}$cotransporter (NBC) (Fig. $2 \mathrm{~B}$ ). Two $\mathrm{NH}_{4} \mathrm{Cl}$ pulses were applied, the first was the control and the second was the test. To estimate the effect of bile acids on the activity of acid-base transporters CDCA (1 $\mathrm{mM})$ and UDCA $(0.1,0.25,0.5$ and $1 \mathrm{mM})$ were administered 3 minutes before the pulse, during the pulse and 5 minutes after the pulse. Acute administration of UDCA did not affect the rate of recovery from the acid or alkali load neither in Hepes-buffered nor in $\mathrm{HCO}_{3}{ }^{-} / \mathrm{CO}_{2}$ - 


\section{ACCEPTED MANUSCRIPT}

buffered solutions (data not shown). In contrast, $1 \mathrm{mM} \mathrm{CDCA}$ strongly inhibited the activity of the acid/base transporters. (Fig. 2A and B) Next we tested whether UDCA administration can influence the inhibitory effect of CDCA. When UDCA and CDCA were added simultaneously, UDCA was unable to prevent the inhibitory effect of CDCA on the ion transporters in all of the investigated concentration. (data not shown) Several studies have shown that prolonged pre-incubation of the cells with UDCA is needed to exert its protective effect.(21, 22, 48, 50) Therefore, in the next step, we pretreated the ducts with UDCA for various time periods ( $5 \mathrm{~h}$ and $24 \mathrm{~h}$ ) and the effect of CDCA on the ion transporters was examined. A $5 \mathrm{~h}$ pre-incubation of the ducts with UDCA $(0.1,0.25,0.5$ and $1 \mathrm{mM}) \mathrm{did}$ not affect the response to CDCA. However, $24 \mathrm{~h}$ pre-treatment-with UDCA significantly decreased the toxic effect of CDCA both in Hepes (Fig. 2A) and in $\mathrm{HCO}_{3}{ }^{\circ} / \mathrm{CO}_{2}$-buffered (Fig. 2B) solutions. The lowest concentration of UDCA which had a protective effect was $0.5 \mathrm{mM}$ (Fig. $2 \mathrm{~A}$ and $\mathrm{B}$ ), whereas at higher concentrations $(1 \mathrm{mM})$ the protective effect of UDCA was significantly decreased. Therefore, we decided to use $0.5 \mathrm{mM}$ UDCA in the subsequent experiments. Summary data of the base fluxes $\left( \pm J\left(\mathrm{~B}^{-} / \mathrm{min}\right)\right)$ are shown on Fig. $2 \mathrm{C}-\mathrm{E}$. As shown, pre-treatment of the ducts with $0.5 \mathrm{mM}$ UDCA prevented the inhibitory effect of CDCA on NHE (Fig. 2C), CBE (Fig. 2D) and NBC (Fig. 2E).

\section{UDCA pre-treatment had no effect on the CDCA-induced calcium signalling}

Several studies have indicated that bile-induced toxic calcium signalling is an initial step in the development of AP. $(25,31,38,58)$ We have previously shown that high concentration of CDCA induces $\left(\mathrm{Ca}^{2+}\right)$ elevation in ductal cells.(59) So in the next step we have examined whether UDCA pre-treatment has any effect on the CDCA-induced $\mathrm{Ca}^{2+}$ signalling. Administration of $0.5 \mathrm{mM}$ UDCA alone had no significant effect on $\left[\mathrm{Ca}^{2+}\right]_{\mathrm{i}}$ (data not shown). In contrast, $1 \mathrm{mM} \mathrm{CDCA}$ induced high and partially reversible $\mathrm{Ca}^{2+}$ signalling in 


\section{ACCEPTED MANUSCRIPT}

pancreatic ducts. (Fig. 3A) Pre-incubation of the ducts with $0.5 \mathrm{mM}$ UDCA for $24 \mathrm{~h}$ did not affect the CDCA-induced increase in $\left[\mathrm{Ca}^{2+}\right]$, (Fig. $3 \mathrm{~A}$ and $\mathrm{B}$ ) indicating that the protective effect of UDCA is unlikely to be caused be the prevention of the elevated $\left[\mathrm{Ca}^{2+}\right]$.

\section{UDCA pretreatment decreased the rate of CDCA-induced mitochondrial injury}

Increasing number of studies indicate the importance of mitochondrial injury in cell death. $(27,28)$ We have previously shown that beside the elevated $\mathrm{Ca}^{2+}$ signalling, CDCA strongly damages mitochondria and causes $\mathrm{ATP}_{\mathrm{i}}$ depletion in pancreatic ducts which may contribute to the inhibitory effect of CDCA on ion transporters due to bioenergetic failure.(29) Therefore, in the next series of experiments we performed both functional and morphological studies to characterize the effect of UDCA pretreament on CDCA-induced mitochondrial injury.

The level of $\mathrm{ATP}_{\mathrm{i}}$ is a good indicator of mitochondrial function; therefore in the first step we measured changes in $\mathrm{ATP}_{\mathrm{i}}$ in cells exposed to CDCA with or without UDCA pretreatment. As shown on Fig. $3 \mathrm{C}$, administration of $1 \mathrm{mM}$ CDCA caused a huge and irreversible ATP loss in PDECs. (Fig. 3C) In contrast, $24 \mathrm{~h}$ preincubation of the cells with 0.5 mM UDCA reduced the rate of CDCA-induced $\mathrm{ATP}_{\mathrm{i}}$ decrease by $57.6 \pm 3.6 \%$ (Fig. $3 \mathrm{C}$ and D). UDCA administration alone did not effect ATP $_{\mathrm{i}}$.

To further analyse the protective effect of UDCA on ductal mitochondria, we also investigated $\Delta \Psi_{\mathrm{m}}$ and $\mathrm{mPTP}$ upon administration of bile acids. Ducts were incubated with 1 M PMRM in order to investigate the changes in $\Delta \Psi_{\mathrm{m}}$ (see Material and Methods section). After the stabilisation of the mitochondrial fluorescence, $1 \mathrm{mM}$ CDCA was applied and the fluorescence signal was monitored. As shown in Fig. 3E, the administration of CDCA resulted in a huge increase in TMRM fluorescence intensity, indicating that this bile acid 


\section{ACCEPTED MANUSCRIPT}

induced marked mitochondrial depolarization. Preincubation of the ducts with $0.5 \mathrm{mM}$ UDCA reduced the CDCA-induced depolarization by $69.4 \pm 4.6 \%$ (Fig. 3E and F).

Since ATP depletion and mitochondrial depolarization are caused by mPTP induction, next we investigated the effect of CDCA on the opening of mPTP using the calcein-cobalt technique. Treatment of the calcein-loaded pancreatic ducts with $1 \mathrm{mM} \mathrm{CDCA}$ decreased the fluorescence excitation of calcein, approximately $1 \mathrm{~min}$ after the addition of the bile acid. (Fig. 3G) Similarly to the $\Delta \Psi_{\mathrm{m}}$ experiments, $24 \mathrm{~h}$ pretreatment of the ducts with $0.5 \mathrm{mM}$ UDCA had a preventive role on mitochondria and decreased the CDCA-induced $\mathrm{mPTP}$ opening by $72.1 \pm 4 \%$. (Fig. $3 \mathrm{G}$ and $\mathrm{H}$ ) Administration of UDCA alone did not affect mPTP.

We also examined the morphology of the ductal mitochondria using electron microscopy (Fig. 4A-D). The mean number of mitochondria in the section of the control, the CDCA, the UDCA and the CDCA+UDCA groups was nearly the same. No morphological alterations were observed in the control and UDCA-treated groups. (Fig. 4A and B) In contrast, incubation of the ducts with $1 \mathrm{mM}$ CDCA for 5 min resulted in mitochondrial swelling and the loss of the mitochondrial inner membrane (Fig. 4C). This swelling could be prevented by UDCA pre-treatment. Moreover, the integrity of the mitochondria was also maintained in the CDCA+UDCA-treated ducts compared to the ducts only treated with CDCA (Fig. 4D)

\section{UDCA pre-treatment prevented the CDCA-induced cell death}

In the next step, we tested whether the toxic effect of CDCA on the mitochondria is associated with cell death. Ducts were treated with $1 \mathrm{mM} \mathrm{CDCA}$ for $5 \mathrm{~min}$, then were incubated in culture media for further $3 \mathrm{~h}$ in order to leave time for development of cell death. Cell death was assessed by TUNEL staining (Fig. 5A and B). This method is based on the labelling of the 3'-OH ends of the fragmented DNA which are generated during cell death. 


\section{ACCEPTED MANUSCRIPT}

Incubation of the pancreatic ducts with CDCA resulted in a significant increase in cell death compared to control, non-treated ducts. (Fig. 5A and B) Although, both apoptosis and necrosis can be characterised by DNA fragmentation,(17) the presence of intact cell organelles, cellular shrinkage and the lack of cellular content release indicate that CDCA rather induces apoptotic cell death than necrosis. $24 \mathrm{~h}$ preincubation with UDCA $(0.5 \mathrm{mM})$ alone caused only a small degree of DNA fragmentation in the ductal cells, but significantly reduced the CDCA-induced apoptotic cell death by $63.3 \pm 5.7 \%$. (Fig. $5 \mathrm{~A}$ and B)

\section{Oral administration of UDCA attenuates CDCA-induced pancreatitis in vivo}

In order to investigate the protective effect of UDCA under in vivo conditions, we utilized a CDCA-induced pancreatitis model. $(53,54)$ We used rats as the model animals because we were unable to administer CDCA intraductally in guinea pigs due to the anatomical topography of the main duct.

Serum amylase activities were significantly elevated after retrograde infusion of CDCA (CDCA group, $983 \pm 100, \mathrm{U} / \mathrm{l})$ compared to intraductally administered physiological saline (control group, $396 \pm 50$ UD). Pretreatment of UDCA for two weeks did not influence the serum amylase activities (UDCA group, $424.7 \pm 20$ ) in control animals; however, it was significantly decreased $(582 \pm 50 \mathrm{U} / \mathrm{l})$ in the UDCA+CDCA group versus the CDCA group. (Fig. 6A)

Pancreatic water content was significantly elevated after retrograde infusion of CDCA $(80 \pm 1 \%)$ compared to intraductally administered physiological saline $(60 \pm 1 \%)$. A two-week pretreatment with UDCA showed no influence on the pancreatic water content $(61 \pm 2 \%)$ in the UDCA group. However in the UDCA+CDCA group, it was significantly decreased $(65 \pm 2 \%)$ versus to the CDCA group. (Fig. 6B) 


\section{ACCEPTED MANUSCRIPT}

Pancreatic damage was characterized by determining the extent of tissue necrosis (Fig. 6C-D). Intraductal infusion of physiological saline with or without UDCA pretreatment didn't cause any acinar cell necrosis. However, retrograde infusion of CDCA caused markedly elevated $(14 \pm 2 \%)$ acinar cell damage, which was significantly ameliorated $(6 \pm 2 \%)$ in the UDCA+CDCA group. (Fig. 6C)

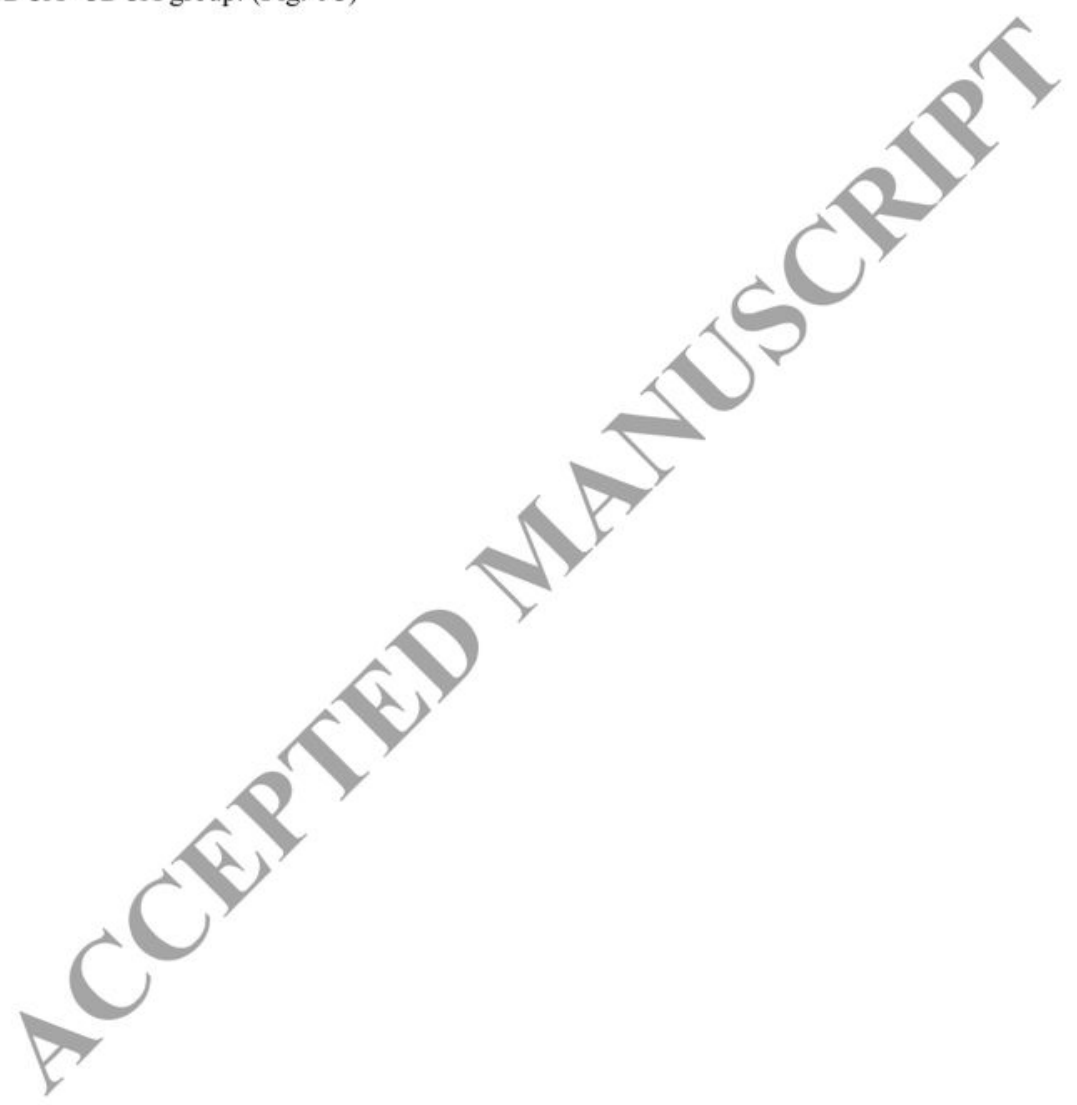




\section{ACCEPTED MANUSCRIPT}

\section{DISCUSSION}

Bile reflux into the pancreas may lead to pancreatic injury and as a result can induce AP.(34) Therefore, a better understanding of the mechanisms underlying bile-induced pancreatic injury and its prevention may provide novel therapeutic tools for the treatment of AP. In the present study, we have shown for the first time that the hydrophilic bile acid, UDCA is able to attenuate the toxic effect of CDCA on pancreatic ducts by preventing CDCA-induced mitochondrial injury.

We used isolated intra-interlobular pancreatic ducts, which is a relable in vitro model for investigating pancreatic ductal damage. The CDCA concentration used in this study was previously shown to induce intracellular $\mathrm{Ca}^{2+}$ signalling, mitøchondrjal injury and inhibition of the acid-base transporters, $(29,59)$ whereas the concentrations of UDCA were chosen on the basis of the literature data. $(42,43)$ Examinations were performed using $0.5 \mathrm{mM}$ UDCA since the protective effect of UDCA was not increased by using higher concentrations (1 $\mathrm{mM})$, whereas lower concentrations of this bile acid $(0.1$ and $0.25 \mathrm{mM})$ had no detectable protective effect. This concentration of UDCA is one magnitude higher than the physiological concentration of bile acid in the blood (9) and several orders of magnitude lower than the concentration of bile acids in the gall bladder or duodenum (10-100 mM). The optimal preincubation time of pancreatic ducts with UDCA was found to be $24 \mathrm{~h}$, indicating that the development of protective action is a complex mechanism which probably include changes at transcriptional level that modulate various signalling and apoptotic pathways.(42, 43, 51, 52)

In the present study, we demonstrated that $24 \mathrm{~h}$ pre-treatment of pancreatic ducts with $0.5 \mathrm{mM}$ UDCA significantly reduced the inhibitory effect of CDCA on the acid/base transporters. Studies on pancreatic acinar cells have indicated that the toxic effect of hydrophobic bile acids is mediated by a sustained $\mathrm{Ca}^{2+}$ signalling. $(15,61)$ We have previously shown that high concentration of CDCA induces a huge and long-lasting elevation of $\left[\mathrm{Ca}^{2+}\right]_{i}$ 


\section{ACCEPTED MANUSCRIPT}

in pancreatic ducts.(59) Therefore, we tested whether the protective effect of UDCA on the acid/base transporters is due to the prevention of CDCA-induced calcium signalling. When pancreatic ducts were exposed to UDCA for $24 \mathrm{~h}$ and CDCA was then added, the extent of calcium elevation did not change, indicating that the protective effect of UDCA is unlikely to be caused by the reduction of $\mathrm{Ca}^{2+}$ signalling. This finding is in accordance with our previous observation on pancreatic ducts, where pre-incubation of the cells with a specific-calcium chelator, BAPTA-AM was unable to prevent the inhibitory effect of CDCA on acid-base transporters.(59)

An increasing number of studies support the concept that mitochondrial damage plays a central role in the bile-induced cellular injury and that UDCA pretreatment is able to attenuate the toxic effect of hydrophobic bile acids on mitochondria. $(8,41-43)$ Therefore, in the next step we investigated the protective effect of UDCA on the function and morphology of pancreatic ductal mitochondria. Administration of CDCA alone induced mPTP opening in the ductal cells. This is an early event in cell death which leads to mitochondrial swelling due to an increase in the mitochondrial inner membrane permeability. MPTP is also characterized by the loss of membrane potential which leads to mitochondrial dysfunction and consequently inhibition of ATP synthesis. We did not investigate the exact mechanism by which CDCA induces mPTP opening. Studies on rat hepatocytes demonstrated that in the presence of the specific MPTP inhibitor, cyclosporine $\mathrm{A}$, the effect of CDCA was completely ameliorated indicating that CDCA selectively acts on mPTP.(45) It has been also demonstrated that CDCA induces $\mathrm{mPTP}$ due to increased membrane fluidity and cytochrome c release in calcium-loaded hepatic mitochondria.(44) In contrast to the effects of CDCA, UDCA alone caused no significant changes in mitochondrial function. However, in combination with CDCA, UDCA was able to prevent the CDCA-induced $\mathrm{mPTP}$, mitochondrial membrane perturbation and the consequently formed decrease in membrane potential. Moreover, UDCA 


\section{ACCEPTED MANUSCRIPT}

prevented the CDCA-induced $\mathrm{ATP}_{\mathrm{i}}$ loss, which provides further evidence that UDCA pretreatment is beneficial to avoid mitochondrial injury. This conclusion was confirmed by electron microscopic studies which showed normal appearance of mitochondria in the UDCA+CDCA group compared to the CDCA group, where mitochondrial swelling and disruption of the inner mitochondrial membrane were observed. The mechanism underlying the mitochondrial protective effect of UDCA is not clear. One of the main inducers of $\mathrm{mPTP}$ is $\mathrm{Ca}^{2+}$ overload and oxidative stress. Although, we have shown that UDCA pre-treatment had no effect on the extent of CDCA-induced $\mathrm{Ca}^{2+}$ elevation, we did not investigate the effect of UDCA on the total $\mathrm{Ca}^{2+}$ load. It is possible that the protective effect of UDCA is due to the reduction of $\mathrm{Ca}^{2+}$ overload or by the inhibition of reactive oxygen species (ROS) production, however further studies are needed to confirm these hypothese

Mitochondrial dysfunction is often associated with cell death either by the reduction of $\mathrm{ATP}_{\mathrm{i}}$ levels or by irreversible alterations in the mitochondrial membrane permeability which induces the release of apoptotic signalling molecules from the mitochondria. Since mitochondria play a central role in cell survival, we wanted to determine if the CDCAinduced mitochondrial injury would result in cell death and to examine the possible protective role of UDCA in this process. Administration of CDCA induced marked DNA fragmentation in intact pancreatic ducts. We speculate that impairment of mitochondrial function plays a central role in this mechanism, but other signalling pathways may be involved. The apoptotic effect of $\mathrm{CDCA}$ and other hydrophobic bile acids have been examined in more detail in hepatocytes. ROS generation, mPTP induction, cytochrom c release and activation of downstream caspases have been shown to be associated with apoptosis. $(65,66)$ It has been also demonstrated that the glycin-conjugated form of CDCA, directly stimulate Fas-dependent cell death due to the activation of the Fas receptor which is independent from the mitochondrial pathway.(13) $24 \mathrm{~h}$ pre-treatment with UDCA effectively reduced the CDCA- 


\section{ACCEPTED MANUSCRIPT}

induced apoptosis as indicated by significantly decreased DNA fragmentation which further confirms the cytoprotective effect of UDCA. The exact mechanism by which UDCA exerts its protective effect was not investigated by our group; however, our results and previous studies on hepatocytes strongly indicate that $\mathrm{mPTP}$ inhibition by UDCA is one of the key mechanisms in the reduction of CDCA-induced cell death in PDECs.

In order to extend our study, we also tested the protective effect of UDCA in vivo. There is no accepted pancreatitis model in guinea pigs; therefore we induced AP in rats by intraductal injection of low concentration of CDCA. $(53,54)$ Under these experimental conditions, CDCA induced acinar cell damage and also increased serum amylase activity. Previous studies on isolated rat and mouse acini demonstrated that the hydrophobic bile acid, TLC-S induces mitochondrial injury, pathological $\mathrm{Ca}^{2+}$ signalling and the generation of ROS. $(7,61-63)$ We speculate that similar intracellular mechanisms may also have arisen in response to CDCA. The CDCA-induced acinar cell injury, hyperamylasemia and pancreatic edema were markedly reduced in the UDCA-treated group. The protective effect of UDCA can be attributed to its ability to reduce mitochondrial injury both in acinar and ductal cells. Several attempts have been made in order to investigate the effect of UDCA on isolated pancreatic acinar cells. Using rat and mouse acinar cells, we found that isolated acinar cells are more sensitive to long term bile acid treatment than ductal cells which made the investigation of the protective effect of UDCA very difficult. Cell viability experiments showed that even low concentrations of bile acids could decrease the viability of isolated rent thats

acinar cells and in contrast to ductal cells, UDCA pre-treatment had no protective effect on acinar cells under our experimental conditions.

Lastly, our results may have important clinical implication in patients with gallstone obstruction, where oral administration of UDCA or its metabolically stable form may reduce the risk of pancreatitis development. The beneficial effect of UDCA treatment has been 


\section{ACCEPTED MANUSCRIPT}

demonstrated in idiopathic recurrent pancreatitis where long-term UDCA treatment reduced the rate of recurrence by prevention of the formation of gallstones.(46, 55, 60) The effect of orally administered UDCA is highly dependent on its metabolism. In rats, most of the UDCA is metabolized to TUDCA (40) which also has cytoprotective effect as demonstrated in the liver. $(4,5,37,50)$ In humans, one of the major metabolites of UDCA is isoursodeoxycholic

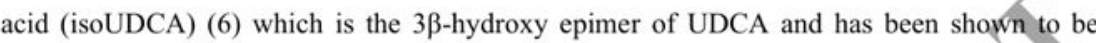
more effective than UDCA.(30) In the current study, we have not investigated the serum concentration of UDCA after oral administration. Notably, since UDCA was administered in an excess dose, we believe that sufficiently high concentration of UDCA (or TUDCA) was present in the serum to exert its protective effect.

Understanding the early injury mechanisms induced by hydrophobic bile acids is extremely important to find a therapeutic target to reduce pancreatic injury. In this study, we confirm and extend our previous observations that mitochondria is a key target in the CDCAinduced cellular injury in PDECs. The hydrophilic bile acid, UDCA inhibits CDCA-induced apoptosis probably by the stabilization of mitochondrial membrane via the block of membrane depolarization and $\mathrm{mPTP}$ and also by prevention of mitochondrial swelling (Fig. 7). Several studies have focused on the inhibition of cellular injury during AP in order to stop or delay the progression of the disease. UDCA may represent a novel option against the bileinduced ductal injurry, however issues for the therapeutic application of this bile acid in AP need further investigation.

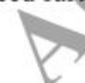

\section{GRANTS}

This study was supported by the Hungarian National Development Agency (TÁMOP-

4.2.2.A-11/1/KONV-2012-0035, TÁMOP-4.2.2-A-11/1/KONV-2012-0052 TÁMOP-4.2.2.A-

11/1/KONV-2012-0073, TÁMOP-4.2.2./B-10/1-2010-0012, and TÁMOP 4.2.4.A/2-11-1- 


\section{ACCEPTED MANUSCRIPT}

2012-0001 'National Excellence Program), the Hungarian Scientific Research Fund (K109756 to V. Venglovecz) and the MTA-SZTE Momentum Grant (LP2014-10/2014).

\section{DISCLOSURES}

The authors hereby declare that there are no conflict of interests to disclose.

\section{REFERENCES}

1. Acosta JM, and Ledesma CL. Gallstone migration as a cause of acute pancreatitis. The New England journal of medicine 290: 484-487, 1974.

2. Alvaro D, Mennone A, and Boyer JL. Effect of ursodeoxycholic acid on intracellular $\mathrm{pH}$ regulation in isolated rat bile duct epithelial cells. The American journal of physiology 265: G783-791, 1993.

3. Argent BE, Arkle S, Cullen MJ, and Green R. Morphological, biochemical and secretory studies on rat pancreatic ducts maintained in tissue culture. Quarterly journal of experimental physiology 71:633-648, 1986.

4. Benz C, Angermuller S, Otto G, Sauer P, Stremmel W, and Stiehl A. Effect of tauroursodeoxycholia acid on bile acid-induced apoptosis in primary human hepatocytes. European journal of clinical investigation 30: 203-209, 2000.

5. Benz C, Angermuller S, Tox U, Kloters-Plachky P, Riedel HD, Sauer P, Stremmel W, and Stiehl A. Effect of tauroursodeoxycholic acid on bile-acid-induced apoptosis and cytolysis in rat hepatocytes. Journal of hepatology 28: 99-106, 1998.

6. Beuers U, Fischer S, Spengler U, and Paumgartner G. Formation of isoursodeoxycholic acid during administration of ursodeoxycholic acid in man. Journal of hepatology 13: 97-103, 1991. 


\section{ACCEPTED MANUSCRIPT}

7. Booth DM, Murphy JA, Mukherjee R, Awais M, Neoptolemos JP, Gerasimenko

OV, Tepikin AV, Petersen OH, Sutton R, and Criddle DN. Reactive oxygen species induced by bile acid induce apoptosis and protect against necrosis in pancreatic acinar cells. Gastroenterology 140: 2116-2125, 2011.

8. Botla R, Spivey JR, Aguilar H, Bronk SF, and Gores GJ. Ursodeoxycholate (UDCA) inhibits the mitochondrial membrane permeability transition indurced by glycochenodeoxycholate: a mechanism of UDCA cytoprotection. The Journal of pharmacology and experimental therapeutics 272: 930-938, 1995.

9. Boyer JL. New concepts of mechanisms of hepatocyte bile formation. Physiological reviews $60: 303-326,1980$.

10. de Caestecker JS, Jazrawi RP, Petroni ML, and Northfield TC. Ursodeoxycholic acid in chronic liver disease. Gut 32: 1061-1065, 1991.

11. Durie PR. Pancreatitis and mutations of the cystic fibrosis gene. The New England journal of medicine 339: 687-688, 1998.

12. Farmer RC, Tweedie J, Maslin S, Reber HA, Adler G, and Kern H. Effects of bile salts on permeability and morphology of main pancreatic duct in cats. Digestive diseases and sciences 29: 740-751, 1984.

13. Faubion WA, Guicciardi ME, Miyoshi H, Bronk SF, Roberts PJ, Svingen PA, Kaufmann SH, and Gores GJ. Toxic bile salts induce rodent hepatocyte apoptosis via direct activation of Fas. The Journal of clinical investigation 103: 137-145, 1999.

14. Festi D, Montagnani M, Azzaroli F, Lodato F, Mazzella G, Roda A, Di Biase AR,

Roda E, Simoni P, and Colecchia A. Clinical efficacy and effectiveness of ursodeoxycholic acid in cholestatic liver diseases. Current clinical pharmacology 2: 155-177, 2007.

15. Gerasimenko JV, Flowerdew SE, Voronina SG, Sukhomlin TK, Tepikin AV, Petersen $\mathrm{OH}$, and Gerasimenko $\mathrm{OV}$. Bile acids induce $\mathrm{Ca} 2+$ release from both the 


\section{ACCEPTED MANUSCRIPT}

endoplasmic reticulum and acidic intracellular calcium stores through activation of inositol trisphosphate receptors and ryanodine receptors. J Biol Chem 281: 40154-40163, 2006.

16. Goldman A, Shahidullah M, Goldman D, Khailova L, Watts G, Delamere N, and Dvorak K. A novel mechanism of acid and bile acid-induced DNA damage involving $\mathrm{Na}+/ \mathrm{H}+$ exchanger: implication for Barrett's oesophagus. Gut 59: 1606-1616, 2010.

\section{Grasl-Kraupp B, Ruttkay-Nedecky B, Koudelka H, Bukowska K, Bursch W, and}

Schulte-Hermann R. In situ detection of fragmented DNA (TUNEL assay) fails to discriminate among apoptosis, necrosis, and autolytic cell death: a cautionary note. Hepatology 21: 1465-1468, 1995.

18. Hegyi P, Gray MA, and Argent BE. Substance P inhibits bicarbonate secretion from guinea pig pancreatic ducts by modulating an anion exchanger. American journal of physiology Cell physiology 285: C268-276, 2003

19. Hegyi P, Rakonczay Z, Jr., Gray MA, and Argent BE. Measurement of intracellular $\mathrm{pH}$ in pancreatic duct cells: a new method for calibrating the fluorescence data. Pancreas 28: 427-434, 2004.

20. Hegyi P, Rakonczay Z, Jr, Tiszlavicz L, Varro A, Toth A, Racz G, Varga G, Gray MA, and Argent BE. Protein kinase $\mathrm{C}$ mediates the inhibitory effect of substance $\mathrm{P}$ on HCO3- secretion from guinea pig pancreatic ducts. American journal of physiology Cell physiology 288: C1030-1041, 2005.

21. Ikegami T, Matsuzaki Y, Fukushima S, Shoda J, Olivier JL, Bouscarel B, and Tanaka N. Suppressive effect of ursodeoxycholic acid on type IIA phospholipase A2 expression in HepG2 cells. Hepatology 41: 896-905, 2005.

22. Im E, Akare S, Powell A, and Martinez JD. Ursodeoxycholic acid can suppress deoxycholic acid-induced apoptosis by stimulating Akt/PKB-dependent survival signaling. Nutrition and cancer 51: 110-116, 2005. 


\section{ACCEPTED MANUSCRIPT}

23. Kim JY, Kim KH, Lee JA, Namkung W, Sun AQ, Ananthanarayanan M, Suchy

FJ, Shin DM, Muallem S, and Lee MG. Transporter-mediated bile acid uptake causes Ca2+-dependent cell death in rat pancreatic acinar cells. Gastroenterology 122: 1941-1953, 2002.

24. Kowal JM, Haanes KA, Christensen NM, and Novak I. Bile acid effects are mediated by ATP release and purinergic signalling in exocrine pancreatic cells. Cell communication and signaling : CCS 13:28, 2015.

25. Kruger B, Albrecht E, and Lerch MM. The role of intracellular calcium signaling in premature protease activation and the onset of pancreatitis. The American journal of pathology 157: 43-50, 2000.

26. Lee HI, Choi CI, Sa JH, Lee YJ, Bae JW, Jang CG, and Lee SY. Ursodeoxycholic acid, an inhibitor of hepatocyte nuclear factor lalpha, did not increase the systemic exposure of pitavastatin. International journal of clinical pharmacology and therapeutics 52: 981-985, 2014.

27. Lemasters JJ, Nieminen AL, Qian T, Trost LC, Elmore SP, Nishimura Y, Crowe RA, Cascio WE, Bradham CA, Brenner DA, and Herman B. The mitochondrial permeability transition in cell death: a common mechanism in necrosis, apoptosis and autophagy. Biochimica et biophysica acta 1366: 177-196, 1998.

28. Lemasters) JJ, Qian T, Bradham CA, Brenner DA, Cascio WE, Trost LC, Nishimura Y, Nieminen AL, and Herman B. Mitochondrial dysfunction in the pathogenesis of necrotic and apoptotic cell death. Journal of bioenergetics and biomembranes 31: 305-319, 1999.

29. Maleth J, Venglovecz V, Razga Z, Tiszlavicz L, Rakonczay Z, Jr., and Hegyi P. Non-conjugated chenodeoxycholate induces severe mitochondrial damage and inhibits bicarbonate transport in pancreatic duct cells. Gut 60: 136-138, 2011. 


\section{ACCEPTED MANUSCRIPT}

30. Marschall HU, Roeb E, Yildiz Y, Busch N, Nguyen H, Purucker E, Thomas HG, and Matern S. Study of human isoursodeoxycholic acid metabolism. Journal of hepatology 26: $863-870,1997$.

31. Mithofer K, Fernandez-del Castillo C, Frick TW, Lewandrowski KB, Rattner DW, and Warshaw AL. Acute hypercalcemia causes acute pancreatitis and ectopic trypsinogen activation in the rat. Gastroenterology 109: 239-246, 1995.

32. Pallagi-Kunstar E, Farkas K, Maleth J, Rakonczay Z, Jr., Nagy F, Molnar T, Szepes Z, Venglovecz V, Lonovics J, Razga Z, Wittmann T, and Hegyi P. Bile acids inhibit $\mathrm{Na}(+) / \mathrm{H}(+)$ exchanger and $\mathrm{Cl}(-) / \mathrm{HCO}(3)(-)$ exchanger activities yia cellular energy breakdown and $\mathrm{Ca}(2)(+)$ overload in human colonic crypts. Pflugers Archiv : European journal of physiology 467: 1277-1290, 2015.

33. Pallagi P, Balla Z, Singh AK, Dosa S, Ivanyi B, Kukor Z, Toth A, Riederer B, Liu Y, Engelhardt R, Jarmay K, Szabo A, Janovszky A, Perides G, Venglovecz V, Maleth J, Wittmann T, Takacs T, Gray MA, Gacser A, Hegyi P, Seidler U, and Rakonczay Z, Jr. The role of pancreatic ductal secretion in protection against acute pancreatitis in mice* Critical care medicine 42: e177-188,2014.

34. Pandol SJ, Saluja AK, Imrie CW, and Banks PA. Acute pancreatitis: bench to the bedside. Gastroenterology 132: 1127-1151, 2007.

35. Perides G, van Acker GJ, Laukkarinen JM, and Steer ML. Experimental acute biliary pancreatitis induced by retrograde infusion of bile acids into the mouse pancreatic duct. Nature protocols 5: 335-341, 2010.

36. Poupon RE, Poupon R, and Balkau B. Ursodiol for the long-term treatment of primary biliary cirrhosis. The UDCA-PBC Study Group. The New England journal of medicine 330: 1342-1347, 1994. 


\section{ACCEPTED MANUSCRIPT}

37. Pusl T, Vennegeerts T, Wimmer R, Denk GU, Beuers U, and Rust C.

Tauroursodeoxycholic acid reduces bile acid-induced apoptosis by modulation of AP-1. Biochemical and biophysical research communications 367: 208-212, 2008.

38. Raraty M, Ward J, Erdemli G, Vaillant C, Neoptolemos JP, Sutton R, and Petersen $\mathbf{O H}$. Calcium-dependent enzyme activation and vacuole formation in the apical granular region of pancreatic acinar cells. Proceedings of the National Academy of Sciences of the United States of America 97: 13126-13131, 2000.

39. Reber HA, and Mosley JG. The effect of bile salts on the pancreatic duct mucosal barrier. The British journal of surgery 67: 59-62, 1980.

40. Roda A, Hrelia P, Paolini M, Calzolari M, Grigolo B, Simoni P, Aldini R, and Forti GC. Pharmacokinetics of ursodeoxycholic acid in rat. Pharmacological research : the official journal of the Italian Pharmacological Society 23:327-335, 1991.

41. Rodrigues CM, Fan G, Ma X, Kren BT, and Steer CJ. A novel role for ursodeoxycholic acid in inhibiting apoptosis by modulating mitochondrial membrane perturbation. The Journal of clinical investigation 101: 2790-2799, 1998.

42. Rodrigues CM, Fan G, Wong PY, Kren BT, and Steer CJ. Ursodeoxycholic acid may inhibit deoxycholic acid-induced apoptosis by modulating mitochondrial transmembrane potential and reactive oxygen species production. Molecular medicine 4: 165-178, 1998.

43. Rodrigues CM, Ma X, Linehan-Stieers C, Fan G, Kren BT, and Steer CJ. Ursodeoxycholic acid prevents cytochrome $\mathrm{c}$ release in apoptosis by inhibiting mitochondrial membrane depolarization and channel formation. Cell death and differentiation 6: 842-854, 1999.

44. Rolo AP, Oliveira PJ, Moreno AJ, and Palmeira CM. Chenodeoxycholate induction of mitochondrial permeability transition pore is associated with increased 


\section{ACCEPTED MANUSCRIPT}

membrane fluidity and cytochrome c release: protective role of carvedilol. Mitochondrion 2: $305-311,2003$

45. Rolo AP, Oliveira PJ, Moreno AJ, and Palmeira CM. Chenodeoxycholate is a potent inducer of the permeability transition pore in rat liver mitochondria. Bioscience reports 21: 73-80, 2001.

\section{Ros E, Navarro S, Bru C, Garcia-Puges A, and Valderrama R Occult} microlithiasis in 'idiopathic' acute pancreatitis: prevention of relapses by cholecystectomy or ursodeoxycholic acid therapy. Gastroenterology 101: 1701-1709, 1991.

47. Rust C, and Beuers U. Medical treatment of primary biliary cirrhosis and primary sclerosing cholangitis. Clinical reviews in allergy \& immunology 28: 135-145, 2005.

48. Saeki T, Yui S, Hirai T, Fujii T, Okada S, and Kanamoto R. Ursodeoxycholic acid protects colon cancer HCT116 cells from deoxycholic acid-induced apoptosis by inhibiting apoptosome formation. Nutrition and cancer 64:617-626, 2012.

49. Scheele GA, Fukuoka SI, Kern HF, and Freedman SD. Pancreatic dysfunction in cystic fibrosis occurs as a result of impairments in luminal pH, apical trafficking of zymogen granule membranes, and solabilization of secretory enzymes. Pancreas 12: 1-9, 1996.

50. Schoemaker MH, Conde de la Rosa L, Buist-Homan M, Vrenken TE, Havinga R, Poelstra K, Haisma HJ, Jansen PL, and Moshage H. Tauroursodeoxycholic acid protects rat hepatocytes from bile acid-induced apoptosis via activation of survival pathways. Hepatology 39: 1563-1573, 2004

51. Sola S, Castro RE, Kren BT, Steer CJ, and Rodrigues CM. Modulation of nuclear steroid receptors by ursodeoxycholic acid inhibits TGF-beta1-induced E2F-1/p53-mediated apoptosis of rat hepatocytes. Biochemistry 43: 8429-8438, 2004.

52. Sola S, Ma X, Castro RE, Kren BT, Steer CJ, and Rodrigues CM. Ursodeoxycholic acid modulates E2F-1 and p53 expression through a caspase-independent 


\section{ACCEPTED MANUSCRIPT}

mechanism in transforming growth factor betal-induced apoptosis of rat hepatocytes. $J$ Biol Chem 278: 48831-48838, 2003.

53. Sun W, Watanabe $\mathbf{Y}$, Toki A, and Wang ZQ. Beneficial effects of hydrocortisone in induced acute pancreatitis of rats. Chinese medical journal 120: 1757-1761, 2007.

54. Sun W, Watanabe $\mathbf{Y}$, and Wang ZQ. Expression and significance of ICAM-1 and its counter receptors LFA-1 and Mac-1 in experimental acute pancreatitis of rats. World journal of gastroenterology: WJG 12: 5005-5009, 2006.

55. Testoni PA, Caporuscio S, Bagnolo F, and Lella F. Idiopathic recurrent pancreatitis: long-term results after ERCP, endoscopic sphincterotomy, or ursodeoxycholic acid treatment. The American journal of gastroenterology 95: 1702-1707, 2000.

56. Thomas JA, Buchsbaum RN, Zimniak A, and Racker E. Intracellular pH measurements in Ehrlich ascites tumor cells utilizing spectroscopic probes generated in situ. Biochemistry 18: 2210-2218, 1979.

57. Thomson $\mathbf{A B}$, and Keelan M. Feeding rats diets containing cheno- or ursodeoxycholic acid or cholestyramine modifies intestinal uptake of glucose and lipids. Digestion 38: 160-170, 1987 .

58. Thorn P, Lawrie AM, Smith PM, Gallacher DV, and Petersen OH. Ca2+ oscillations in pancreatic acinar cells: spatiotemporal relationships and functional implications. Cell dalcium 14: 746-757, 1993.

59. Venglovecz V, Rakonczay Z, Jr., Ozsvari B, Takacs T, Lonovics J, Varro A, Gray MA, Argent BE, and Hegyi P. Effects of bile acids on pancreatic ductal bicarbonate secretion in guinea pig. Gut 57: 1102-1112, 2008.

60. Venneman NG, vanBerge-Henegouwen GP, and van Erpecum KJ. Pharmacological manipulation of biliary water and lipids: potential consequences for 


\section{ACCEPTED MANUSCRIPT}

prevention of acute biliary pancreatitis. Current drug targets Immune, endocrine and metabolic disorders 5: 193-198, 2005.

61. Voronina S, Longbottom R, Sutton R, Petersen $\mathbf{O H}$, and Tepikin A. Bile acids induce calcium signals in mouse pancreatic acinar cells: implications for bile-induced pancreatic pathology. J Physiol 540: 49-55, 2002.

62. Voronina SG, Barrow SL, Gerasimenko OV, Petersen OH, and Tepikin AV. Effects of secretagogues and bile acids on mitochondrial membrane potential of pancreatic acinar cells: comparison of different modes of evaluating DeltaPsim J Biol Chem 279: 27327-27338, 2004

63. Voronina SG, Barrow SL, Simpson AW, Gerasimenko OV, da Silva Xavier G, Rutter GA, Petersen OH, and Tepikin AV. Dynamic changes in cytosolic and mitochondrial ATP levels in pancreatic acinar cells. Gastroenterology 138: 1976-1987, 2010.

64. Wan MH, Huang W, Latawiec D, Jiang K, Booth DM, Elliott V, Mukherjee R, and Xia Q. Review of experimental animal models of biliary acute pancreatitis and recent advances in basic research. HPB the official journal of the International Hepato Pancreato Biliary Association 14: 73-81, 2012

65. Woolbright BL, and Jaeschke H. Novel insight into mechanisms of cholestatic liver injury. World journal of gastroenterology : WJG 18: 4985-4993, 2012.

66. Yerushalmi B, Dahl R, Devereaux MW, Gumpricht E, and Sokol RJ. Bile acidinduced rat hepatocyte apoptosis is inhibited by antioxidants and blockers of the mitochondrial permeability transition. Hepatology 33: 616-626, 2001. 


\section{ACCEPTED MANUSCRIPT}

\section{FIGURE LEGENDS}

Figure 1. Effect of bile acids on the intracellular $\mathrm{pH}\left(\mathrm{pH}_{\mathrm{i}}\right)$ of isolated guinea pig pancreatic ducts. Pancreatic ducts were exposed to $0.1,0.25,0.5$ and $1 \mathrm{mM} \mathrm{CDCA}$ (A and C) or UDCA ( $\mathbf{B}$ and D) in Hepes- ( $\mathbf{A}$ and $\mathbf{B}$ ) and in $\mathrm{HCO}_{3}{ }^{\circ} / \mathrm{CO}_{2}$-buffered ( $\mathbf{C}$ and $\left.\mathbf{D}\right)$ solutions for $5 \mathrm{~min}$. After the removal of bile acids, the $\mathrm{pH}_{\mathrm{i}}$ spontaneously recovered. Bar charts show summary data for the maximal $\mathrm{pH}_{\mathrm{i}}$ change $\left(\Delta \mathrm{pH}_{\max }\right)$ induced by bile acids in Hepes- $(\mathbf{E})$ and in $\mathrm{HCO}_{3}{ } / \mathrm{CO}_{2}$-buffered (F) solutions. The starting $\mathrm{pH}_{\mathrm{i}}$ for the measurment of $\Delta \mathrm{pH}$ was the $\mathrm{pH}_{\mathrm{i}}$ immediately before exposure to bile acids. Data are presented as means 4 SEM. $\mathrm{n}=32-34$ regions of interest from 4-5 ducts. N.D.: not detectable.

Figure 2. Effect of bile acids on the acid-base transporters of isolated guinea pig pancreatic ducts. The activities of the ion transporters were investigated by the ammonium pre-pulse technique (see Materials and Methods). Administration of $1 \mathrm{mM} \mathrm{CDCA}$ was proven to be toxic on acid-base transporters both in standard Hepes- (A) and $\mathrm{HCO}_{3}{ }^{-} / \mathrm{CO}_{2}$-buffered (B) solutions. 0.5 and $1 \mathrm{mM}$ UDCA pre-treatment ameliorated the CDCA-induced toxicity on the transporters both in Hepes- (A) and in $\mathrm{HCO}_{3}{ }_{3} / \mathrm{CO}_{2}$-buffered (B) solutions. Regeneration from acidosis in standard Hepes-buffered solution reflects the activity of NHE (C), whereas the recovery from acidosis (D) and alkalosis (E) in $\mathrm{HCO}_{3}{ }^{-} / \mathrm{CO}_{2}$ containing solutions reflects the activities of $\mathrm{Na}^{+} / \mathrm{HCO}_{3}{ }^{-}$cotransporter and $\mathrm{Cl}^{-} / \mathrm{HCO}_{3}{ }^{-}$exchanger, respectively. $-J\left(\mathrm{~B}^{-}\right)$and $J\left(\mathrm{~B}^{-}\right)$ were calculated from the $\Delta \mathrm{pH} / \Delta \mathrm{t}$ obtained by linear regression analysis of $\mathrm{pH}_{\mathrm{i}}$ measurements made over the first 30 or 60 s, respectively. Data are presented as means \pm SEM. ${ }^{*}: \mathrm{p} \leq 0.05$ vs. the control, $n=36-41$ regions of interest from 6-7 ducts. N.D.: not detectable. 


\section{ACCEPTED MANUSCRIPT}

Figure 3. Effect of bile acids on intracellular $\mathrm{Ca}^{2+}$ concentration $\left(\left[\mathrm{Ca}^{2+}\right]_{i}\right)$, ATP level $\left(\mathrm{ATP}_{\mathrm{i}}\right)$, mitochondrial membrane potential $\left(\Delta \Psi_{\mathrm{m}}\right)$ and mitochondrial permeability transition pore (mPTP) opening of pancreatic ducts. Representative experimental traces showing the effect of $1 \mathrm{mM} \mathrm{CDCA}$ on $\left[\mathrm{Ca}^{2+}\right]_{\mathrm{i}}(\mathbf{A}), \operatorname{ATP}_{\mathrm{i}}(\mathbf{C}), \Delta \Psi_{\mathrm{m}}(\mathbf{E})$ and mPTP opening (G) in non pre-treated and 24h UDCA pre-treated pancreatic ducts. (A) Acute administration of CDCA caused $\mathrm{Ca}^{2+}$ signalization in pancreatic ductal cells which was not affected by UDCA pre-treatment. (C) Decrease in $\mathrm{ATP}_{\mathrm{i}}$ is shown by an increase in fluorescence intensity. $24 \mathrm{~h}$ UDCA pre-treatment markedly decreased the CDCA-induced ATP depletion. (E) Decrease in $\Delta \Psi_{\mathrm{m}}$ is shown by an increase in TMRM fluorescence intensity Administration of $1 \mathrm{mM}$ CDCA caused rapid depolarization of the mitochondrial membrane which was decreased by UDCA pretreatment. (G) mPTP opening is shown by a decrease in fluorescence intensity. CDCA-induced a marked mPTP opening which resulted in significant influx of $\mathrm{Co}^{2+}$ into the mitochondria causing decrease in calcejn fluorescence. $24 \mathrm{~h}$ UDCA pretreatment reduced CDCA-induced $\mathrm{mPTP}$ opening resulting in milder decrease in calcein fluorescence. Summary data for the maximal fluorescence intensity changes are shown in $\mathbf{B}, \mathbf{D}, \mathbf{F}$ and $\mathbf{H}$. Data are presented as means 1 SEM. ${ }^{*}=\mathrm{p} \leq 0.05$ vs. $1 \mathrm{mM} \mathrm{CDCA} . \mathrm{n}=35-40$ regions of interest from 6-7 ducts.

Figure 4. Effect of bile acids on the morphology of pancreatic ductal mitochondria. Representative electron micrograph images of pancreatic ductal mitochondria show normal mitochondria with intact inner membranes in the control (A) and $24 \mathrm{~h}$ UDCA $(0.5 \mathrm{mM})$ pretreated ducts (B). Treatment with $1 \mathrm{mM} \mathrm{CDCA}$ caused mitochondrial swelling after $5 \mathrm{~min}(\mathbf{C})$ which was completely prevented by $24 \mathrm{~h}$ UDCA $(0.5 \mathrm{mM})$ pre-treatment (D). Arrows show mitochondria. 


\section{ACCEPTED MANUSCRIPT}

Figure 5. Effect of UDCA pre-treatment on CDCA-induced cell death on pancreatic ductal epithelial cells (PDECs). (A) Representative pictures of TUNEL positive and eosin stained pancreatic duct segments show that incubation of the pancreatic ducts with $1 \mathrm{mM}$ CDCA (left bottom), increased the rate of dead cells compared to control (left top) non-treated ducts. 5 min administration of UDCA $(0.5 \mathrm{mM})$ alone, had no significant effect on the cells (right top), whereas $24 \mathrm{~h}$ pre-treatment of the ducts with $0.5 \mathrm{mM}$ UDCA (right, bottom) decreased the rate of dead cells in the CDCA-treated group. (B) The bar chart shows the percentage of total cell counts that are TUNEL positive. Data are presented as means \pm SEM. ${ }^{*}=\mathrm{p} \leq 0.05$ vs. Control, \#=p $\leq 0.05$ vs. $1 \mathrm{mM} \mathrm{CDCA}, \mathrm{n}=3-4$

Figure 6. Effect of UDCA pre-treatment on CDCA-induced pancreatitis in rats. (A) Serum amylase activity (U/l), (B) pancreatic oedema and (C) cell necrosis were significantly increased by intraductal administration of CDCA. However 2 weeks UDCA pre-treatment ameliorated each of these severity parameters. (D) Representative histological images of control, UDCA pre-treated, CDCA-induced acute pancreatitis and UDCA pre-treated CDCAinduced acute pancreatitis animals. Control rats were given physiological saline instead of CDCA. P.S.: physiological saline, P.O.: per os, I.D.: intraductal. Data are presented as means \pm SEM. ${ }^{*}=\mathrm{p} \leq 0.05$ vs. Control, $\#=\mathrm{p} \leq 0.05$ vs. $1 \mathrm{mM} \mathrm{CDCA}, \mathrm{n}=6$ animals in each groups. Scale bar $100 \mu \mathrm{m}$.

Figure 7. Proposed model for the protective effect of UDCA. CDCA induces mitochondrial damage by decreasing mitochondrial membrane potential and opening of mitochondrial permeability transition pore (MPTP). UDCA is able to prevent the toxic effect of CDCA by the stabilization of the mitochondrial membrane. $\longrightarrow$, induction; $\longmapsto$-inhibition. 


\section{ACCEPTED MANUSCRIPT}

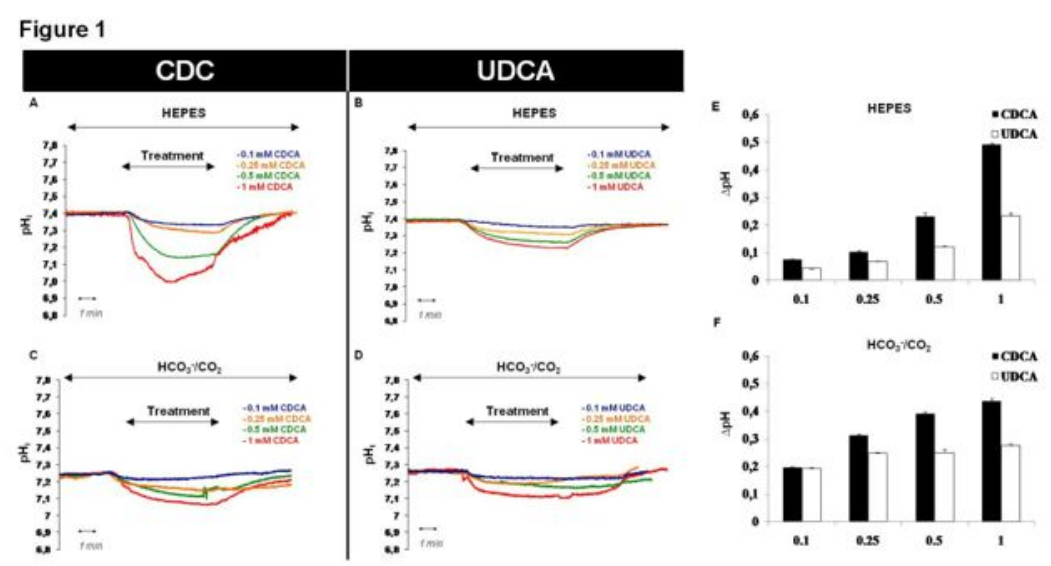

Figure 2

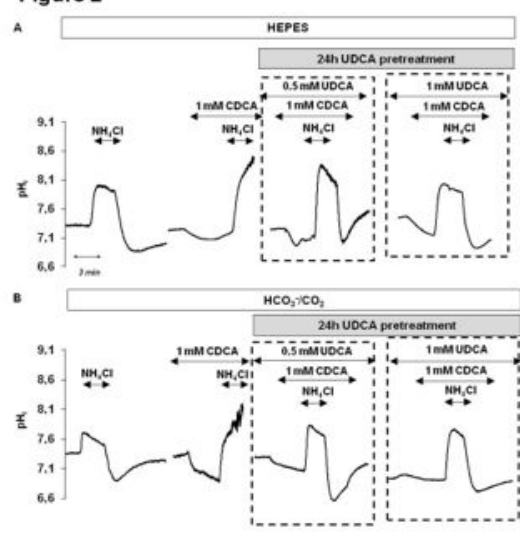

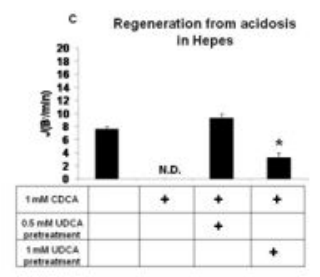

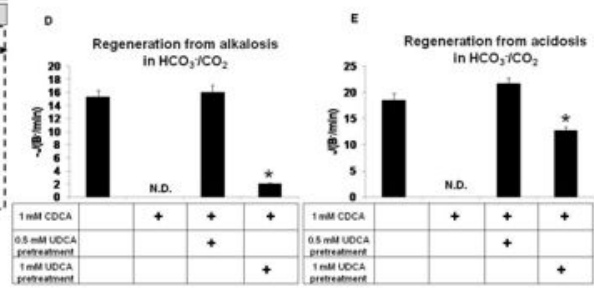




\section{ACCEPTED MANUSCRIPT}

Figure 3
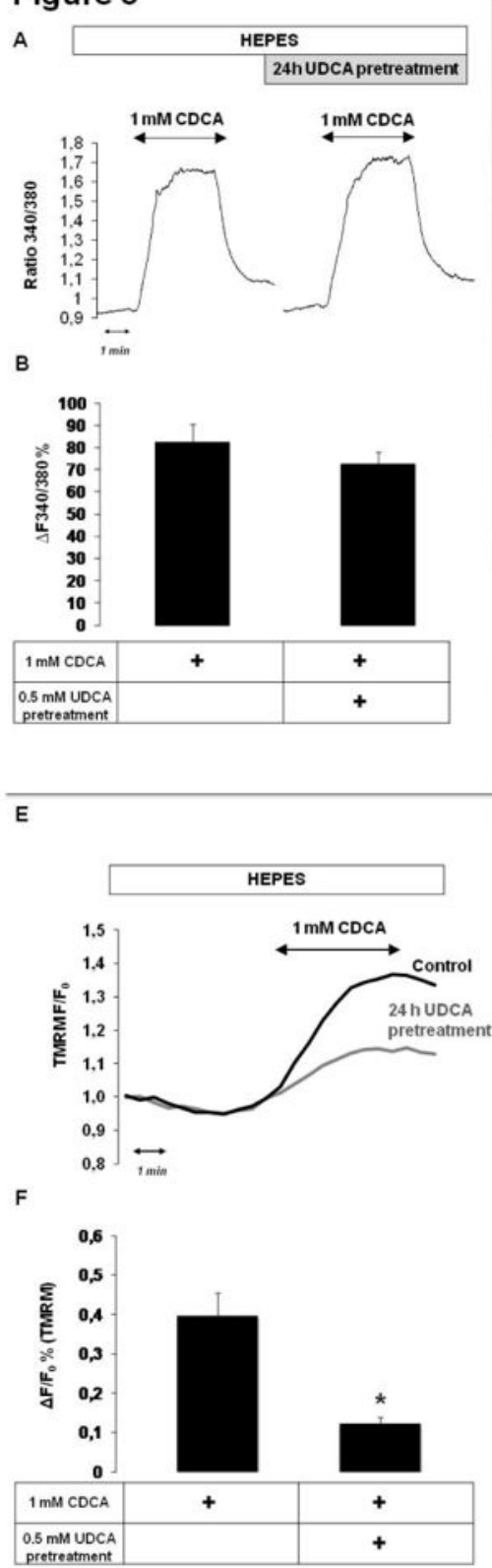

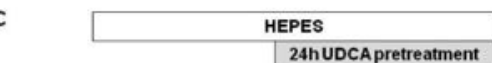

$1,3 \longrightarrow \stackrel{1 \mathrm{mM} \mathrm{CDCA}}{\longrightarrow}$
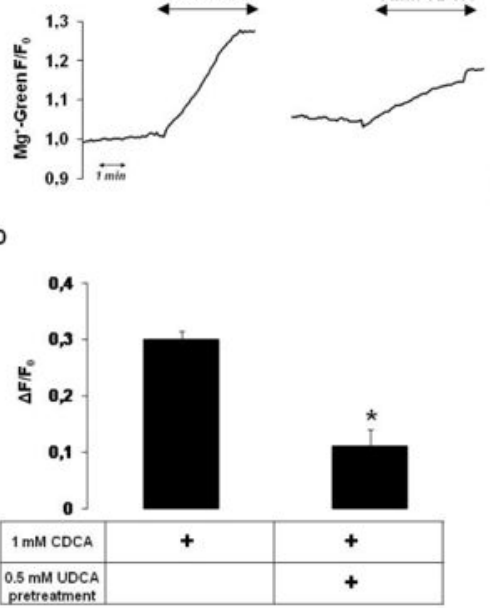

G

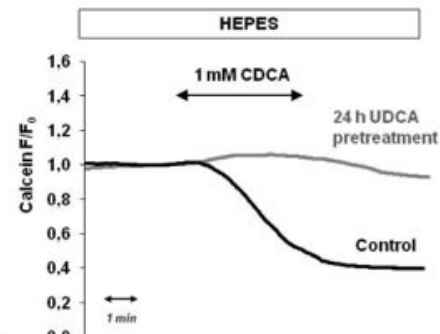

$\mathrm{H}$

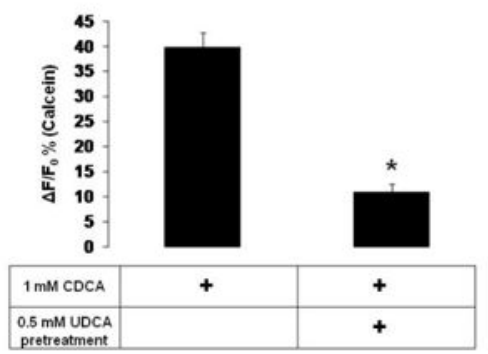




\section{ACCEPTED MANUSCRIPT}

Figure 4

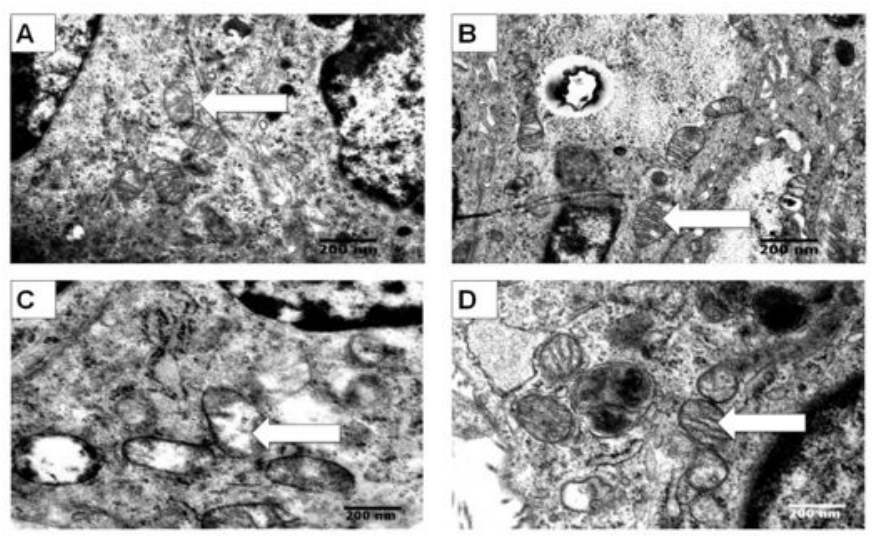

Figure 5

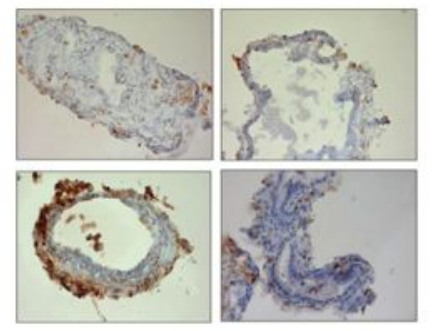

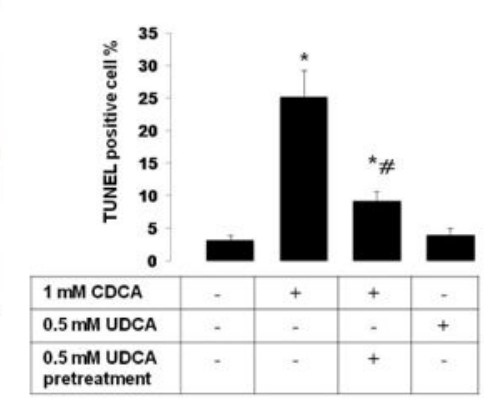




\section{ACCEPTED MANUSCRIPT}

Figure 6
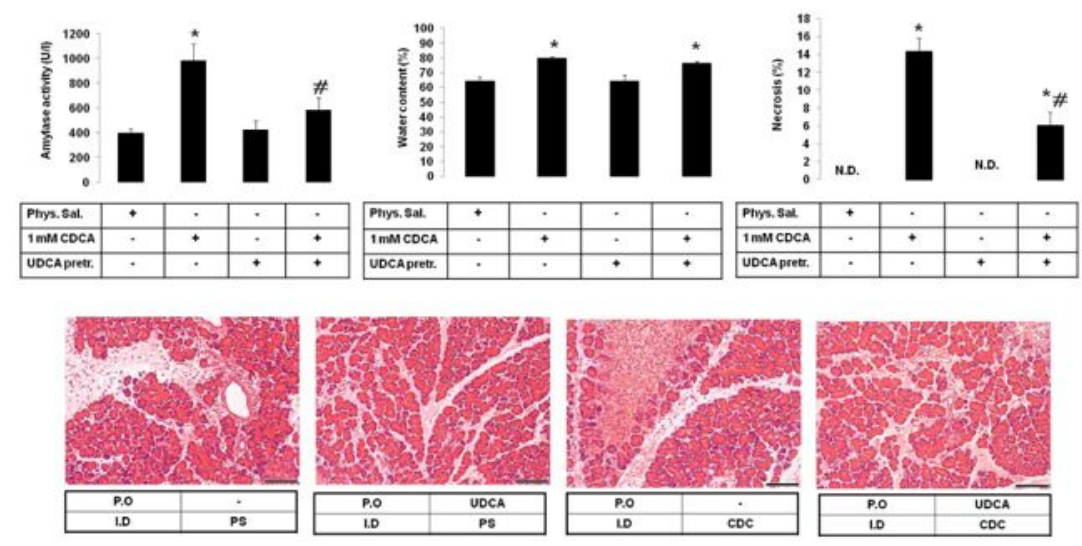

Figure 7

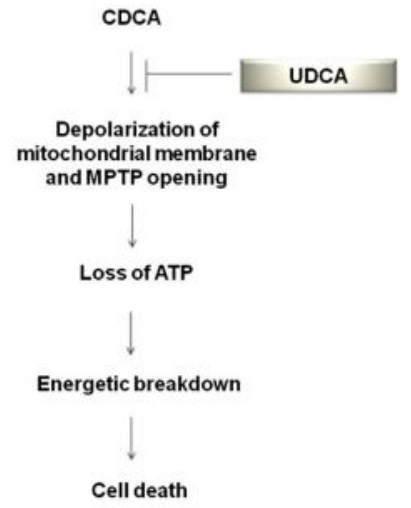

